\title{
Local Calibration of Cracking Models of MEPDG For ONTARIO'S FleXible PAVEMENTS
}

\author{
by \\ Chowdhury Jannatul Sifat E Ahmed \\ Bachelor of Science, Bangladesh University of Engineering \& Technology, 2008
}

\author{
A Thesis \\ presented to Ryerson University \\ in partial fulfillment of the \\ requirements for the degree of \\ Master of Applied Science \\ in the Program of \\ Civil Engineering
}

Toronto, Ontario, Canada, 2017

(C) Chowdhury Jannatul Sifat E Ahmed 2017 


\section{Author's Declaration}

\section{AUTHOR'S DECLARATION FOR ELECTRONIC SUBMISSION OF A THESIS}

I hereby declare that I am the sole author of this thesis. This is a true copy of the thesis, including any required final revisions, as accepted by my examiners.

I authorize Ryerson University to lend this thesis to other institutions or individuals for the purpose of scholarly research.

I further authorize Ryerson University to reproduce this thesis by photocopying or by other means, in total or in part, at the request of other institutions or individuals for the purpose of scholarly research.

I understand that my thesis may be made electronically available to the public. 


\title{
local Calibration of Cracking Models of MEPDG for Flexible Pavements in Ontario \\ By
}

\author{
Chowdhury Jannatul Sifat E Ahmed \\ Master of Applied Science, 2017 \\ Civil Engineering, Ryerson University \\ Toronto, Canada
}

\begin{abstract}
The AASHTO Mechanistic-Empirical Pavement Design Guide (MEPDG) introduces a pavement design method which uses both the mechanistic analyses and empirical models to predict pavement distresses and performance, which needs to be calibrated to local conditions and engineering practices based on local pavement performance data. This thesis focuses on the local calibration of fatigue (both bottom-up and top-down) and thermal cracking models in MEPDG for superpave flexible pavements on Ontario's highways. Simulations were run in the software, after developing a calibration database of Ontario's provincial highway and the predicted data is compared to the observed data. Significant difference is found in the comparisons which need to be minimized by calibrating the distress models. A new regression model is used to optimize the calibration parameters by minimizing the standard deviations of the residuals between the predicted and observed distresses. The challenges encountered and concluding remarks developed during the local calibration process are discussed.
\end{abstract}

Keywords: Local Calibration, Mechanistic Empirical Pavement Design Guide (MEPDG), Cracking Models, Fatigue Cracking, Thermal Cracking, superpave 


\section{Acknowledgements}

First and foremost, my sincere gratitude and gratefulness to the Almighty Allah (SWT) to let me have this opportunity to enhance my academic credentials and to allow me to successfully travel towards the end of this journey. My foremost gratitude goes to my mentor and supervisor Dr. Arnold (Xian-Xun) Yuan, who spontaneously guided me through my graduate research work since my first day at Ryerson University. I am indebted to his suggestions on challenges of study, essential materials, encouragement, continual support, guidance and compassion throughout the work as well as his ideologies and teachings are of immense value to me. Without his remarkable support and impromptu contribution, this thesis would not be possible. His consistent and rigorous mentoring developed my ethics of scientific research and motivated me in the domain of civil engineering research.

I would like to gratefully acknowledge Ministry of Transportation of Ontario (MTO) Highway Infrastructure Innovation Funding Program for funding this research work. I would like to extend my gratitude to Mr. Warren Lee from the MTO, Pavement and Foundation Section, for his generous and sincere support and suggestions.

The Ryerson Research Group led by Dr. Yuan on the MEPDG Local Calibration contributed significantly towards the final product of this study. I would like to specially recognize the help from Afzal Waseem to enlighten me on the operations of AASHTOWare Pavement ME and Gyan Goutam to support developing the input database for the software. I would also like to thank Maryam Amir for her sincere help in completing the study smoothly.

I would also like to extend my heartfelt thanks to Desmond Rogan, the Network Administrator of the Department of Civil Engineering, for his support in Network connections.

For this thesis, I would like to thank Dr. Medhat Shehata and Dr. Jinyuan Liu, members of the oral examination committee, for their valuable comments and suggestions.

Last but not least, I would like to thank my husband, Sabbir Chowdhury, two daughters Sameeha and Sareenah, my parents and family members for their continuous moral support and encouragement on my study and keeping me strong enough to plough through this journey. 


\section{Contents}

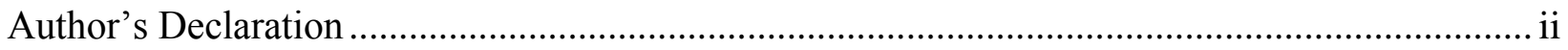

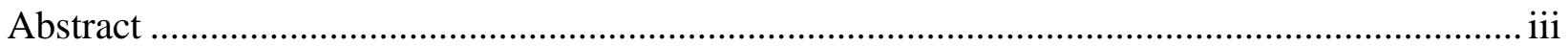

Acknowledgements ........................................................................................................ iv

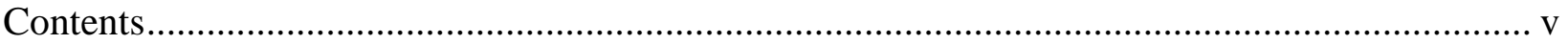

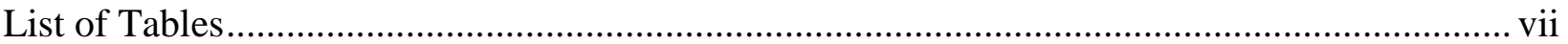

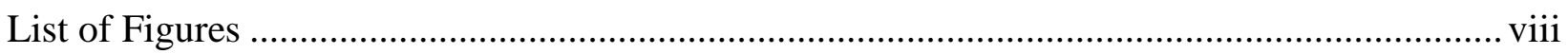

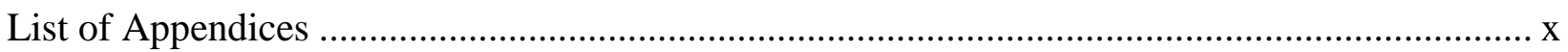

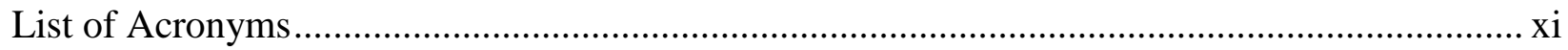

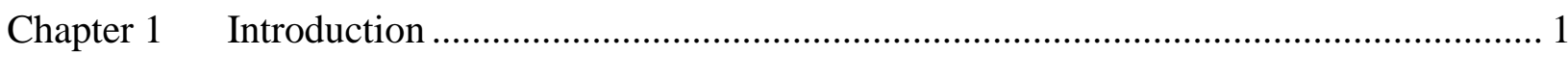

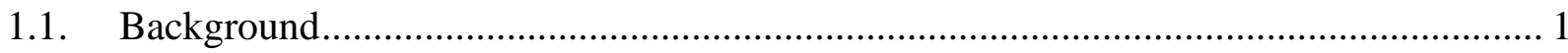

1.2. Needs and Significance of Research .................................................................. 2

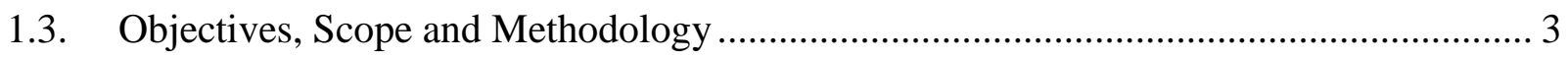

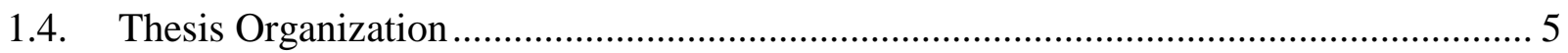

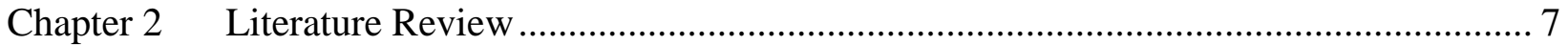

2.1. Historical Development of Pavement Design Method ..................................................... 7

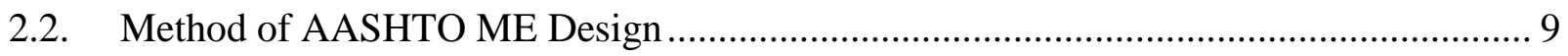

2.2.1. General MEPDG Design Procedure................................................................... 10

2.2.2. AASHTOWare Pavement ME Software _............................................................. 11

2.3. Hierarchical Design Input Levels .......................................................................... 12

2.4. The Key Performance Indicators in MEPDG ............................................................ 14

2.5. The MEPDG Fatigue Cracking Models for Flexible Pavement....................................... 16

2.6. The MEPDG Thermal Cracking Model for Flexible Pavement ...................................... 21

2.7. Existing Local Calibration Studies ........................................................................... 22

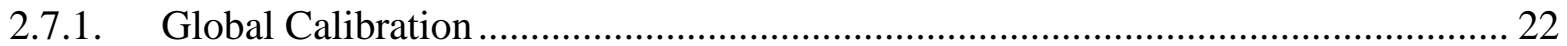



2.7.3. Results from Previous Studies........................................................................... 24

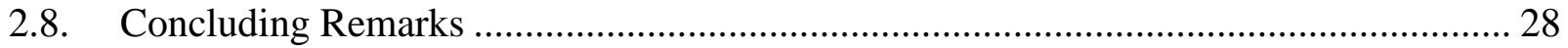

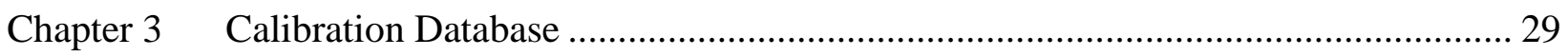

3.1. Required Data for Local Calibration ...................................................................... 29 


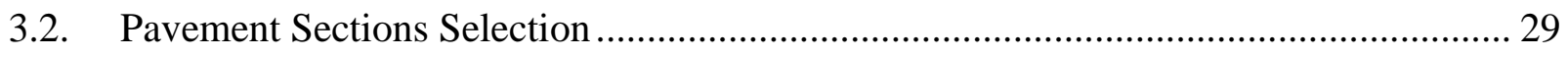

3.3. Major Input Parameters for MEPDG........................................................................ 30

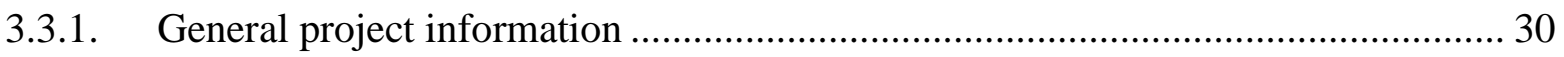

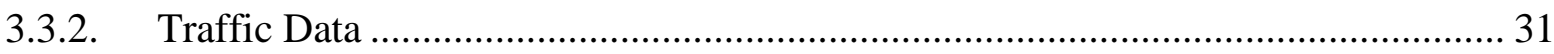

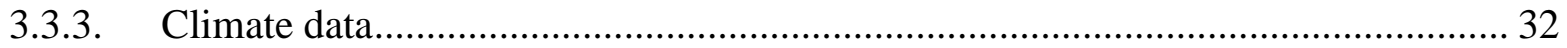

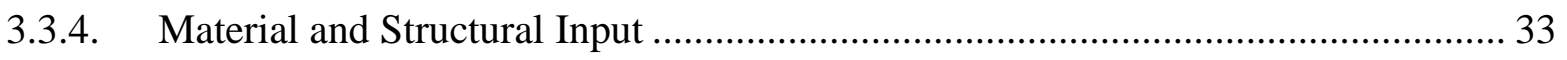

3.4. Preprocessing Protocol for Observed Cracking Data .................................................... 35

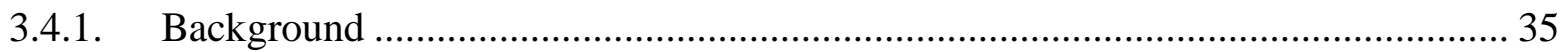

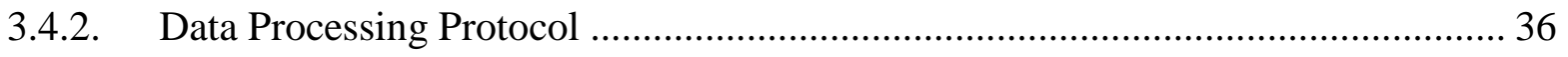

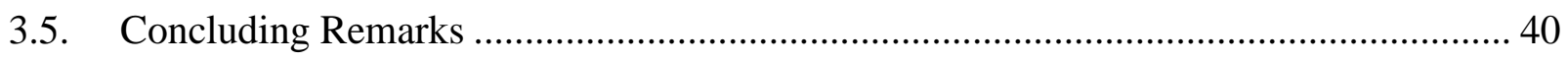

Chapter 4 Local Calibration Methods ................................................................................... 42

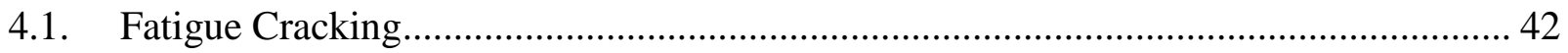

4.1.1. Bottom-Up Alligator Cracking........................................................................ 43

4.1.2. Top-Down Longitudinal Cracking ……………................................................ 43

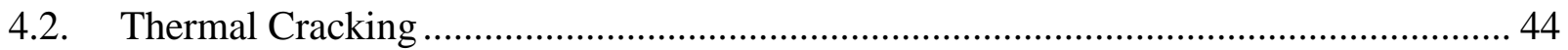

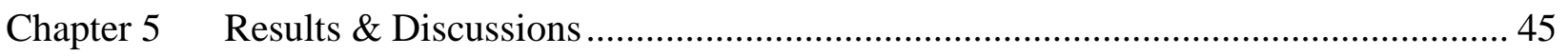

5.1. Fatigue Cracking.................................................................................................. 45

5.1.1. Bottom-up Fatigue (Alligator) Cracking ............................................................ 45

5.1.2 Top-Down Fatigue (Longitudinal) Cracking ......................................................... 51

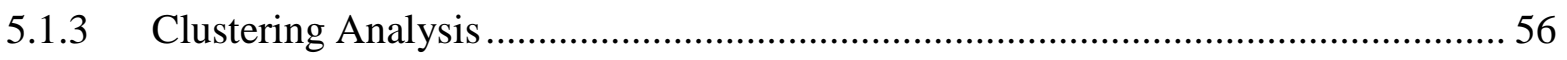

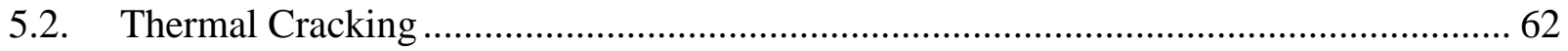

Chapter 6 Summary, Conclusions and Recommendations ..................................................... 65

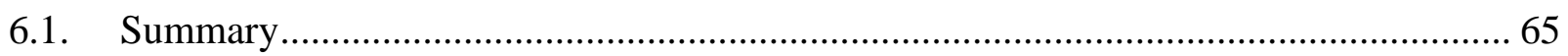

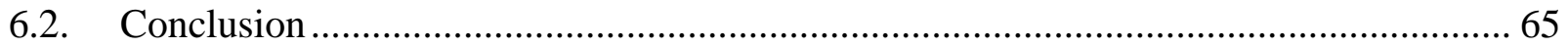

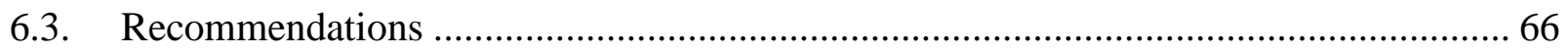

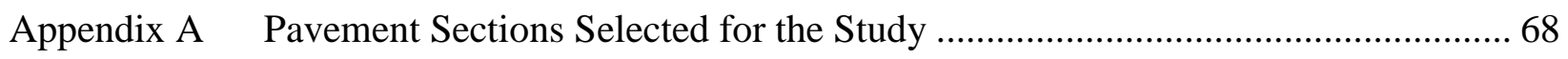

Appendix B Traffic Data for Pavement ME Analysis .............................................................. 71

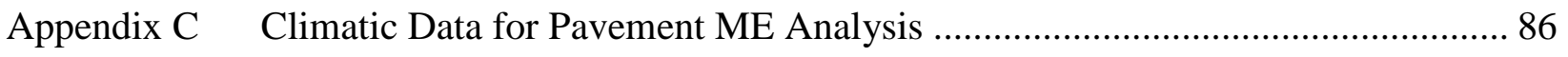

Appendix D Material and Structural Data for Pavement ME Analysis ................................... 90

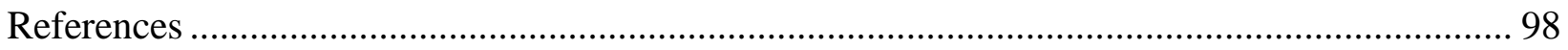




\section{List of Tables}

Table 2.1: Recommended Target Values for Ontario's Flexible Pavement (MTO 2016) ............ 11

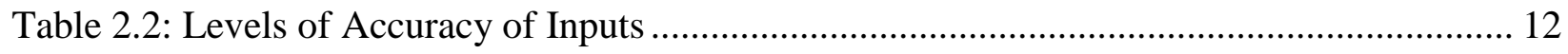

Table 2.3: Calibration Factors for the Alligator Cracking from Previous Studies..................... 26

Table 2.4: Calibration Factors for the Longitudinal cracking from Previous Studies ................. 27

Table 2.5: Calibration Factors of the Thermal cracking from Previous Studies ......................... 27

Table 3.1: General Project Inputs for AASHTOWare Pavement ME ..................................... 31

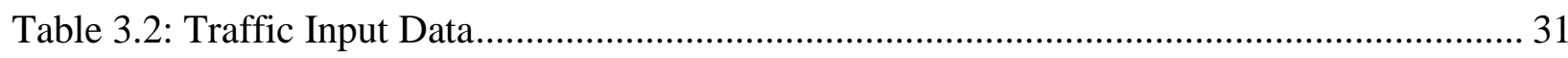

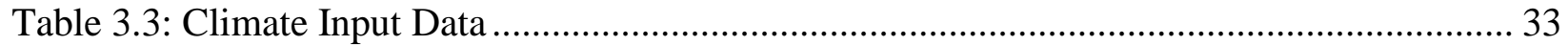

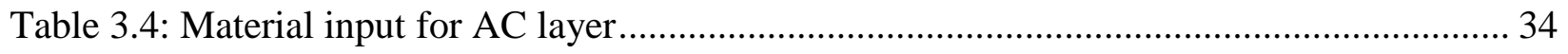

Table 3.5: Material Inputs Requirements for software ..................................................... 34

Table 5.1: Statistical Results for Alligator Damage Comparison .............................................. 48

Table 5.2: Statistical Results for Longitudinal Damage Comparison ...................................... 53

Table 5.3: Statistical Comparison of Alligator Damage for Clustering Analysis ....................... 58

Table 5.4: Statistical Comparison of Longitudinal Damage for Clustering Analysis ................. 61

Table 5.5: Statistical Results for Different Calibration Parameter for Thermal Damage ............. 62 


\section{List of Figures}

Figure 2.1: Conceptual Flowchart of MEPDG.................................................................... 10

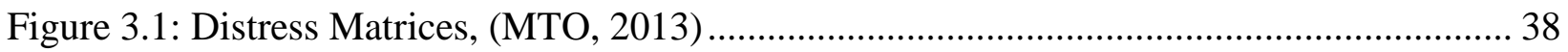

Figure 3.2: Sample calculation for observed data ............................................................... 39

Figure 3.3: Maximum Alligator cracking of the whole section vs Average Alligator cracking of

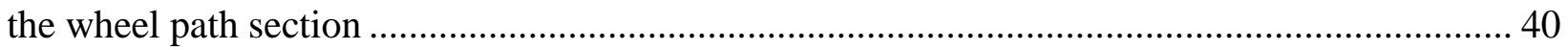

Figure 5.1 Transformed form of Alligator Damage Comparison with Default Parameter (Using

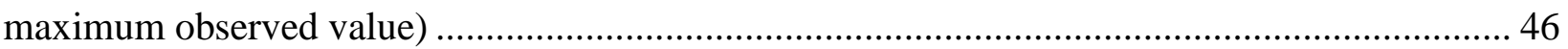

Figure 5.2: Transformed form of Alligator Damage Comparison with 2nd set of Parameter $(\beta f 1=1.0, \beta f 2=0.9, \beta f 3=0.9)$ (Using maximum observed value) ................ 46

Figure 5.3: Transformed form of Damage Comparison with 3rd Set of Parameter $(\beta f 1=1.0$,

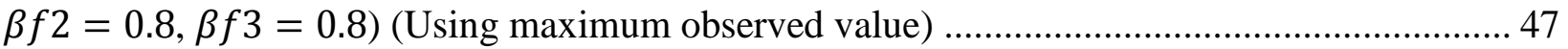

Figure 5.4: Transformed form of Alligator Damage Comparison with 4th Set of Parameter $(\beta f 1=1.0, \beta f 2=0.7, \beta f 3=0.7)($ Using maximum observed value)................ 47

Figure 5.5: Residual plots for the Alligator damage for four sets of Calibration Parameter ........ 48 Figure 5.6: Transformed form of Alligator Damage Comparison $(\beta f 1=1.0, \beta f 2=1.0$,

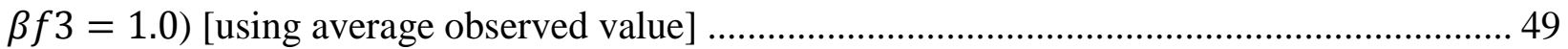

Figure 5.7: Transformed form of Alligator Damage Comparison $(\beta f 1=1.0, \quad \beta f 2=0.9$, $\beta f 3=1.1$ ) [using average observed value]

Figure 5.8: Residual plots for the Alligator damage for two sets of Calibration Parameter (Residuals for the transformed condition) [using average observed value] 50

Figure 5.9: Transformed form of Longitudinal Damage Comparison $(\beta f 1=1.0, \beta f 2=1.0$, $\beta f 3=1.0)$ (Using maximum observed value) 51

Figure 5.10: Transformed form of Longitudinal Damage Comparison $(\beta f 1=1.0, \beta f 2=0.8$, $\beta f 3=0.8)($ Using maximum observed value) 52

Figure 5.11: Residual Plots for Longitudinal Cracking damage(Using maximum observed value)

Figure 5.12: Transformed form of Longitudinal Damage Comparison $(\beta f 1=1.0, \beta f 2=1.0$, $\beta f 3=1.0$ ) (using average observed value) 53 
Figure 5.13: Transformed form of Longitudinal Damage Comparison $(\beta f 1=1.0, \beta f 2=0.9$, $\beta f 3=1.1)$ (using average observed value) .................................................................... 54

Figure 5.14: Residual plots for the Longitudinal Damage (using average observed value) ......... 55

Figure 5.15: Clustering Analysis by Zone (Alligator Damage) ............................................ 56

Figure 5.16: Clustering Analysis by Highway series (Alligator Damage) ............................... 57

Figure 5.17: Clustering Analysis by Top-layer Material (Alligator Damage) ........................... 57

Figure 5.18: Clustering Analysis by Performance Grade (Alligator Damage) .......................... 58

Figure 5.19: Clustering Analysis by Zone (Longitudinal Damage) ........................................ 59

Figure 5.20: Clustering Analysis by Highway Series (Longitudinal Damage).......................... 60

Figure 5.21: Clustering Analysis by Top Layer Material (Longitudinal Damage)..................... 60

Figure 5.22: Clustering Analysis by Top Layer Material Grade (Longitudinal Damage) ........... 61

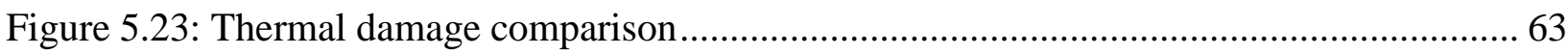

Figure 5.24: Calibration factor vs Predicted value for Thermal Damage .................................. 63 


\section{List of Appendices}

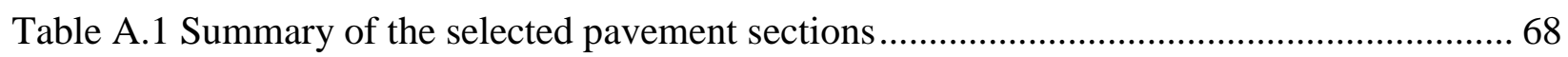

Table B.1: Recommended percentage of truck in design lane for Ontario .................................... 71

Table B.2: Standard speed for different highway class in Ontario ............................................... 72

Table B.3: Forecasting function of AADTT over pavement age ................................................. 73

Table B.4: Summary of TTC and FHWA vehicle class distribution used in AASHTOWare

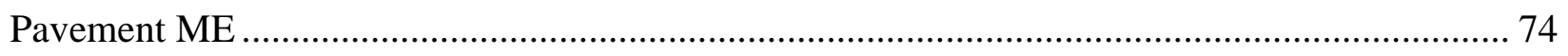

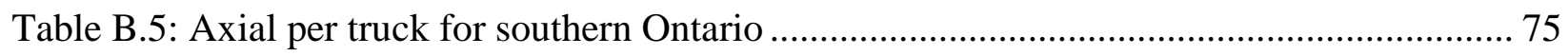

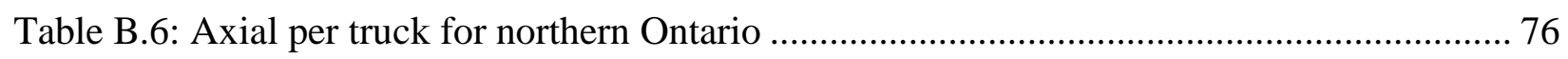

Table B.7: Single axial load distribution for southern Ontario ....................................................... 77

Table B.8: Single axial load distribution for northern Ontario ……………………………......... 78

Table B.9: Tandem axial load distribution for southern Ontario ................................................. 79

Table B.10: Tandem axial load distribution for northern Ontario ……………………………..... 80

Table B.11: Tridem axial load distribution for southern Ontario …………………………….... 81

Table B.12: Tridem axial load distribution for northern Ontario ................................................. 82

Table B.13: Quad axial load distribution for southern Ontario..................................................... 83

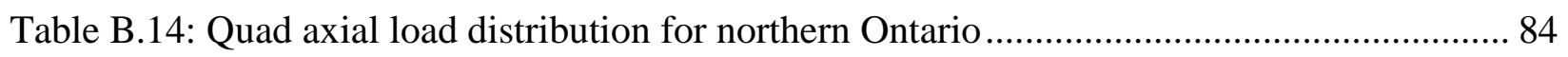

Table B.15: Ontario's traffic information for the selected pavement sections ................................ 85

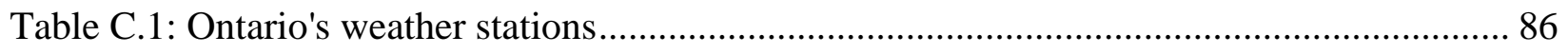

Table C.2: Location parameters for the selected pavement sections ............................................ 87

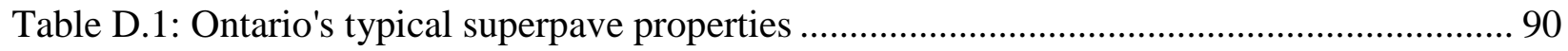

Table D.2: Ontario's typical Marshall mix properties ................................................................... 91

Table D.3: Ontario's recommended asphalt stabilized material properties ................................... 92

Table D.4: Ontario's typical granular material properties .............................................................. 93

Table D.5: Ontario's typical chemically stabilized base material properties ................................ 94

Table D.6: Ontario's typical fine sub-grade soil property ………………………….................... 95

Table D.7: Layer Thickness for the selected pavement sections ................................................... 96 


\section{List of Acronyms}

\begin{tabular}{|c|c|}
\hline AADT & Annual Average Daily Traffic \\
\hline AADTT & Annual Average Daily Truck Traffic \\
\hline \multirow[t]{2}{*}{ AASHO } & American Association of State Highway Official, the predecessor of \\
\hline & AASHTO \\
\hline AASHTO & American Association of State Highway and Transportation Official \\
\hline $\mathrm{AC}$ & Asphalt Concrete \\
\hline ALDF & Axle Load Distribution Factor \\
\hline ARA & Applied Research Associate \\
\hline ARAN & Automatic Road Analyzer \\
\hline ARE & Austin Research Engineers \\
\hline ARS & Average Rectified Slope \\
\hline CBR & California Bearing Ratio \\
\hline CMA & Cold Mix Asphalt \\
\hline CSM & Cementitious Stabilized Materials \\
\hline DMI & Distress Manifestation Index \\
\hline DOT & Department of Transportation \\
\hline ESAL & Equivalent Single Axle Load \\
\hline FHWA & Federal highway Administration \\
\hline GPS & General Pavement Sites \\
\hline GWT & Ground Water Table \\
\hline HIIFP & Highway Infrastructure Innovation Fund Programme \\
\hline HMA & Hot Mix Asphalt \\
\hline $\mathrm{HRB}$ & Highway Research Board \\
\hline HTDF & Hourly Truck Distribution Factor \\
\hline IRI & International Roughness Index \\
\hline LTPP & Long Term Pavement Performance \\
\hline MAAT & Mean Average Annual Temperature \\
\hline MAF & Monthly Adjustment Factor \\
\hline
\end{tabular}




$\begin{array}{ll}\text { ME } & \text { Mechanistic Empirical } \\ \text { MEPDG } & \text { Mechanistic Empirical Pavement Design Guide } \\ \text { MnDOT } & \text { Minnesota Department of Transportation } \\ \text { MoDOT } & \text { Missouri Department of Transportation } \\ \text { MS } & \text { Manual Series } \\ \text { MTO } & \text { Ministry of Transportation, Ontario } \\ \text { NCDOT } & \text { North Caroline Department of Transportation } \\ \text { NCHRP } & \text { National Cooperative Highway Research Programme } \\ \text { PCI } & \text { Pavement Condition Index } \\ \text { PCR } & \text { Pavement Condition Rating } \\ \text { PMS } & \text { Pavement Management System } \\ \text { PSI } & \text { Present Serviceability Index } \\ \text { SHRP } & \text { Strategic Highway Research Programme } \\ \text { SMA } & \text { Stone Mastic Asphalt } \\ \text { SPS } & \text { Specific Pavement Studies } \\ \text { SN } & \text { Structural Number } \\ \text { USCE } & \text { US Corps of Engineers } \\ \text { VCD } & \text { Vehicle Class Distrubtion } \\ \text { WASHO } & \text { Western Association of State Highway Officials } \\ \text { WSDOT } & \text { Washington State Department of Transportation } \\ \text { XML } & \end{array}$




\section{Chapter 1 Introduction}

\subsection{Background}

Similar to many other engineering disciplines, pavement design methods have evolved through a fairly long history from a purely empirical, experience-based method to rational approaches with more mechanistic underpinnings. According to Huang (2004), the Public Roads Soil Classification represented the first step to the modern pavement design method. Then after developing and improving many models, Highway Research Board performed three major road tests from 1940 to 1960: Maryland Road Test, WASHO Road Test and AASHO Road Test. These tests were conducted under controlled conditions and then AASHO Road test was proved to be one of the most important pavement research projects. Based upon that road test, empirical relationships between axle loads and pavement performance with different structural design were developed. Evolution of serviceability concept which compelled the pavement research to focus on performance-based design is also an important outcome from AASHO test.

From the outcomes of AASHO road test, the Interim Guide for the Design of Rigid and Flexible Pavements was developed and published in 1961. According to this guide, empirical equations are used to obtain the thickness of structural layers. These equations are the function of present serviceability index (PSI), traffic axle loading, pavement material characteristics, subgrade modulus, and drainage conditions. This guide was improved continuously through 1972, 1986 and a major change has been made in 1993. In 1993, this guide was renamed as AASHTO Pavement Design Guide, had since been extensively used by many agencies in North America till very recently. But still its pure empirical method sheds lights on the needs to revise the guide. So, in 1996 an AASHTO Joint Task Force on Pavements, NCHRP and FHWA sponsored a research program. The result of this program is The AASHTO Mechanistic-Empirical Pavement Design Guide (MEPDG) and corresponding software that were developed in 2004 by NCHRP Project 1-37A. This guide represents a new method in structural design, where a preliminary design is needed with all layer thickness. Also traffic, environmental and pavement materials information are used as input in this method. After introducing this guide and the 
corresponding software, several updates were done from 2005 to 2013 under the NCHRP Project 1-40D and 9-30A.

According to the MEPDG, the pavement analysis is done in two steps. In the first step, computational mechanistic analysis is performed where critical structural responses such as stress, strain, deformations are calculated. In the second step, pavement distresses and IRI are calculated based upon empirical transfer functions. The transfer functions are sets of empirical distress prediction formulae that relate the critical structural responses to the pavement distresses and performance. The specific distresses considered in the MEPDG for flexible pavements are rut depth, fatigue cracking, thermal cracking, and reflective cracking, whereas the pavement performance refers to the surface smoothness measured in International Roughness Index (IRI), which is a function of the abovementioned pavement distresses and other site factors.

The empirical transfer models have been calibrated with field measured data. By definition, calibration is a process where biases are eliminated and residual errors between observed distress and the predicted distress are minimized. Depending upon the coverage of data used in the process and the purpose, calibration is divided into two types: global calibration where the distress models are calibrated using the pavement sections located throughout North America and local calibration where the calibration is done for the local conditions of a specific local jurisdiction.

The transfer functions in MEPDG all have been globally calibrated and even recalibrated. Yet the models may still not give correct and accurate enough prediction for particular local conditions. Hence, these empirical models require adjustment in the calibration parameter for the local conditions: traffic loading, pavement materials, environmental conditions, maintenance and rehabilitation practices, etc. This adjustment is called local calibration. For this purpose, Guide for local calibration of the MEPDG (AASHTO 2010) was introduced for local calibration studies.

\subsection{Needs and Significance of Research}

Till early 1990s, Ministry of Transportation of Ontario (MTO) used its own pavement design method for the design and rehabilitation of the highways of Ontario. Since late 1990s, MTO has decided to adopt the MEPDG method for future pavement design. Hence under the MTO's Highway Infrastructure Innovation Fund Program (HIIFP), Ryerson research team has carried 
out three projects: 1) development of a local calibration database where the MEPDG was evaluated and the need for local calibration was confirmed (Jannat 2012); 2) Local calibration of MEPDG (Waseem 2013 and Gautam 2015) where the main focus has been on the rutting model; and 3) enhanced local calibration, in order to complete the calibration for the cracking models and the IRI model.

Gulfam Jannat investigated the needs for the local calibration of MEPDG for Ontario's pavement. Currently researches are conducting on MEPDG to fit the method for Ontario's highway design,asset management and maintenance purpose. Although the LTPP database used in the global calibration includes a few pavement sections from Ontario, Jannat's study confirmed the need of local calibration for all empirical distress and IRI models. In particularly, she found that the global models over predicts rutting or permanent deformation, which was confirmed and verified by Waseem (2013) and Gautam (2015). She has also found a great variability in cracking prediction and substantial bias in IRI prediction (Jannat 2012). Subsequent research was mainly focused on the rutting models (Waseem 2013, Gautam 2015). Hamdi (Amin 2015), a research student from University of Waterloo, worked on the local calibration of MEPDG using Ontario's PMS-2 data for the IRI and rutting model under the supervision of Professor Susan Tighe of University of waterloo.

However, the empirical models for surface cracking and IRI has yet to be calibrated. This study will mainly focus on the local calibration of the cracking models in MEPDG. The local calibration of the IRI model will be performed by Maryam Amir, another MASc student at Ryerson as a parallel project.

As mentioned earlier, local calibration is a very important step of the MTO's overall MEPDG implementation plan. It reduces the bias and residual errors of the pavement distresses and performance predicted by the MEPDG. The improved prediction results in more economic and sustainable pavement design and life-cycle management strategies.

\subsection{Objectives, Scope and Methodology}

Therefore, the primary objective of this study is to carry out local calibration for the cracking models in MEPDG for Ontario's flexible pavements using MTO's pavement performance data. The cracking distresses considered in MEPDG include fatigue cracking, thermal cracking, and 
reflective cracking. The fatigue cracking is further divided into bottom-up or alligator cracking and top-down or longitudinal cracking. This study mainly focuses on fatigue cracking and thermal cracking. Due to complexity of the issue and unavailability of a reliable global model by the time of the project was conceived ${ }^{1}$, it was decided that the reflective cracking was not included in this study. In addition, the calibration is confined to pavement design of superpave mixes. Both new and rehabilitated sections are considered in the study.

The general procedures of the "Guide for the Local Calibration of Mechanistic-Empirical Pavement Design Guide" (AASHTO 2010), called the Local Calibration Guide hereafter, are followed in this study. Still, several key issues need to be addressed. They are:

1) development of a representative pavement section database

2) preprocessing of the observed cracking data

3) identification of the appropriate local calibration coefficients to be calibrated, and

4) possible clustering or regression analyses to further enhance the local calibration results.

In 2012, Jannat along with MTO's staff developed a local calibration database including performance history, material and traffic data. But that database was limited to Marshall Mix type's pavements. Since superpave materials have been used in Ontario since 2001, a new database needs to be developed. For this purpose, MTO staff helped identify the historical Superpave road projects and their contract documents were reviewed by this author and Gyan Gautam, another MASc student of this research group. Based upon this, the pavement sections were identified, and the corresponding structural, materials, traffic and climatic data were developed. More detailed discussion of the database development can be found in Chapter 3 of this thesis.

The observed cracking data are another key input for the local calibration. In this study, the field cracking data were collected by MTO using the ARAN-9000 (Automated Road Analyzer) system. However, the ARAN-9000 data collection was mainly tasked for the MTO's pavement management system (PMS), and thus, the cracking data collected cannot be directly used for the local calibration study. Because of this, a data preprocessing method needs to be developed, and the details are discussed in Section 3.4.

\footnotetext{
${ }^{1}$ An enhanced reflective cracking model was developed and included in 2016 into the new AASHTOware Pavement ME Design software.
} 
An extensive literature review is conducted to properly understand the process of the local calibration strategies using cross section calibration process. In doing so, crack data for each section is collected and compared with the predicted data output from AASHTOWare Pavement ME software. The raw data were made ready from the performance data prepared by MTO. This raw data were processed to use as observed crack data. Predicted data are extracted from the output report generated by the AASHTOWare Pavement ME software.fo each section using three types of input: traffic, climate and pavement structure.

Observed and predicted data were compared and regression model is developed to fit the data to eliminate bias. Further conclusion was generated using the standard deviation and the residual plot.

In this research, the author performed a preliminary analysis for the fatigue cracking model and transverse cracking model in MEPDG for the superpave section of Ontario. From the analysis it is concluded that the global models under predicts the distress: fatigue cracking and transverse cracking. Therefore, the local calibration of these models for Ontario's pavements cannot be ignored. Hence it is important to perform exclusive research on local calibration of cracking models for the pavements of Ontario.

Former studies have shown that LTPP data was used with higher accuracy in previous local calibration strategies in various states in North America. This research is done using MTO's Pavement Management System (PMS) database. Since PMS database is not as comprehensive as LTPP database, many constraints came during this research process which are addressed and discussed in details in this thesis.

The optimized design output from MEPDG is more efficient, noting the analysis procedure and enhanced characterization of traffic data and pavement material properties. However, the optimized designed pavement from MEPDG analysis procedure may require different maintenance and rehabilitation actions from those determine with AASHTO design procedures; the life-cycle cost savings, therefore, would differ from the initial construction cost savings.

\subsection{Thesis Organization}

This thesis includes six chapters, four appendices, and a list of bibliographical references.

- Chapter 1 sheds light on the background, objective and scope of this research study. 
- Chapter 2 represents the details review of literature related to local calibration. It describes the core concepts of fatigue cracking and transverse cracking, historical developments of pavement design methods, the details process of MEPDG method and corresponding design software (AASHTOWare Pavement ME), and previous local calibration studies. This chapter also describes the local calibration process and the methodology of the local calibration strategy for this research for the calibration of cracking models for Ontario's pavements.

- Chapter 3 provides the calibration database that is necessary for the local calibration. In this chapter, the data collection and information of the input parameters: general project information, traffic, climate and pavement structure information are summarized. The observed cracking data preprocessing protocol is also discussed.

- Chapter 4 explains the details method of local calibration procedure for the fatigue cracking and thermal cracking model.

- Chapter 5 provides the calibration result and discussion on the alligator (bottom-up) fatigue cracking, the longitudinal (top-down) fatigue cracking and the thermal cracking.

- At the end, Chapter 6 gives the summary of the research results, conclusions and recommendations. 


\section{Chapter 2 Literature Review}

\subsection{Historical Development of Pavement Design Method}

In order to develop a sensible pavement design method scientists and engineers of pavements travelled a very long journey of systematic investigations. This section summarizes a short overview on the gradual developments of method of pavement design.

Pavements were first constructed in the ancient period where no systematic scientific methods were applied. At that time, experience from the previous projects and the self-decision were used to take any steps during the construction of pavements. Thus these projects, whether successful or failed, helped the constructors to gather experience. Gradually the engineers started accumulating the key factors of pavement design and tried to find some basic relationships between these factors and the performance of pavements.

Soil classification is the first attempt that introduced to the modern pavement design. In 1920, Terzaghi and Hogentogler proposed for Public Road soil classification method (Terzaghi and Hogentogler 1929). That time traffic was not too high. Therefore only layer thickness was applied to the pavements so that the shear failure of subgrade can be resisted. Later Highway Research Board (HRB) revised the classification method and divided it into seven groups (A-1 to A-7). After this, California Divisions of Highways introduced California Bearing Ratio (CBR) method in 1928. CBR method is developed so that the bearing capacity and mechanical properties (e.g. shear strength) of subgrade and base materials can be evaluated. Initially CBR was used to classify the soil to its usage as a base or subbase or subgrade in pavements but later U.S. Corporations of Engineers (USCE) adopted and revised this CBR method for its simplicity.

From 1954 to 1969, in order to design the thickness of asphalt pavements Asphalt Institute published eight editions of Manual Series No.1 (MS-1) based on the empirical relations (Huang 2004). From 1956 to 1961, The American Association of State Highway Officials (AASHO) has done a Road Test worth $\$ 27$ million which is proved to be one of the most important researches done in pavement design history. This research includes a road test section in Ottawa, Illinois which later become a part of Interstate- 80 highway. This basic goal of this study was to observe the response of the pavement due to truck traffic. The AASHO Committee 
of Design published the "AASHO Interim Guide for the Design of Rigid and Flexible Pavements" in 1961 based on the significant outcome from this research.

The regression models in the AASHTO design guide were established during the results of the road test, so there are some limitations in using the equations in all regions. The main limitation was that the models were developed from a test that was carried out in one geographic location, traffic loadings, soil type and construction methods and not for a range of conditions. These require some more calculations for the design of pavement outside the original test range and condition. Moreover the original AASHO Road Test was conducted for a period of two years under the same traffic loading, climatic zone and material. So, the method includes some more drawbacks such as: restricted traffic loads, a single climatic area, a small range of materials used etc. So, major updates were done in 1972 so that these regression equations can be used for different traffic, soil and climate conditions. These updates were done based on additional road tests. In 1986, resilient modulus replaced CBR and R-value and it is considered as the main property of pavement materials. The concept of reliability of design, drainage factors, enhanced environmental effects and refined input parameters were added in this version. In 1993, changes were done in rehabilitation design by including overlays. Non-destructive tests were given importance for the evaluation of existing pavements. These updates were based on engineering experiences and physical principles. These changes were done so that the design methods in AASHTO Pavement Design Guide can be applied to design condition rather than those in AASHTO Road Test.

AASHTO Pavement Design Guide was exercised globally because of its straightforward design method. According to this guide, Present Serviceability Index (PSI) is used to measure the overall serviceability of a pavement. Because, PSI is more unbiased than other distress like cracking, patching, rut depth, distortion in flexible pavements. Structural Number (SN) is calculated by using Traffic loadings or ESAL's (W18) and terminal serviceability (Pt). Pavement material strengths are used to determine the layer coefficients $\left(a_{1}, a_{2}, a_{3}\right)$. These structural numbers, layer coefficients and drainage coefficients $\left(\mathrm{m}_{2}, \mathrm{~m}_{3}\right)$ are used as a basis to select the thickness of the layers of pavements.

Thus AASHTO design guide adopted the interrelationships of the pavement and other factors related to the pavement. Still it did not consider many parameters which may have long term effects on pavement. 


\subsection{Method of AASHTO ME Design}

Though AASHTO Design Guide was performing well, still it is purely empirical. So, AASHTO and FHWA jointly launched two research projects aiming to improve pavement design: NCHRP (National Cooperative Highway Research Program) Project 1-37A and NCHRP Project 1-40.

MEPDG means Mechanistic-Empirical Pavement Design Guide. From the name it is obvious that this guide is a combination of two parts: mechanistic theories of engineering and the experimental results. NCHRP Project 1-37A developed this guide, Guide for MechanisticEmpirical Design of New and Rehabilitated Pavement Structures in 2004. The purpose of this guide is to develop a pavement design method which uses both mechanistic models (i.e. mechanistic theories) and the empirical approaches (i.e. experimental results).

The main thinking behind this guide is to develop a sensible pavement design method which uses the mechanistic models. It uses various types of inputs. The method includes three hierarchical input levels to categorize the input parameters. The designer first selects the inputs and trial design for a specific strategy (new pavement or rehabilitation) considering the site condition. Then the acceptability of the trial design is analyzed. The trial design is revised in case of failure of meeting the requirements and the analysis is repeated.

NCHRP Project 1-40A (2006) is a comprehensive independent review of MEPDG and companion software Version 0.7 under NCHRP Project 1-37A (2004). This Project identified a number of problems which were necessary to solve. Then scores of changes to the MEPDG software were made under NCHRP Project 1-40D (2006) and the key findings of this project were summarized in Research Results Digest 308 (2006). Addition of mixture-specific plastic deformation coefficients for individual HMA layers is one of the major findings. Some other changes are the inclusion of recalibration of distress transfer functions and correction of HMA transfer functions.

The AASHTO Mechanistic-Empirical Pavement Design Guide (MEPDG) introduces elaborated M-E based design procedure for the evaluation of both existing and new pavements by adopting AASHTOWare Pavement ME software. This guide has brought an important change in the previous AASHTO method. 


\subsubsection{General MEPDG Design Procedure}

In MEPDG pavement design method there are three types of inputs: material, traffic and climate. As stated earlier there are two parts in MEPDG method: mechanistic part and the empirical part. Unlike the conventional AASHTO method, The MEPDG has adopted a number of inputs (over 100) for a proposed project. MEPDG considered the effect of many small factors (vehicular inputs, seasonal climatic changes, type of construction etc.) during pavement designs. But with the changes of level of influence with respect to the service life or time, these factors were defined by the mechanistic part. These computative mechanistic portions were not introduced in previous pavement design methods as there were some technological constraints. In mechanistic part of the MEPDG, multi-layered elastic theory is used for the prediction of stresses in pavements layers from the inputs. Then some more mechanistic relationships are used to calculate the strains. The results are used in the response models to calculate the accumulated damage over time.

Pavement ME design estimates the pavement responses: stresses, strains and deflections using the mechanistic approach. The empirical part relates the design process to the characterization of materials, traffic and environment. In empirical distress prediction models, the calculated responses are used as inputs so that the cumulative pavement distresses over time can be calculated. These empirical relations in MEPDG are calibrated nationally with distress predictions of sections based on the Long Term Pavement Performance (LTPP) database. This database includes a number of pavement sections from different states of USA and Canada. Hence, the calibration is known as the global calibration. The predicted performance is adjusted based on the observed performance in the field. In other words, the differences between theory and the actual situation are minimized through adjustments.

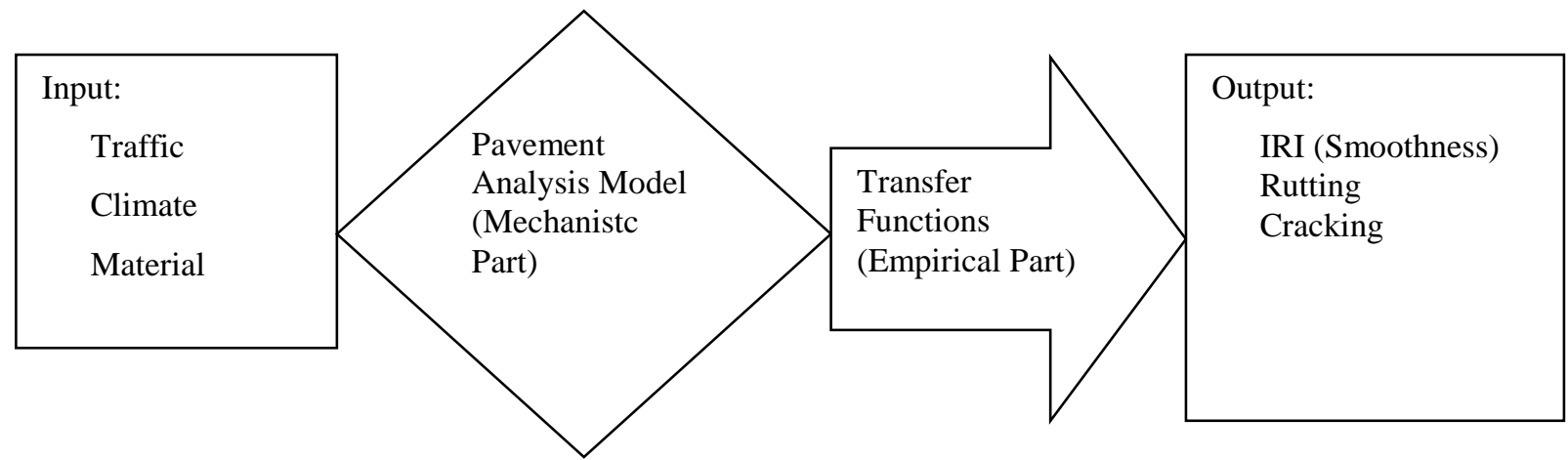

Figure 2.1: Conceptual Flowchart of MEPDG 


\subsubsection{AASHTOWare Pavement ME Software}

Previously the software of MEPDG was named as DARWin-ME in 2011. But, in 2013 the name of the software was changed to AASHTOWare Pavement ME. This software was developed first at late 2004. After that a number of updates were done and latest version was released on July, 2016. This study is based on AASHTOWare Pavement ME version 2.2.

AASHTOWare Pavement ME can import or export the input files. It can keep records of the projects and create data library. The software also provides the advantage of running the analysis of a number of projects simultaneously. Once the analysis is done, the output reports can be obtained in both PDF and Excel formats. The output report summarizes the input parameters (materials, climate, traffic and the calibration parameters) as well as the predicted distresses of the pavement. The output from the software analysis is generally verified against the userspecified design criteria or threshold limits which can be nationally or locally established by the agencies. This verification helps to establish the acceptability or adjustment of the trial design. During the analysis of the pavement, if the performance indicators exceed the specified ranges during the design life, that means the pavement would need reconstruction or rehabilitation. Following table (Table 2.1) shows the default target values provided by the Ministry of Transportation, Ontario (MTO):

Table 2.1: Recommended Target Values for Ontario's Flexible Pavement (MTO 2016)

\begin{tabular}{|l|l|}
\hline Performance Criteria & Default Target Values \\
\hline AC top-down fatigue Cracking & $380 \mathrm{~m} / \mathrm{km}$ \\
\hline AC bottom-up fatigur cracking & $\begin{array}{l}\text { Freeway: } 10 \% \\
\text { Arterial: } 20 \% \\
\text { Collector/Local: } 35 \%\end{array}$ \\
\hline Transverse Cracking (HMA) & $190 \mathrm{~m} / \mathrm{km}$ \\
\hline Rutting (Total Pavement) & $\begin{array}{l}\text { Freeway: } 10 \mathrm{~mm} \\
\text { Arterial/Collector/Local: } 12 \mathrm{~mm}\end{array}$ \\
\hline Rutting (AC Only) & $3 \mathrm{~mm}$ \\
\hline Total Cracking (Reflective + Alligator) & $50 \%$ \\
\hline
\end{tabular}




\subsection{Hierarchical Design Input Levels}

The MEPDG adopts a hierarchical design approach. This approach helps the designer to select the input variables comfortably based on the functional class of highway or reliability of design. As the input data is difficult to meet the expectation, hence the flexibility of the hierarchical approach makes it easy for designers to choose from the default data and related site specific data depending on the need and scope of the project. The analysis procedure and the pavement response models are same at all levels of designs. Based on the input parameters (traffic, materials and pavement condition) hierarchical approach is classified in three input levels. These are shown in Table 2.2:

Table 2.2: Levels of Accuracy of Inputs

\begin{tabular}{|l|l|l|}
\hline Level & Level of accuracy & Input parameters \\
\hline Level 1 & Highest & Site features \\
\hline Level 2 & Intermediate & Data from agencies \\
\hline Level 3 & Lowest & Regional or global default values \\
\hline
\end{tabular}

Level 1 is for highest accuracy of inputs with the highest reliability. This level is usually used for the design of heaviest traffic corridors, safety problems, or early failure problems. The parameters in this level are measured directly on site so that the level of uncertainty can be minimal. Level 1 is generally used for unusual site features, materials or traffic conditions that are not similar to the inference space which is used to develop the correlations. The calculation in this requires expensive experimentation. So calculations are done when the outcome of the early project failure exhibits high economical risks.

Level 2 is the intermediate level of accuracy. This level is generally used for routine design. The input values are collected from the other site-specific data that are less costly to measure and then the input parameters are determined using correlations or regression equations. This level also presents non project specific regional values.

Level 3 is the lowest level of accuracy in input parameters and thus requires the minimum site specific data. This level is for low volume roads or where there are minimal consequences of early failure (NCHRP 2004). The input parameters are selected based on the global and regional default values. 
The hierarchy level in MEPDG is created for the traffic and material input. So the levels are based on the amount of available traffic and material data. The traffic input requirements for MEPDG are:

1. Traffic Volume - Base year information
a. Two-way annual average daily truck traffic (AADTT)
b. Number of lanes in the design direction
c. Percent trucks in design direction
d. Percent truck in design lane
e. Vehicle operational speed (mph)

2. Traffic Volume Adjustment Factors
a. Monthly Adjustment Factors (MAF)
b. Vehicle Class Distribution (VCD)
c. Hourly Truck Distribution Factors (HTDF)
d. Traffic Growth Factors (No growth/Linear/Compound)

3. Axle Load Distribution Factors (ALDF)
a. Single, Tandem, Tridem, and Quad axles

4. General Traffic Inputs
a. Mean wheel location (inches from the lane marking)
b. Traffic wander standard deviation (in.)
c. Design lane width (ft.)
d. Number of axles per truck
e. Axle configuration
f. Tire pressure
g. Wheel spacing
h. Axle spacing
i. Average axle width

The materials for the flexible pavement are classified as below categories in MEPDG:

1. Hot Mix Asphalt-Dense Graded (HMA)

2. Open graded asphalt treated materials

3. Cold Mix Asphalt (CMA)

4. Cementitious Stabilized Materials (CSM) 
5. Non-stabilized granular base/subbase

6. Subgrade soils

7. Bedrock

\subsection{The Key Performance Indicators in MEPDG}

MEPDG considers the following performance prediction indicators for flexible pavement:

- $\quad$ Load Associated Cracking

$>$ Alligator or Bottom-up fatigue cracking

$>$ Longitudinal or Surface-down or Top-down fatigue cracking

- Non-load associated Thermal or transverse cracking

- Reflective cracking

- Permanent deformation or Rutting

- Smoothness or IRI (International Roughness Index)

Fatigue cracks are the results of continual traffic loading. When these cracks initiate at the bottom of asphalt layer and propagate to the surface, these are called as bottom-up cracking. Generally tensile and shear stresses and strains are generated in all stabilized layers under repeated traffic loads. Continual loading causes repeated bending action in the AC layers. These bending actions generate tensile and shear stresses and strains at the bottom of the layer. Crack initiates at the point where the tensile stresses and strains are critical and then gradually propagates through the entire HMA layer. The critical tensile stresses and strains depend upon several factors. Stiffness of the layer and the load configuration are given priority on other factors. Also critical strain depends upon the stiffness of the mix which varies with the layer depth. So ultimately the location of the critical strain is affected. After initiation of the damage, the repeated action of traffic increases the crack propagation through the entire layer. Ultimately water seeps in the lower unbound layer which results in the weakening in the pavement structure and the performance. Fatigue cracking is responsible for the water infiltration to the unbounded layers which may cause structural deterioration, pumping of materials and rutting. This crack initiation and its propagation occur in all stabilized layers and thus decrease the entire structural capacity of each layer. Finally the increased cracks interconnect and form a network of polygon blocks which resembles the skin of an alligator. That's why this cracking is also known as 
alligator cracking. The block size can range from a few millimeters to about a meter. The block size is indicative of the level (depth) at which failure is taking place.

When the cracks initiate at top of asphalt layer and propagate to bottom, these are known as top-down cracking. This type of crack occurs due to high tensile stresses resulting from a tire-pavement interaction and asphalt binder aging (Myers 2001). There are two major mechanisms for top-down cracking. One is near-tire mechanism: shear is generated which results in surface tension at the tire edge which induces crack initiation in thicker HMA layers. The other one is bending mechanism: bending is generated which creates surface tension away from the tire which governs the crack initiation in HMA layers of thin to medium thickness (NCHRP 2010). This distress is calculated as feet $/ \mathrm{mile}$ or $\mathrm{m} / \mathrm{km}$.

Thermal cracking or transverse cracking (thermal fracture) is a non-load associated type of cracking. Hardening of asphalt, changing in daily and seasonal temperature seasonal or constant cold weather exposure are the main reason of transverse cracking. Transverse crack follows a course almost at right angles to the pavement centerline. Full cracks tend to be regularly spaced along the length of the road and the half or part transverse crack occurs at shorter distances. Transverse cracking is computed as feet of cracking per mile or meter/ kilometer.

Rutting is the longitudinal permanent deformation along the wheel path due to the repeated traffic loading which produce densification and shear deformation in all layers of pavement. Rutting is occurred in two stages. In the initial stage of loading the depression is more than the increased upheaval zone i.e. the increased traffic increases the density of pavement. In the final stage the depression is equal to the increased upheaval zone i.e. the densification is complete and the further rutting is occurring by the material displacements. Rutting is measures in the MEPDG in inches or millimeters and appears as a permanent deformation occurring along the wheel paths.

IRI (International Roughness Index) or smoothness defines the characteristics of longitudinal profile of a traveled wheel path. It was developed by the World Bank in 1980 (WSDOT 2005). It is used to determine the functional serviceability of the pavement design. The commonly recommended units are meters per kilometer $(\mathrm{m} / \mathrm{km})$ or millimeters per meter $(\mathrm{mm} / \mathrm{m})$. The IRI is based on the average rectified slope (ARS), which is a filtered ratio of a standard vehicle's accumulated suspension motion (in $\mathrm{mm}$, inches, etc.) divided by the distance 
travelled by the vehicle during the measurement $(\mathrm{km}, \mathrm{mi}$, etc.). IRI is then equal to ARS multiplied by 1,000 (WSDOT 2005). The MEPDG predicts the IRI through an empirical function combining the other performance indicators.

\subsection{The MEPDG Fatigue Cracking Models for Flexible Pavement}

Computation of fatigue cracking is based on Miner's cumulative damage concept. According to this concept damage can be expressed as the ratio of actual traffic for a period to the allowable failure repetitions under conditions prevailing in that period.

$$
D=\sum_{i=1}^{T} \frac{n_{i}}{N_{f}}
$$

where,

$D=$ Damage;

$T=$ Total number of periods;

$n_{i}=$ Actual traffic for $i$ period; and

$N_{f}=$ Allowable failure repetitions to fatigue cracking.

Some well-known factors that influence the damage of asphalt mixture are: asphalt type, asphalt content and air-void content. Other factors are temperature, frequency, and rest periods of the applied load. Material properties may also affect the fatigue life. It is important that mix properties should be balanced properly to optimize fatigue cracking of any mixtures.

The most commonly used model for the prediction of the number of load repetitions that cause fatigue cracking depends upon the tensile strain and mix stiffness (modulus). For top-down cracking the critical locations of the tensile strains can be found in the surface. For bottom-up cracking these locations are detected in the bottom of asphalt layer. The general mathematical form of the number of load repetitions is:

$$
N_{f}=C k_{1} \varepsilon_{t}^{-k_{2}} E^{-k_{3}}
$$

where,

$$
\begin{array}{ll}
N_{f} & =\text { Number of repetitions to fatigue cracking; } \\
\varepsilon_{t} & =\text { Tensile strain at the critical location; } \\
k_{1}, k_{2}, k_{3} & =\text { Laboratory regression coefficients; } \\
E & =\text { Stiffness of the material; and } \\
C & =\text { Laboratory to field adjustment factor. }
\end{array}
$$


Eq. (2.2) calculates the fatigue life in terms of the allowable number of loading repetitions before crack initiations. Using the field adjustment factors, Eq. 2.2 can be modelled for the crack propagation. Again making some differences in laboratory regression coefficients and the laboratory to field adjustment factors in Eq. 2.2, different fatigue cracking models was developed. Among these models, the two most common models were developed by Shell Oil and the Asphalt Institute. Before explaining these two models the phenomena of two types of controlled loading that are applied in laboratory to characterize the fatigue are needed to be understood. These are constant stress and constant strain loading conditions.

Globally calibrated distress prediction models are included in the software of MEPDG. These distress models are calibrated using the pavement sections located throughout North America. The whole process for the fatigue cracking has been described in Appendices II Calibration of Fatigue Cracking Model (NCHRP 2004). The calibration process includes the following steps:

1. Performance data is collected from the LTPP database for each field section.

2. AASHTOWare Pavement ME is used to run the simulation by using a different set of calibration coefficients in the number of load repetition model.

3. The predicted data is compared to the observed data. The coefficient combination with the least scatter of the data and the correct trends is selected.

4. The predicted data is then correlated to the observed data by minimizing the square of the errors.

\section{- Data for Calibration}

> LTPP database was used mainly to obtain the calibration data. These data were obtained from the General Pavement Sites (GPS) and the Special Pavement Sites (SPS). For any missing data, default value was used.

$>$ The main objective of the fatigue cracking model is to calculate the amount of loadrelated cracking for calibration. For the calibration of the fatigue model the considered factors are: temperature, total HMA layer thickness, pavement type and rehabilitation strategy, the resilient modulus of the subgrade soil, mix stiffness and the magnitude of cracking. 
Random field sections are selected to ensure the presence of fatigue cracking and bias, precision and accuracy are considered during the evaluation of model.

For the calibration and the validation of the model the selected criteria are consistency of measurements, time-series distress data, materials characterization and testing, number of layers, traffic, rehabilitation and new construction, maximum use of test sections between model studies, non-conventional mixtures, and experimental optimization/efficiency. To meet these criteria the considered LTPP studies are GPS, SPS-1 and SPS-5.

$>136$ (94 new and 42 overlay) test sections have been used for the calibration. The fatigue data were provided according to the severity level (low, medium and high) for each sections. The LTPP sections had a length of 500 feet. According to NCHRP (2004) the total fatigue cracking will be the addition of the summation of the three fatigue cracking severity values without using any weights for each severity category. For the bottom-up cracking, the percentage of the cracked area is the summation of the measured alligator cracking divided by the total area of the lane $\left(12^{\prime} * 500^{\prime}=6000\right.$ $\mathrm{ft} 2$ ). But for longitudinal cracking (top-down), the value is converted from longitudinal feet per 500 feet to longitudinal feet per mile. For this the summation of the measured longitudinal fatigue cracking, in the LTPP database, is multiplied by 10.56 .

Finally it should be remembered during the calibration process that the bottom-up fatigue cracking results in "alligator cracking" distress alone and surface-down fatigue cracking is associated with "longitudinal cracking"

- $\quad$ Simulation Process

At first calibration parameters are used in the general, mathematical euqation of fatigue model (Eq.2.2) which is replicated below. In later discussion this Eq. will be used as $\boldsymbol{N}_{\boldsymbol{f}}$ model or fatigue model.

$$
N_{f}=\beta_{f 1} k_{1}\left(\varepsilon_{t}\right)^{-\beta_{f 2} k_{2}}(E)^{-\beta_{f 3} k_{3}}
$$

where,

$$
\begin{array}{ll}
N_{f} & =\text { Number of repetitions to fatigue cracking; } \\
\varepsilon_{t} & =\text { Tensile strain at the critical location; }
\end{array}
$$




$$
\begin{array}{cl}
k_{1}, k_{2}, k_{3} & =\text { Laboratory regression coefficients; } \\
\mathrm{E} & =\text { Stiffness of the material; and } \\
\beta_{f 1}, \beta_{f 2}, \beta_{f 3} & =\text { Calibration parameters. }
\end{array}
$$

\section{- $\quad$ Selection of Coefficients}

According to Shell Oil Model,

$$
\begin{aligned}
& k_{1}=\left(1+\frac{13909 E^{-0.4}-1}{1+\exp ^{\left(1.354 h_{a c}-5.408\right)}}\right)\left(0.0252 P I-0.00126 P I\left(V_{b}\right)+0.00673 V_{b}-0.0167\right)^{5} \\
& k_{2}=5 \\
& k_{3}=1.4
\end{aligned}
$$

According to Asphalt Institute MS-1,

$$
\begin{gathered}
k_{1}=0.004325 * 10^{4.84\left(\frac{V_{b}}{V_{a}+V_{b}}-0.69\right)} \\
k_{2}=3.291 \\
k_{3}=0.854
\end{gathered}
$$

In the MS-1 model the values of $0.8,1.0$ and 1.2 are used for the calibration factor on the strain $\left(\beta_{f 2}\right)$, and the values of $0.8,1.5$ and 2.5 are used for the modulus calibration factor $\left(\beta_{f 3}\right)$. For the Shell Oil model the values of 0.9, 1.0, 1.1 are used for $\beta_{f 2}$ and $\beta_{f 3}$.

Out of 94 new sections, 82 sections are selected and then the simulation process is done for both models. Then both are evaluated to select the model that will provide the most accurate solution in calibration process. Then it is found that the Shell Oil Model is more scatter than the MS-1 model. Moreover the MS-1 model shows a definite trend between damage and cracking for the sections greater than 4"-6" AC layer and thin AC sections. So MS-1 model can be selected for the fatigue damage percentage prediction for MEPDG.

Now to derive the accurate shift function the Eq. (19) can be rewrite as:

$$
N_{f}=0.00432 C \beta_{f 1}\left(\frac{1}{\varepsilon_{t}}\right)^{3.291 * \beta_{f 2}}\left(\frac{1}{E}\right)^{0.854 * \beta_{f 3}}
$$

After running the simulation the final values for the calibration factors are set as 1.2 and 1.5 for $\beta_{f 2}$ and $\beta_{f 3}$ correspondingly. So the revised MS-1 bottom-up fatigue cracking model is:

$$
N_{f}=0.00432 C \beta_{f 1}\left(\frac{1}{\varepsilon_{t}}\right)^{3.9492}\left(\frac{1}{E}\right)^{1.281}
$$


Here $\beta_{f 1}$ can be written as, $\beta_{f 1}=\beta_{f 1}^{\prime} * k_{1}^{\prime}$; where $k_{1}^{\prime}$ is used to shift the thin AC layer sections $(<4$ inches $)$.

$$
k_{1}^{\prime}=\frac{1}{0.000398+\frac{0.0036}{1+e^{\left(11.02-3.49 * h_{a c}\right)}}}
$$

The transfer function in the bottom-up cracking is based on the assumption that the fatigue cracking should be $50 \%$ at a damage of $100 \%$. The calibrated model is:

$$
F . C .=\frac{6000}{1+e^{\left(C_{1} C_{1}+C_{2} C_{2} \log _{10} 100 D\right)}} \frac{1}{60}
$$

where,

F.C. is in $\%$ of total lane area

$D=$ Damage in percentage

$$
\begin{aligned}
& C_{1}=1.0 \\
& C_{2}=1.0
\end{aligned}
$$

$$
\begin{aligned}
& C_{1}^{\prime}=-2 * C_{2}{ }^{\prime} \\
& C_{2}{ }^{\prime}=-2.40874-39.748 *\left(1+h_{a c}\right)^{-2.856}
\end{aligned}
$$

The 6000 in the alligator cracking - damage function is the total area of the lane (12 feet wide and 500 feet length). The (1/60) value is a conversion to obtain the cracking in percentage, not in square feet.

For the top-down fatigue cracking,

$$
N_{f}=0.00432 C \beta_{f 1}^{\prime} * k_{1}^{\prime}\left(\frac{1}{\varepsilon_{t}}\right)^{3.9492}\left(\frac{1}{E}\right)^{1.281}
$$

where,

$$
k_{1}^{\prime}=\frac{1}{0.0001+\frac{29.884}{1+e^{\left(30.544-5.7357 * h_{a c}\right)}}}
$$

The transfer function in the top-down fatigue cracking is based on the assumption that the longitudinal surface fatigue cracking should be $5000 \mathrm{ft} / \mathrm{mile}$ at a damage of $100 \%$. The calibrated model is:

$$
F . C .=\frac{1000}{1+e^{\left(C_{3}-C_{4} \ln \mathrm{D}\right)}} * 10.56
$$

where, 
F.C. is in feet per mile.

$D=$ Damage in percentage

$C_{3}, C_{4}$ are calibration parameters determined by using Microsoft solver.

Note that, in Eq. (2.7) "1000" is the maximum length of linear cracking which can occur in two wheel paths of a 500 feet section $(2 * 500$ feet length). The (10.56) factor is a conversion to feet per mile units.

\subsection{The MEPDG Thermal Cracking Model for Flexible Pavement}

The amount of crack propagation for a given thermal cooling cycle is predicted by following the Paris law of crack propagation (NCHRP 2004):

$$
\Delta C=A(\Delta K)^{n}
$$

where,

$\Delta C=$ Change in the crack depth due to a cooling cycle

$\Delta K=$ Change in the stress intensity factor due to a cooling cycle

$A, n=$ Fracture parameters for the HMA mixture

$n=0.8\left[1+\frac{1}{m}\right]$;

$m=$ Slope of the log-linear compliance curve.

The parameters $A$ and $n$ are obtained from the experimental results based on the indirect tensile creep compliance test as Eq. 2.9 (AASHTO 2008):

$$
A=k_{t} \beta_{t} 10^{\left\{4.389-2.52 \log \left(E_{A C} \sigma_{m} n\right)\right\}}
$$

where,

$k_{t}=$ Calibration Coefficient for input level (Level $1=1.5$; Level $2=0.5$; and Level $3=1.5$ )

$\beta_{t}=$ Local calibration factor

$E_{A C}=$ HMA indirect tensile modulus, psi

$\sigma_{m}=$ Mixture tensile strength, $\mathrm{psi}$

A simplified Eq. developed from linear elastic fracture mechanics is used to incorporate the stress intensity factor, $K$ :

$$
K=\sigma_{\text {tip }}\left(0.45+1.99 C_{0}{ }^{0.56}\right)
$$

where,

$$
\sigma_{t i p}=\text { Far-field stress from pavement response model at depth of crack tip, psi }
$$


$C_{0}=$ Current crack length, $\mathrm{ft}$

MEPDG predicts the amount of thermal cracking by using an assumed relationship between the standard normal cumulative distribution function (CDF) of the log crack depth to HMA layer thickness ratio and the percent of cracking (AASHTO 2008).

$$
T C=\beta_{t 1} N\left[\frac{1}{\sigma_{d}} \log \left(\frac{C_{d}}{h_{A C}}\right)\right]
$$

where,

$T C=$ Observed amount of thermal cracking, $\mathrm{ft} / \mathrm{mile}$

$\beta_{t 1}=$ Regression coefficient determined through calibration (400)

$N[z]=$ Standard normal cumulative distribution function evaluated at $[\mathrm{z}]$

$\sigma_{d}=$ Standard deviation of the log crack depth in the pavement

$C_{d}=$ Crack depth, in. and

$h_{A C}=$ Thickness of AC surface layer, in.

It needs to be mentioned here that $\beta_{t 1}$ sets the upper limit for the amount of cracking that can be achieved in the model. The original model used by NCHRP was intended to allow up to 200 feet in a section length of 500 feet (i.e 400 feet in a section length of 1000 feet). Therefore, $\beta_{t 1}$ is fixed at 400 for this research as well. (NCHRP, 2004)

\subsection{Existing Local Calibration Studies}

Existing studies on the two types of calibration processes, global and local calibration, are reviewed.

\subsubsection{Global Calibration}

Global distress prediction models are calibrated using te pavement sections. The calibration process involves performance data collection, simulation using MEPDG software, comparison of observed data and finally correlation of the predicted data to the observed data by minimizing square of errors, as described in section 2.5.

The calibration is accomplished by modifying empirical calibration parameters or transfer functions in the model utilizing calibration parameters. These calibration parameters are necessary to compensate for model simplification and limitations in simulating actual pavement and material behavior. 


\subsubsection{Local Calibration Procedures}

Initially the steps of the local calibration procedure were explained in NCHRP 1-40B (Von Quintus et al. 2009). According to this there are three steps:

1. Verification of MEPDG performance models with national calibration factors.

2. Calibration of the model coefficients.

3. Validation of MEPDG performance models with local calibration factors.

Later these three steps were elaborated in detail to 11(eleven) steps in NCHRP 1-40B. These 11 steps of the procedure of the local calibration are described below (Guide for the Local Calibration of the Mechanical-Empirical Pavement Design Guide, AASHTO 2010):

\section{Step 1: Selection of Hierarchical Level for Each Input Parameter}

The selection depends upon the available resources and required accuracy. The hierarchy level has a significant effect on the standard error of each distress prediction model. So the selection of proper level is very important.

\section{Step 2: Development of Experimental Design and Matrix}

Proper experimental design plan should be developed for the calibration of the MEPDG distress models. Sampling should include all primary factors e.g. pavement type, surface layer type, thickness and subgrade soil type.

\section{Step 3: Estimation of Sample Size for Each Distress Prediction Models}

For this a number of pavement sections are needed to be selected. This step is necessary to estimate the sample size or number of roadway segments to confirm the adequacy of the global calibration coefficients and determine the local calibration coefficients for a specific distress prediction model.

\section{Step 4: Selection of Road Segments}

Pavement segments should be selected from full-scale pavement section, Accelerated Pavement Testing (APT) pads and combination of these two pavement sections for the maximum benefit. In this study, sections from the MTO-PMS-2 in Ontario will be used whose data is already available.

\section{Step 5: Extraction and Evaluation of Distress and Project data}


Distress, material properties, evaluation data including any other needed information should be extracted and evaluated. Maximum distress values should be considered to meet the corresponding design criteria.

\section{Step 6: Conduction of Field and Forensic Investigations}

This is done to obtain missing structural information for selected pavement sections.

\section{Step 7: Asses Local Bias: Validation of Global Default Model}

In this step the performance indicators for each segment of pavement are estimated and then compared to the field observations on the basis of bias and standard error. A null hypothesis is constructed as below:

$$
H_{0}: \sum\left(y_{\text {Measured }}-y_{\text {predicted }}\right)=0
$$

where,

$y_{\text {Measured }}=$ Measured value; and

$y_{\text {predicted }}=$ Predicted value.

If the hypothesis is not satisfactory then the models are recalibrated.

Step 8: Elimination of local Bias in Distress Prediction Models

Based on the bias and errors the calibration coefficients are adjusted.

\section{Step 9: Asses the Standard Error of the Estimate}

In this step, comparison of standard error of calibrated pavement sections and global calibration are conducted. If the readjusted coefficients results in lower standard error then these should be used. Otherwise, the calibration coefficients are needed to be adjusted again.

\section{Step 10: Reduce standard Error of the Estimate}

If the standard error is significantly larger than that from global default models then calibration coefficients are adjusted by numerical optimization and other methods.

\section{Step 11: Interpretation of Results, Deciding on Adequacy of Calibration Parameters}

The effects of the parameters are measured at different reliability levels. Thus the adequacies of the parameters are checked.

\subsubsection{Results from Previous Studies}

Many state or regional agencies have started local calibration for the local conditions throughout the North America. In this section the literature reviews are mainly focused on the fatigue cracking (bottom-up and top-down) model of MEPDG. 
Kang and Adams (2007) have calibrated the fatigue damage model in flexible pavement and identified two calibration factors for Midwest Region (Michigan, Ohio and Winconsin). Database from these three DOT's were collected and the calibration were done. The pavement performance data from Michigan and Ohio shows irregular trends. So, Wisconsin's data was used for calibration. After calibration values were determined with Wisconsin's data, the field data from Ohio and Michigan were compared to the prediction models using (1) default calibration values in the MEPDG and (2) calibration values for Wisconsin data.

Muthadi (2007) and Jadoun (2011) have completed complete their research works on local calibration of MEPGD for North Carolina separately. Both have calibrated the model for the alligator cracking and permanent deformation. In Muthadi's research work, fifty three (53) pavement sections were selected from which thirty (30) sections were from LTPP database and twenty three (23) sections are from the NCDOT. In Jadoun's research work, Material properties and fatigue characterization were developed for all 12 asphalt mix that is used commonly in North Carolina before local calibration. His study also followed a conversion model developed by Corley-Lay et al. (2010) to convert the alligator cracking ratings to equivalent LTPP ratings. LTPP distress models were compared to the NCDOT models for 23 LTPP pavement sections in North Carolina and significant differences were found. So the models were recalibrated for the alligator cracking.

$\mathrm{Li}$ et al. (2009) developed procedures to calibrate the MEPDG performance models for flexible pavement for Washington State. Fatigue damage, longitudinal cracking, alligator cracking, and rutting models were considered. Data from the Washington State Pavement Management System (WSPMS) was used.

Souliman et al. (2010) calibrated the MEPDG performance prediction models for alligator cracking, longitudinal cracking, rutting and IRI for Arizona. Thirty nine (39) pavement sections from LTPP database were used in this study.

Momin (2011) calibrated the MEPDG performance prediction models for alligator cracking, longitudinal cracking, rutting and IRI for North Eastern United States. LTPP database has been used in this study. For longitudinal fatigue cracking, the maximum length of linear cracking which can occur in two wheel paths has been considered as: "1856" instead of " 1000 ".

Hall et al. (2011) have completed the calibration of the MEPDG for flexible pavement design in Arkansas by using LTPP and PMS database. They have calibrated the alligator 
cracking models. Defaults values of some calibration parameters were used due to lack of data. The coefficients were optimized by using the solver function in Microsoft Excel. This paper recommends to establish more additional sites and robust data collections for the full implementation of MEPDG in Arkansas. This paper also emphasize on collecting the data for transverse cracking.

William and Shaidur (2013) calibrated fatigue prediction models for rehabilitated pavements for Oregon. Both alligator and longitudinal cracking models were calibrated and the coefficients were optimized by using the solver function in Microsoft Excel. Then after analyzing the comparison between the results before and after the calibration process, significant differences were found and both cracking models were improved by local calibration. Calibration on the thermal cracking was done also.

Tarefder et al. (2013) calibrated the distress models of rutting, alligator cracking, longitudinal cracking and IRI for New Mexico. Total twenty-four (24) pavement sections of New Mexico and both LTPP and NMDOT database were used for the calibration.

Mallela et al. (2013) calibrated the distress models of rutting, fatigue cracking, transverse cracking, reflective cracking and IRI for Colorado.

The local calibration factors of the fatigue cracking model and the thermal cracking model from the previous local calibration studies are summarized and presented in Table 2.4, 2.5 and 2.6.

Table 2.3: Calibration Factors for the Alligator Cracking from Previous Studies

\begin{tabular}{|c|c|c|c|c|c|c|}
\hline \multirow{2}{*}{ References } & \multirow{2}{*}{ Location } & \multicolumn{5}{|c|}{ Calibration Factors } \\
\hline & & $\beta_{f_{1}}$ & $\beta_{f_{2}}$ & $\beta_{f_{3}}$ & $C_{1}$ & $C_{2}$ \\
\hline $\begin{array}{l}\text { Kang and } \\
\text { Adams (2007) }\end{array}$ & $\begin{array}{l}\text { Midwest Region } \\
\text { (Michigan, Ohio and } \\
\text { Winconsin) }\end{array}$ & 1.0 & 1.2 & 1.5 & 1.0 & 1.0 \\
\hline Muthadi (2007) & North Carolina & 0.007566 & 3.9492 & 1.281 & 0.437199 & 0.150494 \\
\hline Jadoun (2011) & North Carolina & 3.5 & 0.72364 & 0.6 & 0.24277 & 0.24277 \\
\hline Li et al. (2009) & Washington & 0.96 & 0.97 & 1.03 & 1.071 & 1.0 \\
\hline $\begin{array}{l}\text { Souliman et al. } \\
\text { (2010) }\end{array}$ & Arizona & 0.729 & 0.8 & 0.8 & 0.732 & 0.732 \\
\hline Momin (2011) & North Eastern US & - & - & - & -0.06883 & 1.27706 \\
\hline $\begin{array}{l}\text { Hall et al. } \\
(2011)\end{array}$ & Arkansas & - & - & - & 0.688 & 0.294 \\
\hline $\begin{array}{l}\text { Williams and } \\
\text { Shaidur (2013) }\end{array}$ & Oregon & - & - & - & 0.56 & 0.225 \\
\hline Tarefder et al. & New Mexico & - & - & - & 0.625 & 0.25 \\
\hline
\end{tabular}




\begin{tabular}{|l|l|l|l|l|l|l|}
\hline$(2013)$ & & & & & & \\
\hline $\begin{array}{l}\text { Mallela et al. } \\
(2013)\end{array}$ & Colorado & 130.3674 & 1 & 1.217799 & 0.07 & 2.35 \\
\hline
\end{tabular}

Table 2.4: Calibration Factors for the Longitudinal cracking from Previous Studies

\begin{tabular}{|l|l|l|l|l|l|l|}
\hline \multirow{2}{*}{ References } & \multirow{2}{*}{ Location } & \multicolumn{5}{|c|}{ Calibration Factors } \\
\cline { 3 - 8 } & & $\beta_{f_{1}}$ & $\beta_{f_{2}}$ & $\beta_{f_{3}}$ & $C_{3}$ & $C_{4}$ \\
\hline $\begin{array}{l}\text { Kang and Adams } \\
\text { (2007) }\end{array}$ & $\begin{array}{l}\text { Midwest Region (Michigan, Ohio } \\
\text { and Winconsin) }\end{array}$ & 1.0 & 1.2 & 1.5 & 7.0 & 3.5 \\
\hline Li et al. (2009) & Washington & 0.96 & 0.97 & 1.03 & 6.42 & 3.596 \\
\hline Souliman et al. (2010) & Arizona & 0.729 & 0.8 & 0.8 & 1.607 & 0.803 \\
\hline Momin (2011) & North Eastern US & - & - & - & -1.0 & 2.0 \\
\hline $\begin{array}{l}\text { Williams and Shaidur } \\
\text { (2013) }\end{array}$ & Oregon & - & - & - & 1.453 & 0.097 \\
\hline Tarefder et al. (2013) & New Mexico & - & - & - & 3.0 & 0.3 \\
\hline
\end{tabular}

Table 2.5: Calibration Factors of the Thermal cracking from Previous Studies

\begin{tabular}{|l|l|l|l|}
\hline \multirow{2}{*}{ References } & \multirow{2}{*}{ Location } & \multicolumn{2}{|l|}{ Calibration Factors } \\
\cline { 3 - 4 } & & Input Level & $\mathrm{K}$ \\
\hline William and Shaidur (2013) & Oregon & 3 & 10 \\
\hline Mallela et al. (2013) & Colorado & 1 & 7.5 \\
\hline
\end{tabular}

AASHTO Pavement ME Design has been already implemented by Indiana, Missouri and Kansas. The Indiana Department of Transportation (INDOT)is using MEPDG since 2009 considering over 100 sections in this procedure. Initially INDOT have used the 1993 AASHTO Guide for the design procedure, before they started using MEPDG. Therefore, they have compared the MEPDG procedure with 1993 AASHTO Guide and found ignorable changes. Hence they are using the default models. (Ashphaltpro 2015)

From the above discussion and the review of completed local calibration studies from other states and agencies, the following conclusions are drawn:

- Eq. (2.2) is the general fatigue cracking model and Eq. (2.3) is the fatigue cracking model with the calibration parameters for both bottom-up and top-down fatigue cracking.

- Eq. (2.6) and (2.7) are the transfer function for the bottom-up fatigue cracking and the top-down fatigue cracking respectively.

- Local calibrations of fatigue cracking model(s) are referring to Eq. (2.3), (2.6) and (2.7). 
- Fatigue damage transfer functions (Eq. 2.6 and Eq. 2.7) for the bottom-up fatigue cracking and the top-down fatigue cracking are needed to be calibrated. So there are four calibration parameters in total $\left(\mathrm{C}_{1}, \mathrm{C}_{2}, \mathrm{C}_{3}, \mathrm{C}_{4}\right)$ for the bottom-up fatigue cracking and the top-down fatigue cracking. Again, the fatigue damage transfer functions are the function of D (Eq. 2.1) which is a function of $N_{f}$ (Eq. 2.3). So, in Eq. (2.3), the calibration parameters $\beta_{f 1}, \beta_{f 2}, \beta_{f 3}$ are also needed to be adjusted.

- For thermal cracking model, $\mathrm{K}_{\mathrm{t}}$ in Eq. (2.9) can be calibrated for different input level. Hence this parameter needed to be calibrated.

\subsection{Concluding Remarks}

It can be concluded from this literature review that the MEPDG and the corresponding AASHTOWare Pavement ME is a capable tool for pavement design. But it needs substantial and ongoing local calibration efforts from research community before it can be integrated into the pavement design procedure. In addition, designs based on the AASHTOWare software need to be compared to the existing design procedures as a quality control check till the new approach gains more experience and confidence, and more accurate performance models are developed and integrated to the design programme.

The literatures review on former studies concludes that many states have practised local calibration on cracking model. Local calibration was done for the fatigue cracking model mainly. Very few states have done calibration of the thermal cracking model and reflective cracking model. All of these states have followed LTPP protocol for processing the observed distress whereas the preprocessing the observed distress in this research was one of the major constraints, as discussed in Section 3.4. 


\section{Chapter 3 Calibration Database}

Database development is the first step of local calibration. This Chapter presents a detailed discussion of the selection of pavement sections used for the calibration, the input data for the pavement analyses, and the processing protocol of the observed crack data.

\subsection{Required Data for Local Calibration}

Since local calibration procedure includes comparison of observed and the predicted data, hence the process of local calibration of the cracking models requires two types of data: observed crack data and predicted crack data for the selected pavement sections. The observed data are collected from the MTO's database. Then further processing was done to use the data as the observed data for the calibration. The predicted crack data are the output results of the AASHTOWare pavement design software (version 2.2) for each section which needs detailed input and level of accuracy for each selected pavement sections. The major inputs are:

- General project information

- Traffic data

- Climate data

- Pavement material and structural data

The details of processing the database are discussed below.

\subsection{Pavement Sections Selection}

Ontario has more than 16,500 lane-km pavements. These pavements are divided into about 1,800 pavement sections. These sections are under the supervision of the Ministry of Transportation of Ontario (MTO) (Li et al. 2008). Majority of these pavements are flexible. Local calibration study needs a minimum number of road sections to fit the outcomes for the entire pavement by minimizing the biases in the results. According to the Guide for the Local Calibration of the Mechanical-Empirical Pavement Design Guide (AASHTO 2010) the general split of the sample is $80 / 20$ i.e. $80 \%$ data should be used for the calibration and $20 \%$ data should be used in validation. Since there is a lot of variation in LTPP data, so the guide recommends selecting 
minimum number of sections which are no more than 30 sections in number. In this research study, the recommendation from the guide has been followed. For more details of the database development refer to Gautam (2015).

MTO has started using Superpave since 2001. As of 2015, there have been in total 87 projects that used Superpave mix in the top asphalt layer(s), which exhibits corresponds to 164 sections in the PMS(Pavement Management System). These sections with different pavement materials and route types are from five different regions of Ontario separated by MTO. From these sections the pavement sections with small length, intersection improvement, composite feature, SMA top and widening project are omitted. After screening, 78 sections are considered for the calibration process and 39 sections are considered for validation. The input data for these sections are collected from MTO staff to prepare the calibration database (Database table in Appendix A). Since in AASHROWare Pavement ME Version 2.2 could not generate the report of a number of sections (bug problem, confirmed with the ARA), therefore at the end only 51 sections were used for the calibration process.

\subsection{Major Input Parameters for MEPDG}

Accurate inputs related to material, traffic and climate are important for the AASHTOWare pavement design analysis. The major input parameters the software for the successful local calibration of new, reconstructed and rehabilitated flexible pavement sections are discussed below:

\subsubsection{General project information}

In this section, general information will be discussed which comprise of design life, existing pavement constructions date, pavement overlay construction date, traffic open date, and new construction or rehabilitation history. General information needed for AASHTOWare Pavement ME is summarized in Table 3.1. During analysis 50\% reliability has been chosen in the software and the other values are selected based on the Ontario's Default Parameter Guide and MTO's PMS-2 database. 
Table 3.1: General Project Inputs for AASHTOWare Pavement ME

\begin{tabular}{|c|c|c|c|}
\hline Name & Required Input & $\begin{array}{l}\text { Input } \\
\text { Level }\end{array}$ & \begin{tabular}{|l|} 
Input \\
Source \\
\end{tabular} \\
\hline $\begin{array}{l}\text { General } \\
\text { Information }\end{array}$ & $\begin{array}{l}\text { - Design Type } \\
\text { - Pavement Type } \\
\text { - Design Life } \\
\text { - Base construction (month, year) } \\
\text { - Pavement construction date (month, } \\
\text { - year) } \\
\text { - Overlay construction (month, year) } \\
\text { - Traffic opening (month, year) }\end{array}$ & 1 & MTO 2016 \\
\hline $\begin{array}{l}\text { Pavement Distress } \\
\text { for Comparison }\end{array}$ & $\begin{array}{l}\text { - Initial IRI }(\mathrm{m} / \mathrm{km}) \\
\text { - Terminal IRI } \\
\text { - AC top-down fatigue cracking }(\mathrm{m} / \mathrm{km}) \\
\text { - AC bottom-up fatigue cracking }(\mathrm{m} / \mathrm{km}) \\
\text { - AC thermal fracture }(\mathrm{m} / \mathrm{km}) \\
\text { - Permanent deformation - total }(\mathrm{mm}) \\
\text { - Permanent deformation - AC only }(\mathrm{mm})\end{array}$ & 2 & MTO 2016 \\
\hline
\end{tabular}

\subsubsection{Traffic Data}

There are 41 traffic inputs spread in 7 main groups in AASHTOWare Pavement ME. These are annual average daily truck traffic (AADTT), traffic volume adjustment, axle distribution, traffic capacity, axle configuration, lateral traffic wander and wheel base. Traffic inputs are given in Table 3.2.

Table 3.2: Traffic Input Data

\begin{tabular}{|c|c|c|c|}
\hline Name & Input Requirement & $\begin{array}{l}\text { Input } \\
\text { level }\end{array}$ & Source \\
\hline $\begin{array}{l}\text { Annual Average } \\
\text { Daily Truck } \\
\text { Traffic } \\
\text { (AADTT) }\end{array}$ & $\begin{array}{ll}- & \text { Two way ADTT } \\
- & \text { Number of lanes in the design direction } \\
- & \text { Percent of trucks in design direction } \\
- & \text { Percent of trucks in design lane } \\
\text { - } & \text { Operational speed }\end{array}$ & $\begin{array}{l}1 \\
1 \\
3 \\
2 \\
3\end{array}$ & $\begin{array}{l}\text { MTO Database } \\
\text { MTO Database } \\
\text { Local calibration } \\
\text { Guide } \\
\text { MTO } 2014 \\
\text { MTO } 2014\end{array}$ \\
\hline $\begin{array}{l}\text { Traffic Volume } \\
\text { Adjustment } \\
\text { factors }\end{array}$ & $\begin{array}{ll}\text { - } & \text { Vehicle class distribution } \\
\text { - } & \text { Traffic Growth rate } \\
\text { - } & \text { Growth function } \\
\text { - } & \text { Monthly adjustment factor } \\
\text { Hourly Adjustment factor }\end{array}$ & $\begin{array}{l}2 \\
1 \\
1 \\
3 \\
3\end{array}$ & $\begin{array}{l}\text { MTO Database } \\
\text { MTO Database } \\
\text { MTO Database } \\
\text { Software Default } \\
\text { Software Default }\end{array}$ \\
\hline Axle Per Truck & $\begin{array}{ll}- & \text { Single Axle Per Truck } \\
- & \text { Tandem Axle Per Truck } \\
\end{array}$ & 2 & MTO 2014 \\
\hline
\end{tabular}




\begin{tabular}{|c|c|c|c|}
\hline & $\begin{array}{ll}\text { - } & \text { Tridem Axle Per Truck } \\
\text { - } & \text { Quad axles Axle Per Truck }\end{array}$ & & \\
\hline $\begin{array}{l}\text { Axle } \\
\text { Distribution }\end{array}$ & $\begin{array}{ll}- & \text { Single Axle Distribution } \\
\text { - } & \text { Tandem Axle Distribution } \\
\text { - } & \text { Tridem Axle Distribution } \\
\text { - } & \text { Quad axles Axle Distribution } \\
\end{array}$ & $\begin{array}{l}2 \\
2 \\
2 \\
2\end{array}$ & $\begin{array}{l}\text { MTO } 2014 \\
\text { MTO } 2014 \\
\text { MTO } 2014 \\
\text { MTO } 2014 \\
\end{array}$ \\
\hline $\begin{array}{l}\text { Axial } \\
\text { Configuration }\end{array}$ & $\begin{array}{ll}\text { - } & \text { Average axle width }(\mathrm{m}) \\
\text { - } & \text { Dual tire spacing }(\mathrm{mm}) \\
\text { - } & \text { Tire pressure }(\mathrm{kPa}) \\
\text { - } & \text { Number of Axles per Truck } \\
\text { - } & \text { Tandem axle spacing }(\mathrm{m}) \\
\text { - } & \text { Tridem axle spacing }(\mathrm{m}) \\
\text { - } & \text { Quad axle spacing }(\mathrm{m})\end{array}$ & $\begin{array}{l}3 \\
3 \\
3 \\
2 \\
2 \\
2 \\
2\end{array}$ & $\begin{array}{l}\text { Software Default } \\
\text { Software Default } \\
\text { Software Default } \\
\text { MTO } 2014 \\
\text { MTO } 2014 \\
\text { MTO } 2014 \\
\text { MTO } 2014\end{array}$ \\
\hline $\begin{array}{l}\text { Lateral Traffic } \\
\text { Wander }\end{array}$ & $\begin{array}{ll}- & \text { Mean wheel location }(\mathrm{mm}) \\
- & \text { Traffic wander standard deviation } \\
(\mathrm{mm}) & \\
- & \text { Design lane width }(\mathrm{m}) \\
\end{array}$ & $\begin{array}{l}3 \\
3 \\
1\end{array}$ & $\begin{array}{l}\text { Software Default } \\
\text { Software Default } \\
\text { MTO Database }\end{array}$ \\
\hline Wheel Base & $\begin{array}{ll} & \text { Average spacing of short axles } \\
(\mathrm{m}) & \\
- & \text { Average spacing of medium axles } \\
(\mathrm{m}) & \\
- & \text { Average spacing of long axles (m) } \\
- & \text { Percent of trucks with short axles } \\
(\%) & \\
- & \text { Percent of trucks with medium } \\
\text { axles }(\%) \\
- & (\mathrm{vi}) \text { Percent of trucks with long } \\
\text { axles }(\%)\end{array}$ & $\begin{array}{l}2 \\
2 \\
2 \\
3 \\
3 \\
3\end{array}$ & $\begin{array}{l}\text { MTO } 2014 \\
\text { MTO } 2014 \\
\text { MTO } 2014 \\
\text { Software Default } \\
\text { Software Default } \\
\text { Software Default }\end{array}$ \\
\hline
\end{tabular}

Note that, for some inputs, default parameter of AASHTOWare Pavement ME Version 2.2 has been selected i.e. the source is Manual of Practice (MOP).

\subsubsection{Climate data}

Pavement performance is heavily dependent on the local climate and gets affected by changes in local temperature, season and frost depth considerably. These needs to be input in MEPDG, hence, they need to be observed and correlated to pavement performance. The climate parameters are obtained from weather stations close to the project location. The AASHTOWare pavement ME software includes a large database of weather stations throughout USA and Canada these days. This database for each weather station contains climatic inputs for multiple years. Each weather station data includes hourly data for air temperature, wind speed, sunshine, precipitation 
and humidity for several months. Several major weather stations have hourly limited data of 60 to 66 months, this is not always the case hence software requires at least 24 months actual weather station data for computational purposes (NCHRP 2004).

Moisture and temperature distributions through the pavement structure are predicted using these climate inputs. Asphalt concrete stiffness is sensitive to temperature variations and unbound material stiffness is sensitive to moisture variations. Regional climate profile defines the aging effects in a pavement. Whereas, extreme weather conditions such as temperature, precipitation, continuous freeze-thaw cycles and depth of water table influences extreme long term distresses significantly. Local climate is enforced by inputting location parameters (latitude, longitude and elevation), which then indicates location of surrounding weather stations. The climate input data required for AASHTOWare Pavement ME are given in Table 3.3.

Table 3.3: Climate Input Data

\begin{tabular}{|l|ll|l|l|}
\hline Item & Input & Input Level & Source \\
\hline \multirow{3}{*}{ Climate Parameters } & $\bullet$ & Latitude & 1 & \\
& $\bullet$ & Longitude & 1 & Google maps \\
& $\bullet$ & Elevation & 1 & \\
\hline Ground Water Location & Ground Water Table & 3 & MTO Database \\
\hline
\end{tabular}

The parameters latitude, longitude and elevation of the pavement sections that are collected from the Google maps are summarized in Appendix C. For the depth of ground water table (GWT), the default value for the regional condition $(6.1 \mathrm{~m})$ is used.

\subsubsection{Material and Structural Input}

Typically, the design of a flexible pavement can be in two types of structural layers, namely, AC layer and unbound (granular and fine) layer by using different types of material. AC layer mainly uses Superpave, stone matrix asphalt (SMA), Marshall mix and asphalt stabilized material, whereas, Granular materials, chemically stabilized base materials and fine sub-grade soil are used for unbound layer in Ontario's roads, which are presented in Appendix D.

The AASHTOWare needs material properties of the pavement layers for mechanistic analysis to obtain the pavement responses and distresses under local condition. The material inputs are categorized into 5 main groups for $\mathrm{AC}$ layer and 3 groups for unbound layer, as presented in Tables 3.4 and 3.5 respectively. In terms of the accuracy level, the Level 1 (project 
specific) material properties are preferred. However, many properties such as aggregate gradation, air voids, binder content are difficult, but not impossible to obtain or retrieve. For this reason and to facilitate the local calibration, the MTO has developed a guide document that specifies the default values for those parameters that are not easy to obtain their project-specific values (MTO 2012).

Table 3.4: Material input for AC layer

\begin{tabular}{|c|c|c|c|}
\hline Parameter & Input Requirement & $\begin{array}{l}\text { Level of } \\
\text { input }\end{array}$ & Sources \\
\hline Asphalt Layers & $\begin{array}{l}\text { Thickness (mm) } \\
\text { Material types }\end{array}$ & $\begin{array}{l}1 \\
1\end{array}$ & $\begin{array}{l}\text { Construction Contract } \\
\text { Documents }\end{array}$ \\
\hline \multirow{3}{*}{$\begin{array}{l}\text { Volumetric Mixture } \\
\text { Properties }\end{array}$} & Unit weight $(\mathrm{Kg} / \mathrm{m} 3)$ & 2 & MTO 2014 \\
\hline & Effective binder content (\%) & 2 & MTO 2014 \\
\hline & Air voids (\%) & 2 & MTO 2014 \\
\hline Poison's Ratio & Poison's Ratio & 3 & Software Default \\
\hline \multirow[t]{7}{*}{ Mechanical Properties } & Dynamic modulus & \multirow{6}{*}{$\begin{array}{l}3 \\
2\end{array}$} & Software default \\
\hline & Aggregate Gradation & & MTO 2014 \\
\hline & $\mathrm{G}^{*}$ Predictive Model & & Software Default \\
\hline & Reference temperature (Co) & & Software Default \\
\hline & Asphalt binder & & MTO 2014 \\
\hline & $\begin{array}{l}\text { Indirect tensile strength at }-10 \\
{ }^{\circ} \mathrm{C}(\mathrm{MPa})\end{array}$ & & Software default \\
\hline & Creep compliance (1/GPa) & 3 & Software Default \\
\hline \multirow[t]{3}{*}{ Thermal } & Thermal conductivity $(\mathrm{W} / \mathrm{m}-\mathrm{K})$ & \multirow{3}{*}{$\begin{array}{l}3 \\
3 \\
3\end{array}$} & Software Default \\
\hline & Heat capacity $(\mathrm{J} / \mathrm{kg}-\mathrm{K})$ & & Software Default \\
\hline & Thermal Contraction & & Software Default \\
\hline
\end{tabular}

Table 3.5: Material Inputs Requirements for software

\begin{tabular}{|l|l|l|l|}
\hline Parameter & Input Requirement & Level of input & Sources \\
\hline \multirow{2}{*}{ Unbound Layers } & Thickness (mm) & 1 & This Research \\
& Material types & 1 & \\
\hline \multirow{3}{*}{ Mechanical Properties } & Resilient Modulus & 1 & This Research \\
& Poison's Ratio & 3 & Software Default \\
& Coefficient of Lateral Earth Pressure & 3 & Software Default \\
\hline \multirow{3}{*}{ Others } & Aggregate Gradation & 2 & \multirow{2}{*}{ MTO 2012 } \\
\hline
\end{tabular}




\subsection{Preprocessing Protocol for Observed Cracking Data}

\subsubsection{Background}

Observed cracking data is a key input of the calibration study. However, as mentioned earlier, the field measured data provided by MTO using the ARAN-9000 LCMS technology cannot be directly used in calibration for two reasons:

First, there is no direct match between the cracking morphology detected from the LCMS images and the cracking mechanisms evaluated in MEPDG. The ARAN9000 vehicle is equipped with specialized tools to collect calibrated and repeatable measurement of several pavement distress parameters such as roughness, rutting, and crack measurement. For crack measurements in particular, ARAN9000 employs the LCMS, a laser-scanning technology to measure the three dimensional features of all cracking damages. The collected multiple streams of data are uploaded, processed and analyzed using iVision software, a proprietary desktop application. The iVision allows synchronized viewing of right-of-way imagery, pavement imagery and pavement condition data. From iVision analysis, not only precise level pavement condition data, but other roadside assets as well, is collected and utilized in the asset management procedure of MTO. The pre and post processing tool ivision utilizes the three dimensional captures to separate the noise from the raw data and identify different types of distresses, namely rutting, cracking, IRI. This tool differentiates between observed types of distresses based on their geometrical features and locations on the pavement (Roadtalk, 2016). The morphologically based cracking report as the cracking extent and severity is sufficient for pavement management because it provides adequate information for asset management decision-making. However, the same report without identifying the root causes of the cracking cannot be used for local calibration. Unfortunately, this cannot be easily resolved unless more accurate sensing technology has been applied in pavement evaluation.

Second, pavement sections in MTO's current PMS, and thus the sections in the local calibration databased developed above, are not defined the same way as the sections in LTPP was defined. In the local calibration database, the length of pavement sections varies from 0.7 kilometer to 30 kilometer. However, the LTPP database specifies 500 feet (152.4 meter) as the standard length of a pavement section [NCHRP (2004)]. As reviewed in Chapter 2, the development and global calibration of the cracking models, as well as the local calibration in the USA, were all hinged upon the standard dimension of the pavement sections. The Local 
Calibration Guide (AASHTO 2010) also suggests the use of the same dimension of the pavement section as in LTPP database. If not properly done, this length difference may result in data inconsistency, which may cause unnecessary model bias after local calibration. It may also result in invalid design thresholds for cracking distresses. While analyzing the raw data, it was found that the crack damage is more in shorter length and is decreasing with increase in section length. So, converting the PMS-2 performance data into MEPDG format is one of the major constraints in this study.

With the data given as they are, the best one can do is to follow some mutually agreed data process protocol so that other people in local calibration, if they so wish, can repeat the work and obtain the same results. Fortunately, MTO maintains the raw crack data recorded for each section at every $50 \mathrm{~m}$ interval. These data can be used to derive a consistent observed cracking damage value that is comparable to the cracking damage defined in LTPP and MEPDG.

\subsubsection{Data Processing Protocol}

As explained in the previous section, to keep consistency with the global calibration of the MEPDG format, the 500ft section length should be used in this local calibration study as well. However, the crack data by the Ministry of Transportation of Ontario (MTO) using ARAN9000 vehicle are summarized and reported at every $50 \mathrm{~m}$ interval. In addition, the reported cracks are classified based on shape, location, and severity level. Depending upon its shape and geometrical feature, a crack is reported as an alligator, longitudinal or transverse crack. To report the location of each crack, iVision divide the pavement along the direction perpendicular to traffic flow into five zones, as shown in Figure 3.1, in the direction from shoulder to median: Pavement Edge, Wheel Path 1, Midline, Wheel Path 2, and Centre line. Each type of the cracks is further reported based upon three severity levels: severe, moderate and low.

Because of these, the crack data processing protocol contains several decisions. First, what cracks are considered to be fatigue cracks and what to be thermal cracks? For fatigue cracks, what are bottom-down cracks and what are top-down cracks? Second, how are cracks of different severity levels aggregated into one crack damage value? In other words, should they be summed, simply averaged, or weighted averaged? Third, how to aggregate ARAN data into the sections while using AASHTOWare Pavement ME software. 
Fatigue cracking is a load associated type of cracking. Continuous or repetitive loading on the pavement causes this kind of cracks. They are of two types, namely, bottom-up cracking and top-down cracking. Thermal cracking or transverse cracking (thermal fracture) is a nonload associated type of cracking. Hardening of asphalt, changing in daily and seasonal temperature seasonal or constant cold weather exposure are the main reason of transverse cracking. Transverse crack follows a course almost at right angles to the pavement centerline. When these cracks initiate at the bottom of asphalt layer and propagate to the surface, these are called as bottom-up cracking. This crack initiation and its propagation occur in all stabilized layers and thus decrease the entire structural capacity of each layer. Finally the increased cracks interconnect and form a network of polygon blocks which resembles the skin of an alligator. That's why this cracking is also known as alligator cracking. When the cracks initiate at top of asphalt layer and propagate to bottom, these are known as top-down cracking. Now the cracks on a section length was differentiated into categories (slight, moderate and severe, as described in Figure 3.1) by ARAN9000 vehicle, while collecting the data. These crack length were summed and crack width gets averaged. Each sections considered in the local calibration database are not in $500 \mathrm{ft}$ or $150 \mathrm{~m}$ standard length. Therefore, pavement sections used in this study was decomposed into $150 \mathrm{~m}$ long segments to match with MEPDG format, It was an important issue to select method of aggregation of ARAN data into the segmented sections. This study considered two aggregation methods: The first one is the maximum value of the $150 \mathrm{~m}$ crack damage, and the second is the mean or the average value. This needs to be note here that ivision, software that processes ARAN9000 database, differentiates cracks by their geometrical features and location of the cracks, not by root cause of the distress. (MTO, 2013)

Fatigue distress data (both alligator and longitudinal fatigue cracking) are collected from four different areas of pavement sections: wheel-path, mid-lane, pavement edge and center line. Data are recorded as crack extend (unit meter) for thermal cracking. A sample drawing is shown Figure 3.1 to point out these distresses (MTO, 2013). 


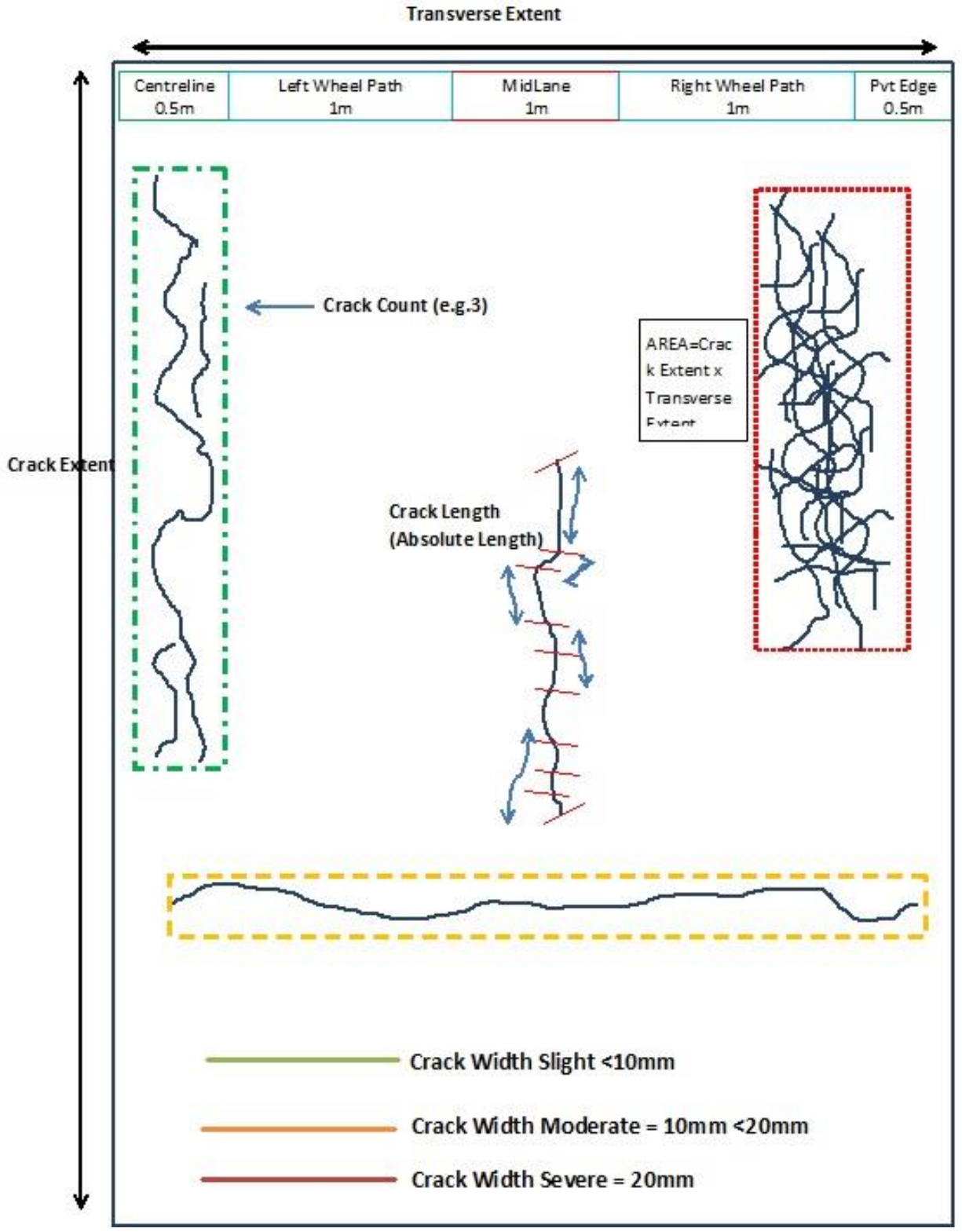

Figure 3.1: Distress Matrices, (MTO, 2013)

Hence, for each segment of a pavement section, there are twelve distress data for fatigue cracking and three data for thermal cracking. After calculating crack data, crack damage are calculated. For alligator damage, crack data are divided by section area (since data are recorded as square-meter). For longitudinal damage, crack data are divided by section length and multiplied by 1000 to get the data in meter/kilometer. Thermal damage calculation is same as longitudinal damage. 
Since in ARAN database, crack data at 50-meter interval for each pavement section are recorded, therefore the crack data in the adjacent section are accumulated to obtain the data at 150-meter length of pavement section. This process is explained below:

Assume that $L$ is the length of a pavement section of 450-meter. $L$ is divided into three segments of 150-meter each. The segments are $A, B$ and $C$. These three segments are further divided into three parts. Each part is 50-meter long.

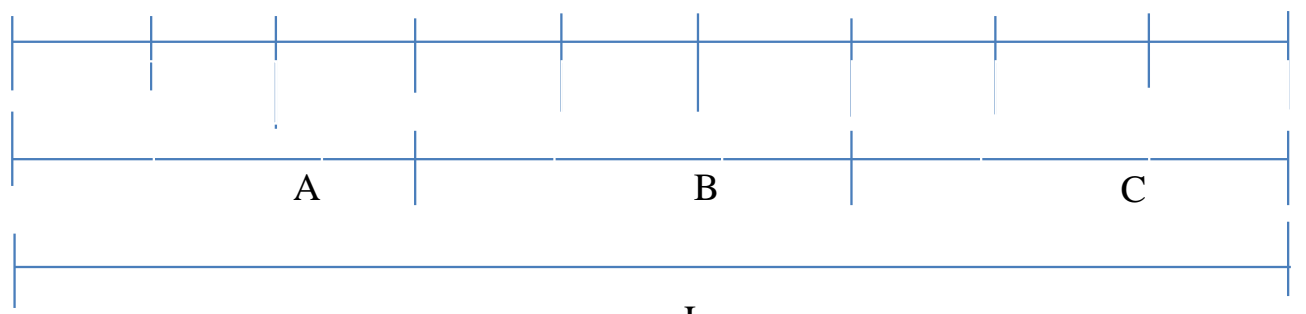

$\mathrm{L}$

Figure 3.2: Sample calculation for observed data

Here, $L=$ Length of Pavement Section $=\mathrm{A}+\mathrm{B}+\mathrm{C}=450$-meter.

$A=\mathrm{a}_{1}+\mathrm{a}_{2}+\mathrm{a}_{3}=150 \mathrm{~m} ; B=\mathrm{b}_{1}+\mathrm{b}_{2}+\mathrm{b}_{3}=150 \mathrm{~m} ;$ and $C=\mathrm{c}_{1}+\mathrm{c}_{2}+\mathrm{c}_{3}=150 \mathrm{~m}$.

$a_{1}=a_{2}=a_{3}=b_{1}=b_{2}=b_{3}=c_{1}=c_{2}=c_{3}=50$ meter.

From these three segments $\mathrm{A}, \mathrm{B}$ and $\mathrm{C}$, the maximum crack damage will be used as the observed value for this pavement section.

Thus a long pavement section can be divided into a number of small segments of 50meter length and the observed crack damage can be obtained by doing necessary calculations. At the end, a number of crack data for each 150-meter length are obtained for a pavement section. Observed data were processed in two ways:

1. Maximum cracking data of the $150 \mathrm{~m}$ segment - while taking maximum data, complete pavement section was considered. Maximum cracking data were obtained for both Fatigue cracking and Thermal cracking.

2. Average cracking data of the $150 \mathrm{~m}$ segment - while taking average cracking data, only wheel path location were used. Only Fatigue cracking data was obtained while generating average cracking data. 
A visual representation of the difference of the two sets of data (Alligator damage of Maximum of whole section vs Average of Wheelpath location) is illustrated in Figure 3.3. The mean and standard deviation for Max of whole section is $(13.4651,15.8993)$ and the same for mean and standard for Average of Wheelpath location is $(1.9697,3.8263)$.

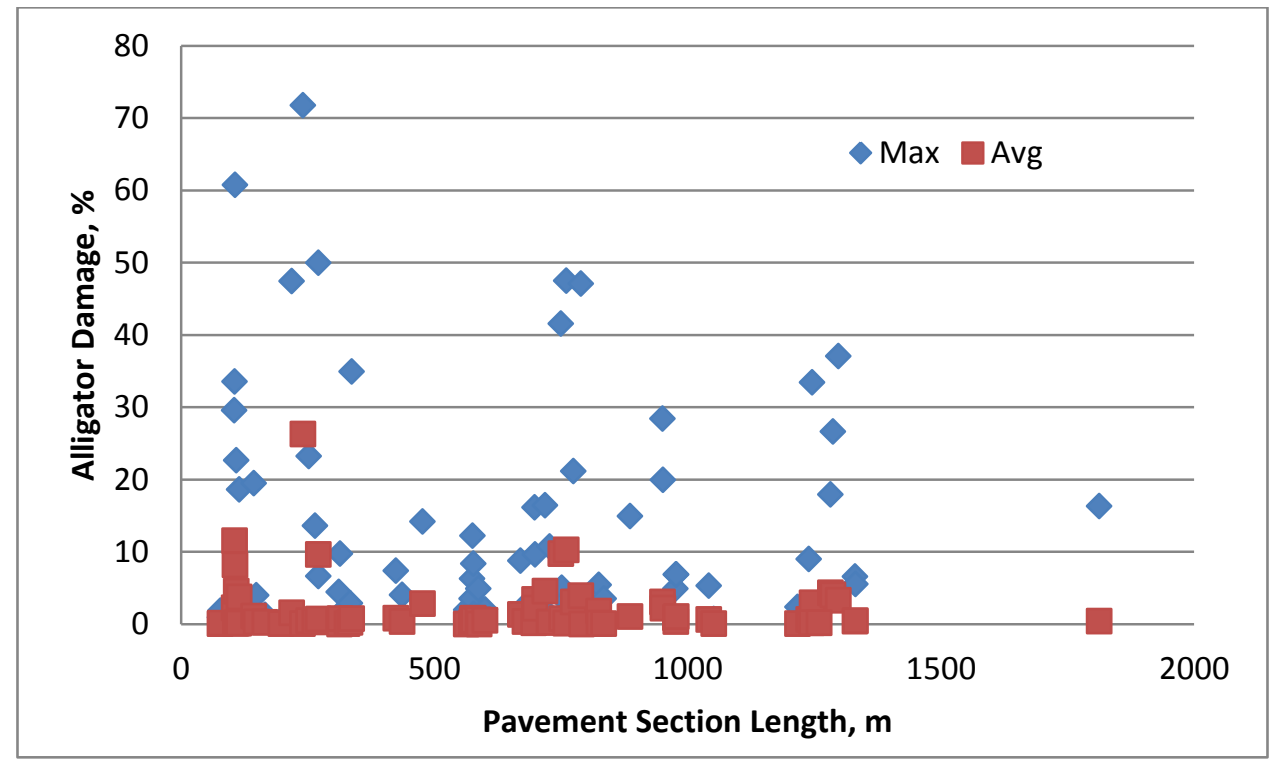

Figure 3.3: Maximum Alligator cracking of the whole section vs Average Alligator cracking of the wheel path section

A weighted average has been used in the data input, after processing the observed data for thermal cracking. Weighted value for the observed cracking is considered by using the following formula:

Transverse Damage $=\frac{1}{9} \times($ Low $+3 \times$ Medium $+5 \times$ High $)$

\subsection{Concluding Remarks}

This chapter discussed the details of three major categories of input data (i.e., traffic, climate and materials) requirement and the field-measured performance data. Pavement sections for local calibration were selected by screening based on the quality of historical pavement performance data retrieved from the MTO database.

For all the selected sections, observed distress data and related section name, route name, route direction, station beginning mile, station end mile, facility type, functional class, AADTT, 
sub-grade modulus, axle configuration, vehicle class, materials properties etc. were collected and compiled to the proper format for the use of local calibration. Latitude, longitude and elevation for specific section are collected from google map and complied accordingly in to the data file. Finally, these integrated data will be used for pavement analysis as discussed in the following local calibration studies. 


\section{Chapter 4 Local Calibration Methods}

Although this study follows the general principles and steps of the AASHTO local calibration guide in general, there are still particular technical issues that need to be addressed in the analysis. This chapter discusses these issues for different cracking models.

\subsection{Fatigue Cracking}

As stated previously, the main objective of local calibration is to minimize the bias and the residual sum of squares (RSS). The bias is the total sum of the differences between the observed and the predicted cracks, whereas the RSS is the summation of the squares of all bias. In equation, they are expressed as

$$
\begin{aligned}
& \text { Bias }=\sum\left(y_{\text {measured }}-x_{\text {predicted }}\right) \\
& \text { RSS }=\sum\left(y_{\text {measured }}-x_{\text {predicted }}\right)^{2}
\end{aligned}
$$

where,

$$
\begin{aligned}
& y_{\text {measured }}=\text { Observed value } \\
& x_{\text {predicted }}=\text { Predicted value }
\end{aligned}
$$

By following the Local Calibration Method, the null hypothesis was evaluated which is:

$$
\mathrm{H}_{0}=\Sigma\left(y_{\text {measured }}-x_{\text {predicted }}\right)=0
$$

Transfer functions for the bottom-up fatigue cracking (Eq. 2.6) and the top-down fatigue cracking (Eq. 2.7) are needed to be calibrated. Again, the fatigue damage transfer functions are the function of pavement's cumulative damage (D) (Eq. 2.1). Since Damage (D) is a function of $N_{f}$ model (Eq. 2.3), there are three calibration parameter, namely $\beta_{f 1}, \beta_{f 2}, \beta_{f 3}$, for $N_{f}$ model and two calibration parameter for each transfer function $\left(\mathrm{C}_{1}, \mathrm{C}_{2}\right.$, for bottom up cracking and $\mathrm{C}_{3}$, $\mathrm{C}_{4}$, for top down cracking).

In this research, the calibration parameters $\beta_{f 1}, \beta_{f 2}, \beta_{f 3}$ may be adjusted. $\beta_{f 1}$ was not adjusted because this is the coefficient for layer thickness, and all the pavement sections used in this research had a layer thickness more than 4 inch. Therefore, $\beta_{f 1}$ will not be adjusted and is taken the default value 1 . The other two parameters $\beta_{f 2}, \beta_{f 3}$ are adjusted in MEPDG software and using regression analysis, calibrations parameters are adjusted. This needs to be mentioned here that calibration parameters $\left(\beta_{f 1}, \beta_{f 2}, \beta_{f 3}\right)$ for fatigue cracking models (i.e. $N_{f}$ model) is 
same for both Bottom-up and Top-down cracks, since a single fatigue model refers to both of them.

\subsubsection{Bottom-Up Alligator Cracking}

In this research study, at first the observed cracking data and the predicted cracking data are compared using the default calibration value in the AASHTOWare Pavement ME software at $50 \%$ reliability. After that, a graph was plotted to compare the damages. Transfer function for Bottom-up cracking (Eq. 2.6) can be written also as below:

$$
\log _{10} 100 D=\frac{1}{C_{2} C_{2}^{\prime \prime}} \ln \left(\frac{100}{F C_{\text {Pred }}}-1\right)+\frac{2 C_{1}}{C_{2}}
$$

The above equation (Eq. 4.4) can be transformed into the following equation (Eq. 4.5). This is needed so as to transform the transfer function to be used in the form of a straight line. Using predicted value of the distress, ln 100D was determined. Left hand side of the Eq. 4.5 was derived using observed value. These derived values were utilized in Eq. 4.5 and then a regression analysis was driven.

$$
\ln \left(\frac{100}{F C_{o b s}}-1\right) \times \frac{1}{C_{2}^{\prime \prime}}=-2 C_{1}+C_{2} \log _{10} 100 D
$$

From the regression model, the intercepts and the slope were used to calculate new predicted distress and the residual plot was drawn. Same procedure is repeated by changing the calibration parameter of fatigue model. The procedure was repeated for four sets of parameter, namely, a. Default Parameter, i.e., $\beta_{\mathrm{f} 1}=1.0, \beta_{\mathrm{f} 2}=1.0, \beta_{\mathrm{f} 3}=1.0 ;$ b. $\beta_{\mathrm{f} 1}=1.0, \beta_{\mathrm{f} 2}=0.9$, $\beta_{\mathrm{f} 3}=0.9 ;$ c. $\beta_{\mathrm{f} 1}=1.0, \beta_{\mathrm{f} 2}=0.7, \beta_{\mathrm{f} 3}=0.7 ;$ d. $\beta_{\mathrm{f} 1}=1.0, \beta_{\mathrm{f} 2}=0.8, \beta_{\mathrm{f} 3}=0.8$.

\subsubsection{Top-Down Longitudinal Cracking}

Literature review concludes similar calibration process for top-down fatigue cracking model in different states in US for the local condition like the bottom-up fatigue cracking:

In this research study, like bottom-up fatigue cracking, same procedure has been conducted for the top-down fatigue cracking. Transfer function for Top-down cracking (Eq. 2.7) can be written also as below:

$$
\ln \mathrm{D}=\frac{1}{C_{4}}\left\{C_{3}-\ln \left(\frac{10560}{F C_{\text {Pred }}}-1\right)\right\}
$$


The above equation (Eq. 4.6) can be further transformed into the following equation (Eq. 4.7). This is needed so as to transform the transfer function to be used in the form of a straight line. Using predicted value of the distress, $\log _{10} \mathrm{D}$ was determined. Left hand side of the Eq. 4.7 was derived using observed value. These derived values were utilized in Eq. 4.7 and then a regression analysis was driven.

$$
\ln \left(\frac{10560}{F C_{o b s}}-1\right)=C_{3}-C_{4} \ln \mathrm{D}
$$

From the regression model, the intercepts and the slope were used to calculate new predicted distress and the residual plot was drawn. Same procedure is repeated by changing the calibration parameter of fatigue model. The procedure was repeated for two sets of parameter, namely, a. Default Parameter, i.e., $\beta_{\mathrm{f} 1}=1.0, \beta_{\mathrm{f} 2}=1.0, \beta_{\mathrm{f} 3}=1.0 ; \mathrm{b}$. $\beta_{\mathrm{f} 1}=1.0, \beta_{\mathrm{f} 2}=0.8$, $\beta_{\mathrm{f} 3}=0.8$,

\subsection{Thermal Cracking}

A few numbers of states in US did the local calibration of thermal cracking. In this research study, NCHRP 1-37A has been followed to calibrate thermal cracking model. The procedure has been explained in section 2.5 .

Since the software allows to adjust the calibration parameter $\left(\mathrm{K}_{\mathrm{t}}\right)$ only, therefore, this parameter is adjusted solely to obtain the optimum result. Calibration parameter in the thermal cracking model (Eq.2.9) was adjusted arbitrarily and the results of the same was compared with observed data up to a point where minimum attainable bias was detected. The set of calibration parameter which produced the minimum bias was considered to be the optimum set of calibration

parameter. It may be mentioned here that $\beta_{t 1}$ is fixed at 400 for this research as explained in section 2.6. 


\section{Chapter 5 Results \& Discussions}

\subsection{Fatigue Cracking}

Bottom-up cracking analysis is done with both maximum and average observed cracking data. Same process has been followed for top-down cracking. Lastly, clustering analysis is conducted for both bottom-up and top-down cracking analysis for more investigations.

\subsubsection{Bottom-up Fatigue (Alligator) Cracking}

At first, bottom-up cracking analysis is done with the maximum observed cracking data. Later average observed cracking data is used for further analysis. Lastly, clustering analysis is conducted for more investigations.

\subsubsection{Using Maximum Observed Cracking Data}

At first the analysis is done for the maximum observed distress. Four sets of calibration parameter for the fatigue model are used. These are: $\left(\beta_{f 1}=1.0, \beta_{f 2}=1.0, \beta_{f 3}=1.0\right),\left(\beta_{f 1}=\right.$ $\left.1.0, \beta_{f 2}=0.9, \beta_{f 3}=0.9\right),\left(\beta_{f 1}=1.0, \beta_{f 2}=0.8, \beta_{f 3}=0.8\right)$ and $\left(\beta_{f 1}=1.0, \beta_{f 2}=0.7\right.$, $\left.\beta_{f 3}=0.7\right)$. The damage comparisons are presented below:

Figures 5.1, 5.2, 5.3 and 5.4 are showing no significant patterns between the predicted and observed cracking. However, some clustering analyses have been conducted, which is presented later in this chapter to investigate the presence of any trends. Set plots are presented below for the transformed form of the transfer equation. 


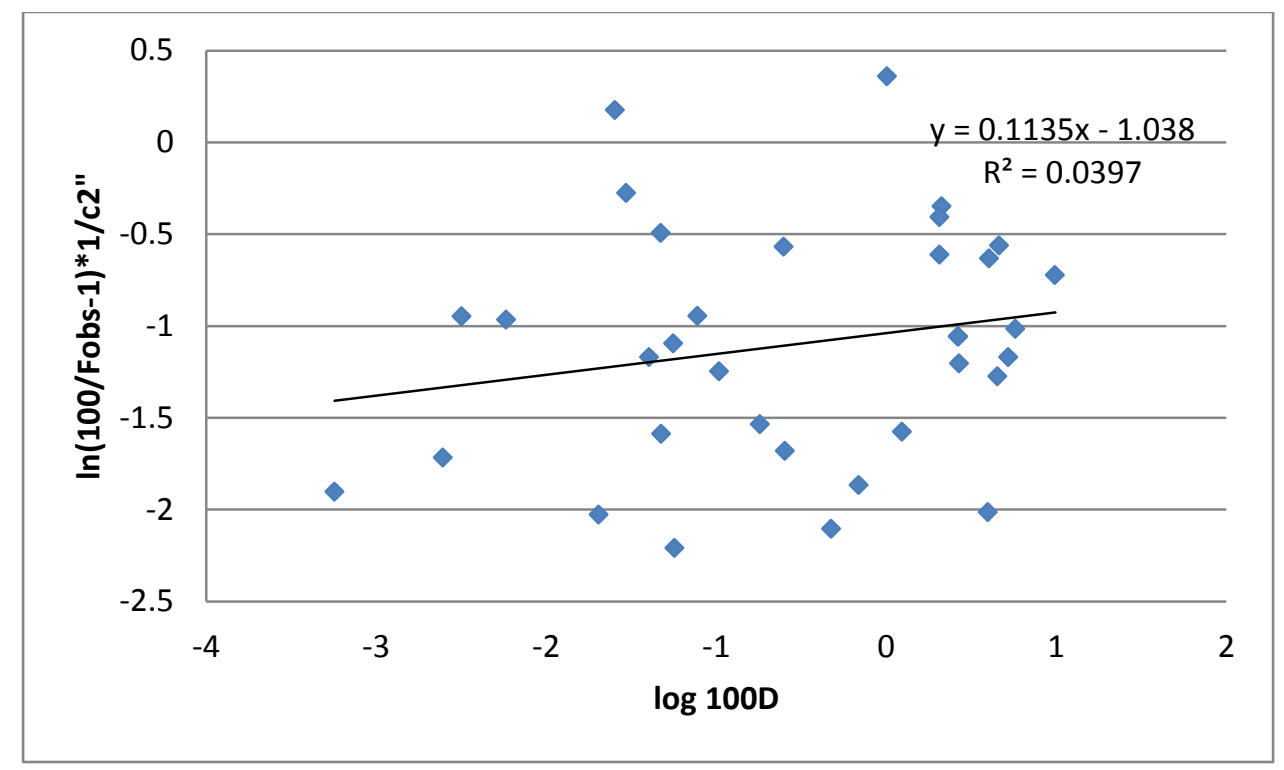

Figure 5.1 Transformed form of Alligator Damage Comparison with Default Parameter (Using maximum observed value)

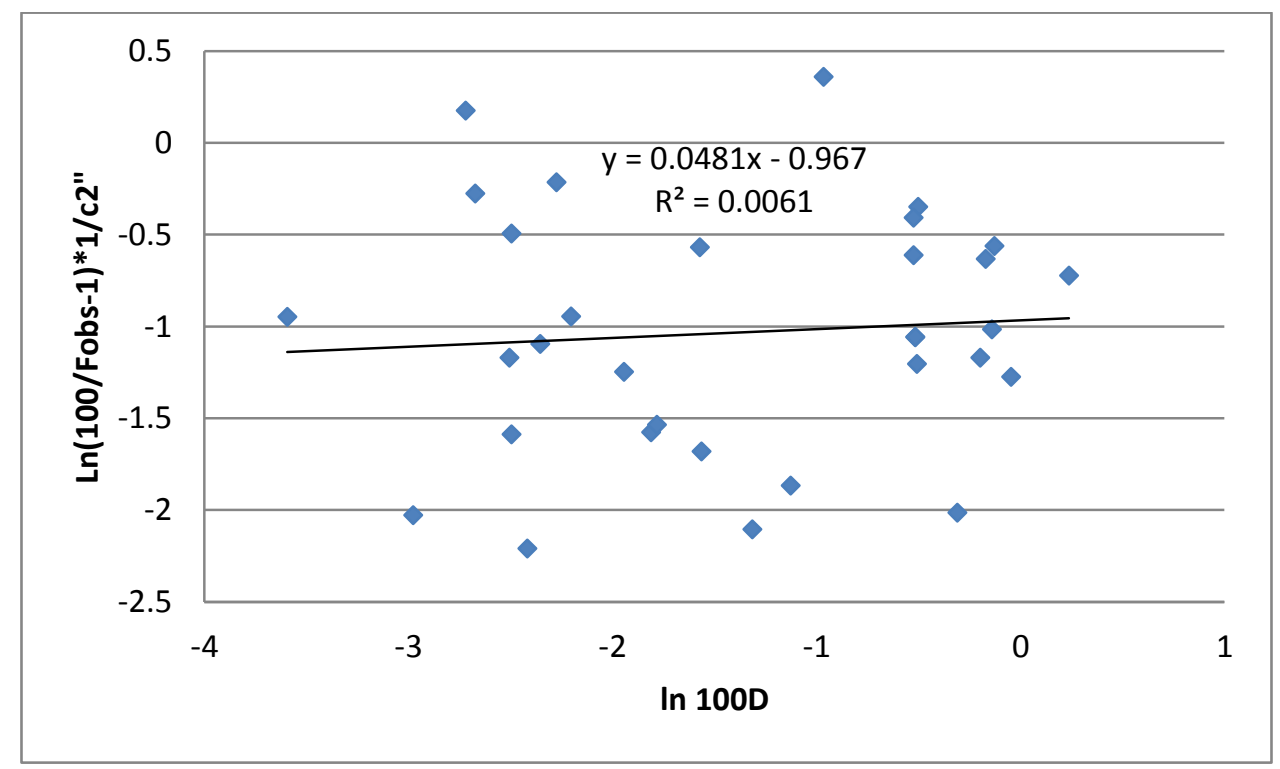

Figure 5.2: Transformed form of Alligator Damage Comparison with 2 nd set of Parameter $\left(\beta_{f 1}=1.0, \beta_{f 2}=0.9, \beta_{f 3}=0.9\right)$ (Using maximum observed value) 


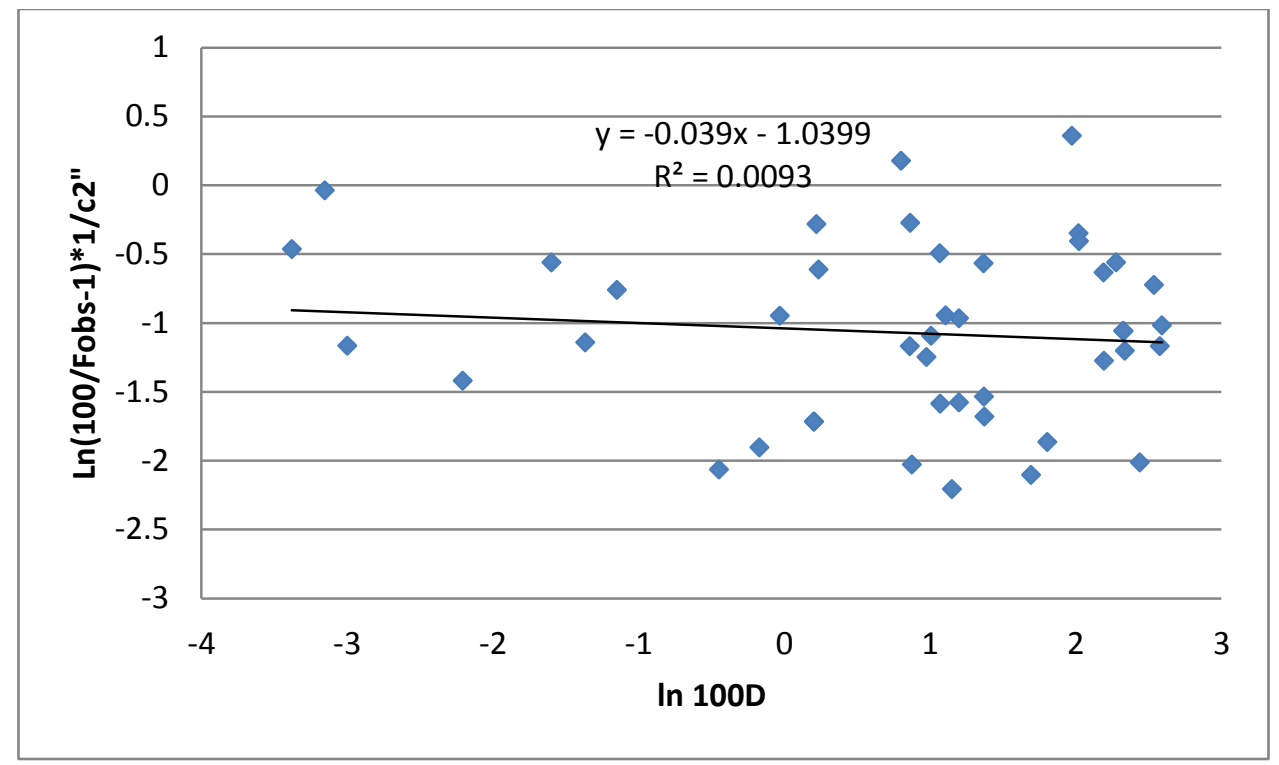

Figure 5.3: Transformed form of Damage Comparison with 3rd Set of Parameter $\left(\beta_{f 1}=1.0\right.$, $\left.\beta_{f 2}=0.8, \beta_{f 3}=0.8\right)$ (Using maximum observed value)

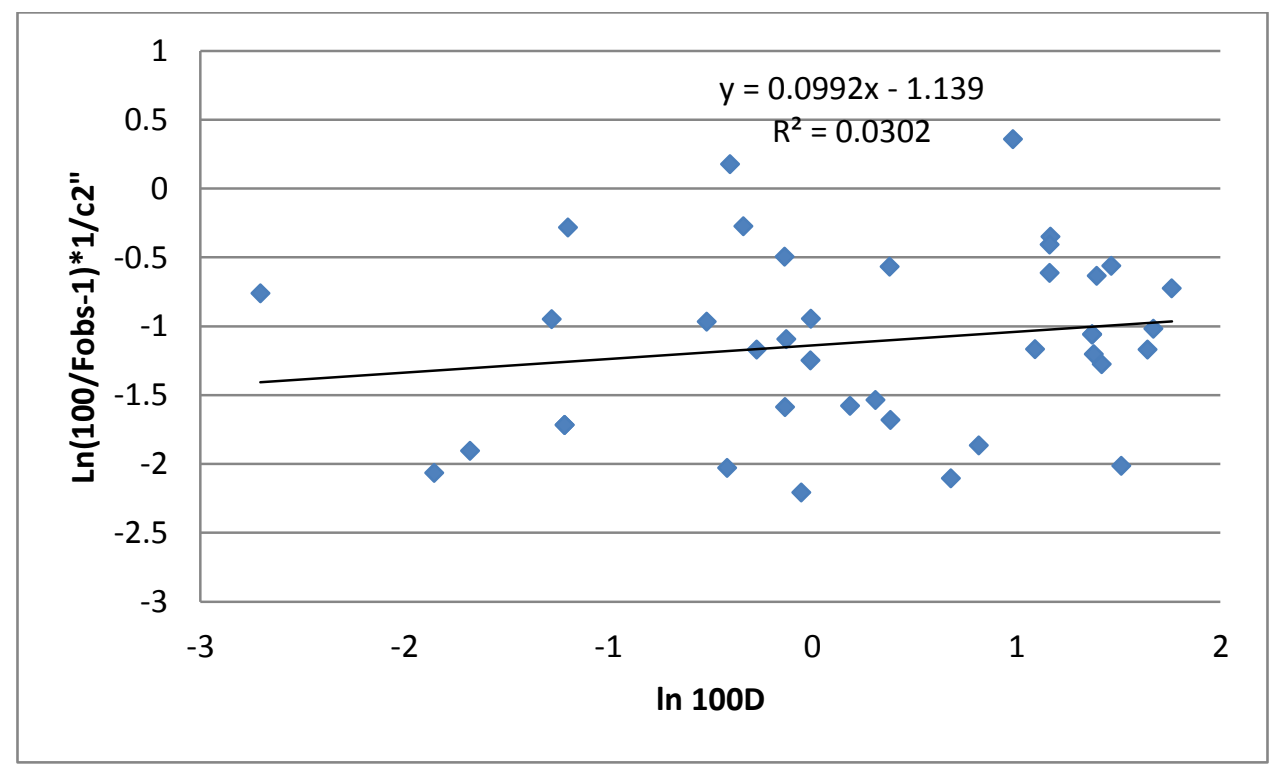

Figure 5.4: Transformed form of Alligator Damage Comparison with 4th Set of Parameter $\left(\beta_{f 1}=1.0, \beta_{f 2}=0.7, \beta_{f 3}=0.7\right)$ (Using maximum observed value)

The above illustrations (Figures 5.1, 5.2, 5.3 and 5.4) are meant to suggest the magnitude of $\mathrm{C}_{1}$ and $\mathrm{C}_{2}$. But the above sets of plots do not suggest any strong correlations between Predicted and observed cracking readings. 
Residual plots (residual for the transformed condition) for these dataset are presented in Figure 5.5, which depicts the fact that the residuals are fairly uniformly scattered on both side of $\mathrm{X}$ axis, but carries no slopes, meaning that there is hardly any correlation.

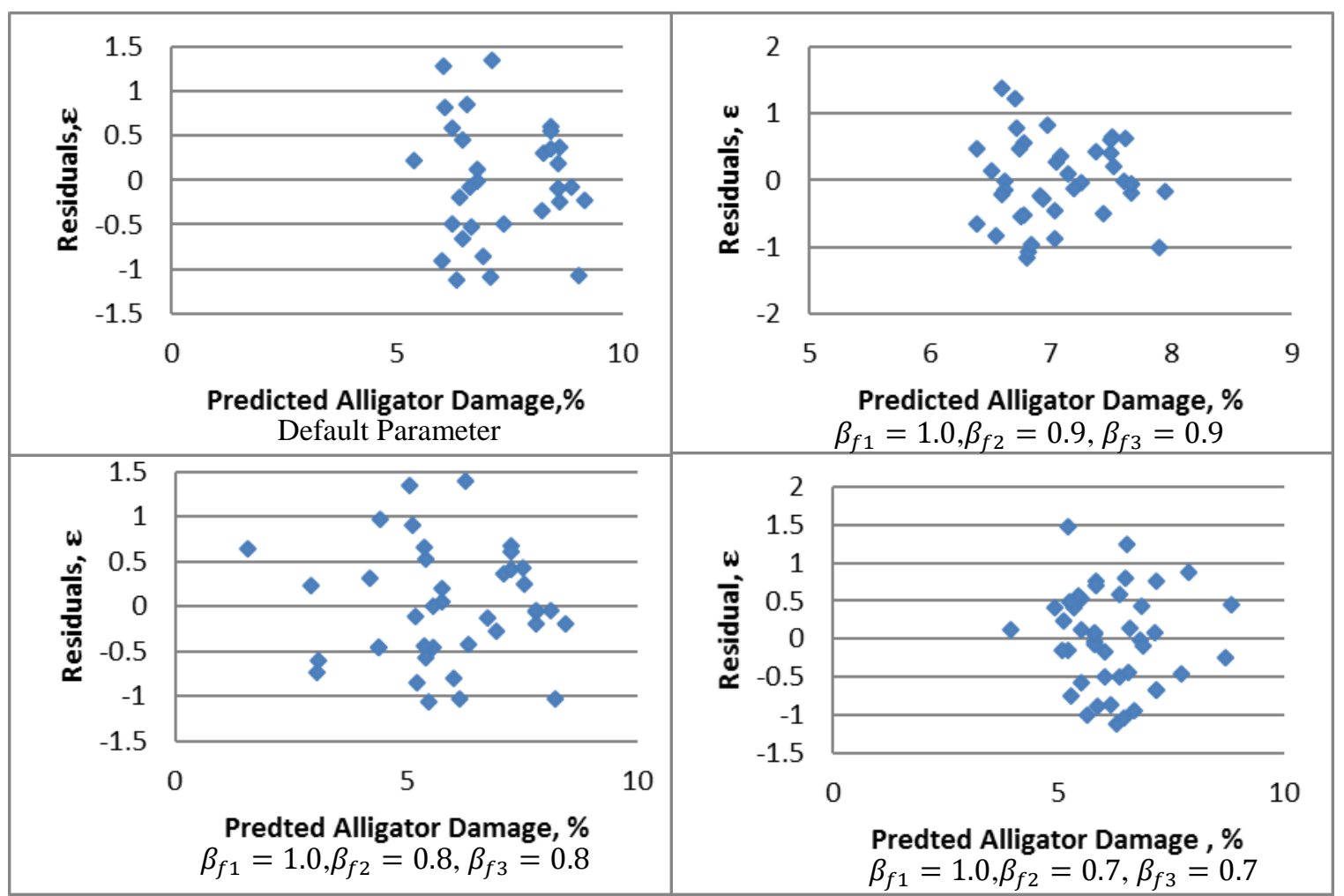

Figure 5.5: Residual plots for the Alligator damage for four sets of Calibration Parameter

The statistical results and parameters of these analyses are summarized in Table 5.1.

Table 5.1: Statistical Results for Alligator Damage Comparison

\begin{tabular}{|l|l|l|l|l|}
\hline $\begin{array}{l}\text { Calibration } \\
\text { Parameter Set in } \\
\text { Fatigue Model }\end{array}$ & $\begin{array}{l}\text { No. Of } \\
\text { Observations }\end{array}$ & Bias & $\mathbf{R}^{\mathbf{2}}$ & $\begin{array}{l}\text { Standard } \\
\text { Deviation }\end{array}$ \\
\hline$\beta_{f^{1}}=1.0, \beta_{f^{2}}=1.0, \beta_{f 3}=1.0$ & 32 & -211.7310 & 0.0081 & 17.3607 \\
\hline$\beta_{f 1}=1.0, \beta_{f 2}=0.9, \beta_{f 3}=0.9$ & 34 & -208.6626 & 0.0016 & 16.4983 \\
\hline$\beta_{f 1}=1.0, \beta_{f 2}=0.8, \beta_{f 3}=0.8$ & 39 & -238.1983 & 0.0008 & 15.9738 \\
\hline$\beta_{f 1}=1.0, \beta_{f 2}=0.7, \beta_{f 3}=0.7$ & 44 & -287.1817 & 0.00006 & 16.1363 \\
\hline
\end{tabular}

Note: The numbers of observations are different because with different calibration factor, predicted damage of some section gave zero value for which further calculation cannot be possible 
From the Table 5.1, it is evident that we ended up with very small fitting statistics, large bias and significantly high standard deviation. This eventually indicates that the analyses did not indicate any conclusive pattern.

\subsubsection{Using Average Observed Cracking Data}

Further analyses are done with average alligator distress for wheel-path direction only. This time two sets of parameter are used: $\left(\beta_{f 1}=1.0, \beta_{f 2}=1.0, \beta_{f 3}=1.0\right),\left(\beta_{f 1}=1.0, \beta_{f 2}=0.9\right.$, $\beta_{f 3}=1.1$ ). Damage comparisons, transformed forms of the comparison and they are presented below:

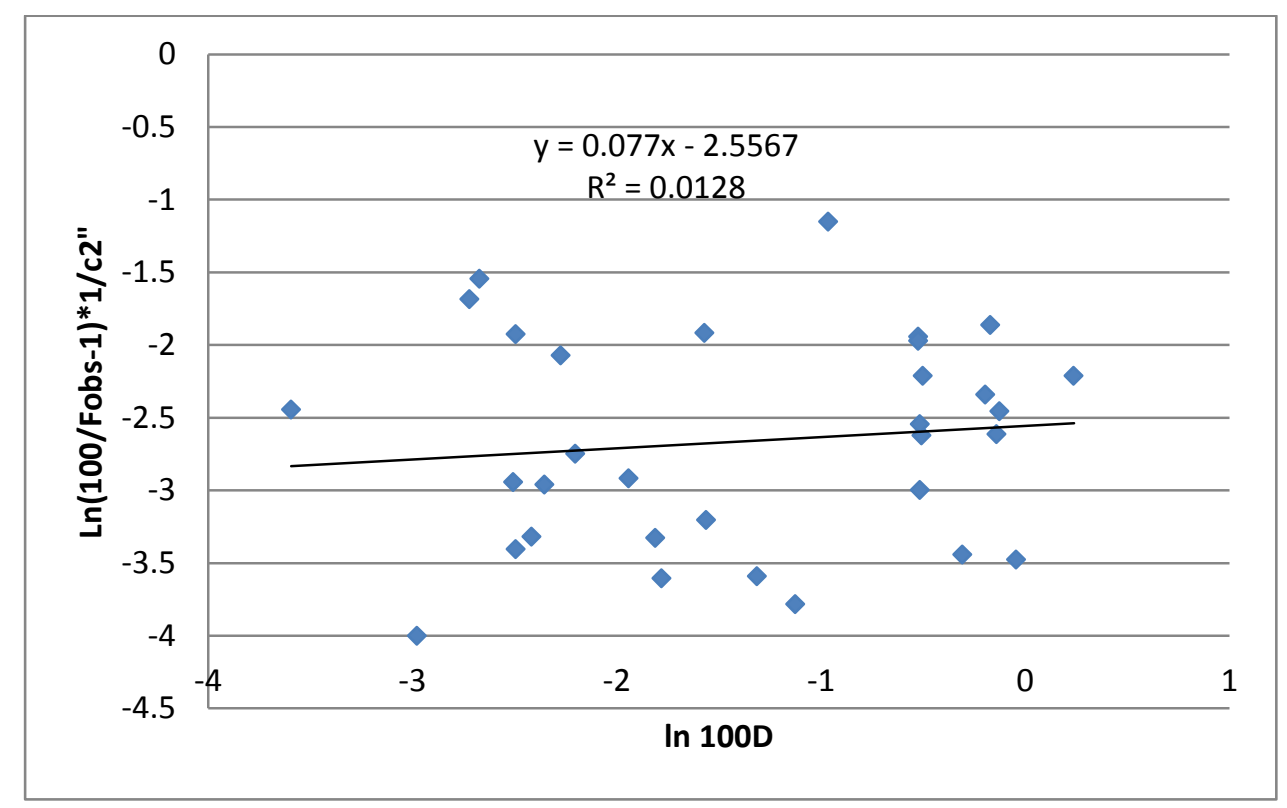

Figure 5.6: Transformed form of Alligator Damage Comparison $\left(\beta_{f 1}=1.0, \beta_{f 2}=1.0, \beta_{f 3}=\right.$ 1.0) [using average observed value] 


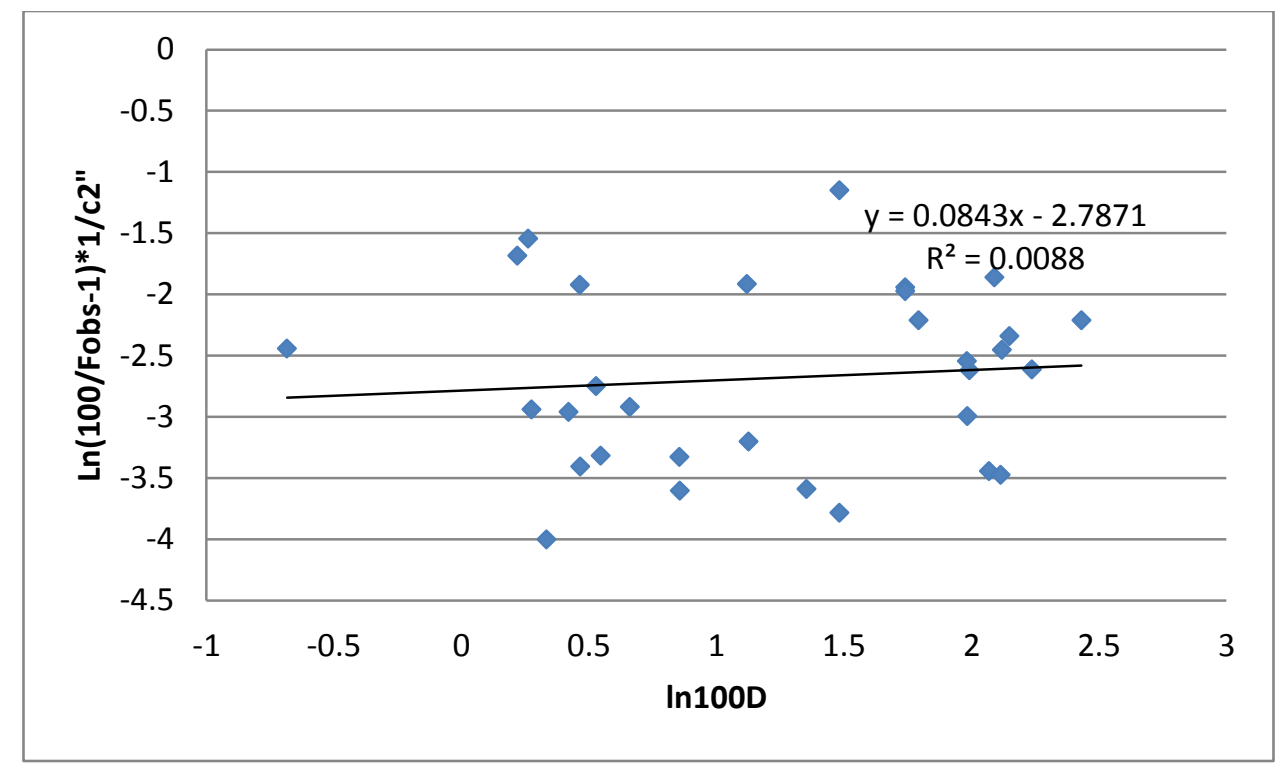

Figure 5.7: Transformed form of Alligator Damage Comparison $\left(\beta_{f 1}=1.0, \beta_{f 2}=0.9, \beta_{f 3}=\right.$ 1.1) [using average observed value]

From the above presentation (Figure 5.6 and 5.7), it is evident that there is minimal or no evidence of any correlation between the predicted and observed Alligator damage. Set plots are presented below for the transformed form of the transfer equation.

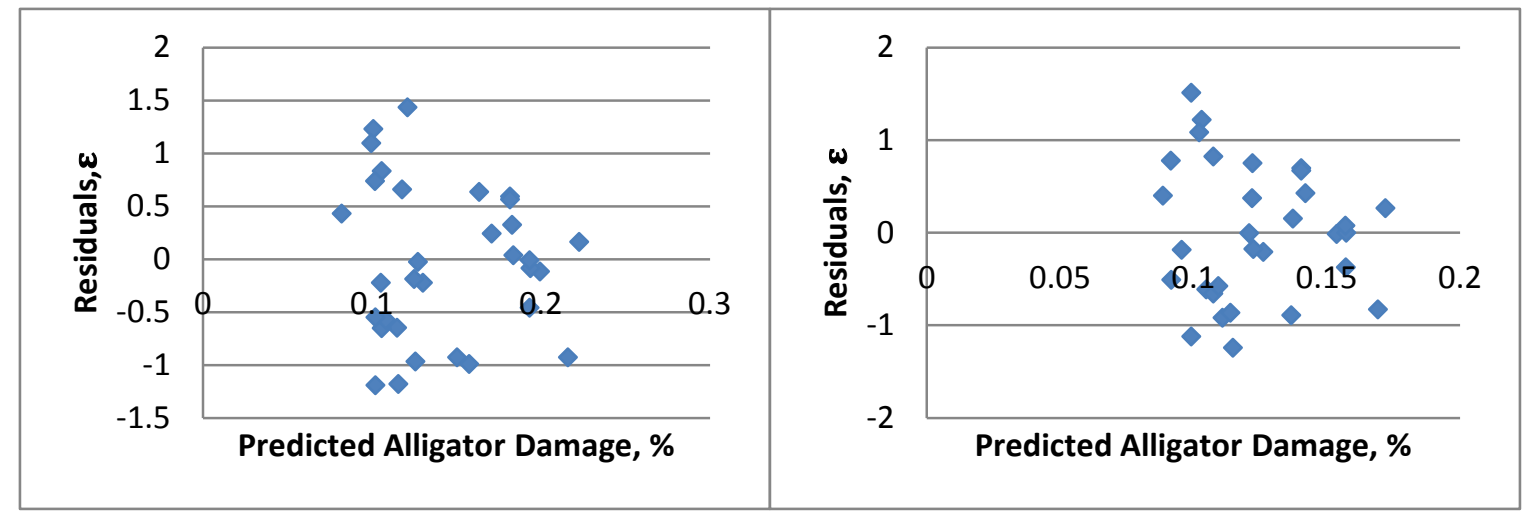

Figure 5.8: Residual plots for the Alligator damage for two sets of Calibration Parameter (Residuals for the transformed condition) [using average observed value]

If the residuals error plots are compared between Maximum (of whole section) observed value and Average (of wheelpath location) observed value (Figure 5.6 and 5.7) showed that the residual errors for Maximum observed value were closely and equally scattered on both of sides of zero line, whereas in Figure 5.8, residuals for Average observed value, they were relatively 
widely scattered. On the other side, for maximum observed value for whole section analysis, prediction calibration returned very poor results of $\mathrm{R}^{2}$ value which shows no or little correlation between predicted and observed values. Similarly, for average observed value for wheelpath section shows extremely poor correlation with relatively high standard error. In a nut shell, the above representation does not reflect any strong relationship between the predicted damage and the observed damage.

\subsubsection{Top-Down Fatigue (Longitudinal) Cracking}

At first, top-down cracking analysis is done with the maximum observed cracking data. Later average observed cracking data is used for further analysis.

\subsubsection{Using Maximum Observed Cracking Data}

At first the analysis is done for the maximum observed distress. In previous chapter (Chapter 4) four sets of calibration parameter are used for alligator cracking. Since $\left(\beta_{f 1}=1.0, \beta_{f 2}=0.8\right.$, $\beta_{f 3}=0.8$ ) provides less bias, therefore two sets of calibration parameter in the fatigue model are used for the longitudinal cracking. These are: $\left(\beta_{f 1}=1.0, \beta_{f 2}=1.0, \beta_{f 3}=1.0\right)$ and $\left(\beta_{f 1}=1.0\right.$, $\left.\beta_{f 2}=0.8, \beta_{f 3}=0.8\right)$. The damage comparisons are presented below:

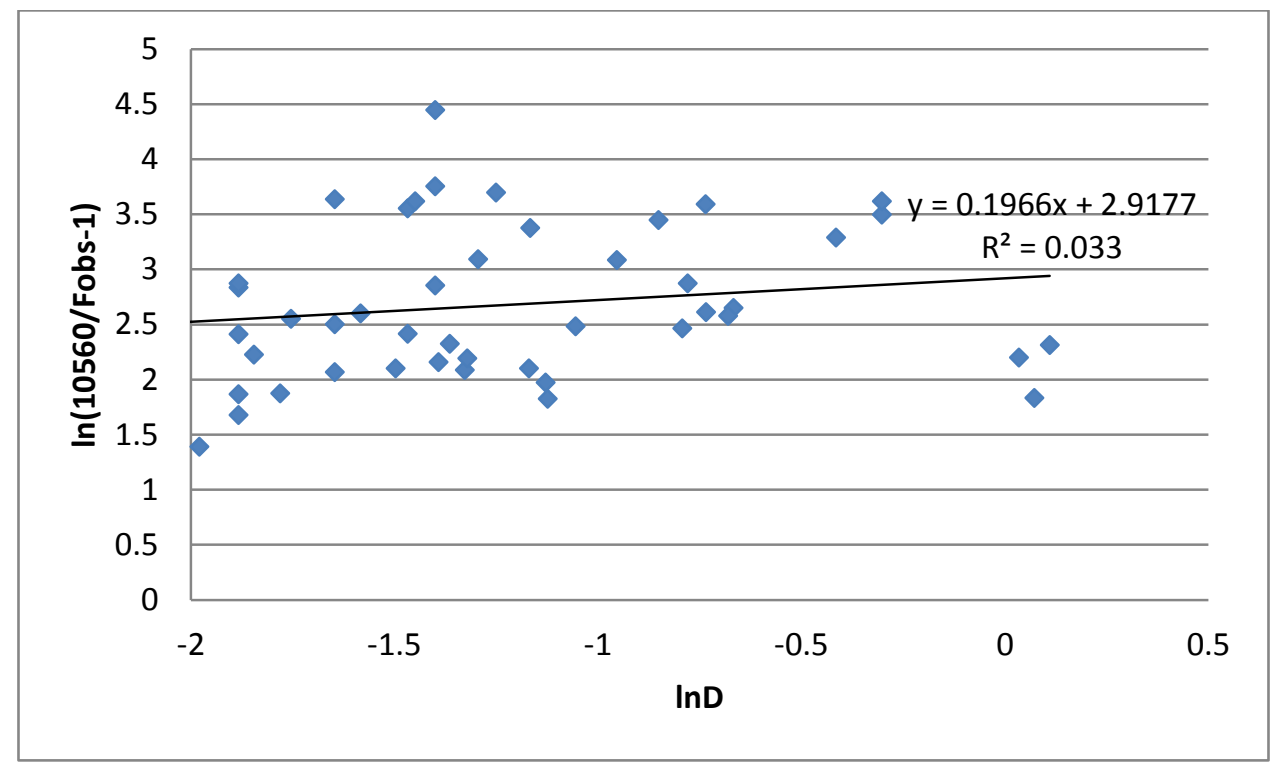

Figure 5.9: Transformed form of Longitudinal Damage Comparison $\left(\beta_{f 1}=1.0, \beta_{f 2}=1.0\right.$, $\left.\beta_{f 3}=1.0\right)$ (Using maximum observed value) 


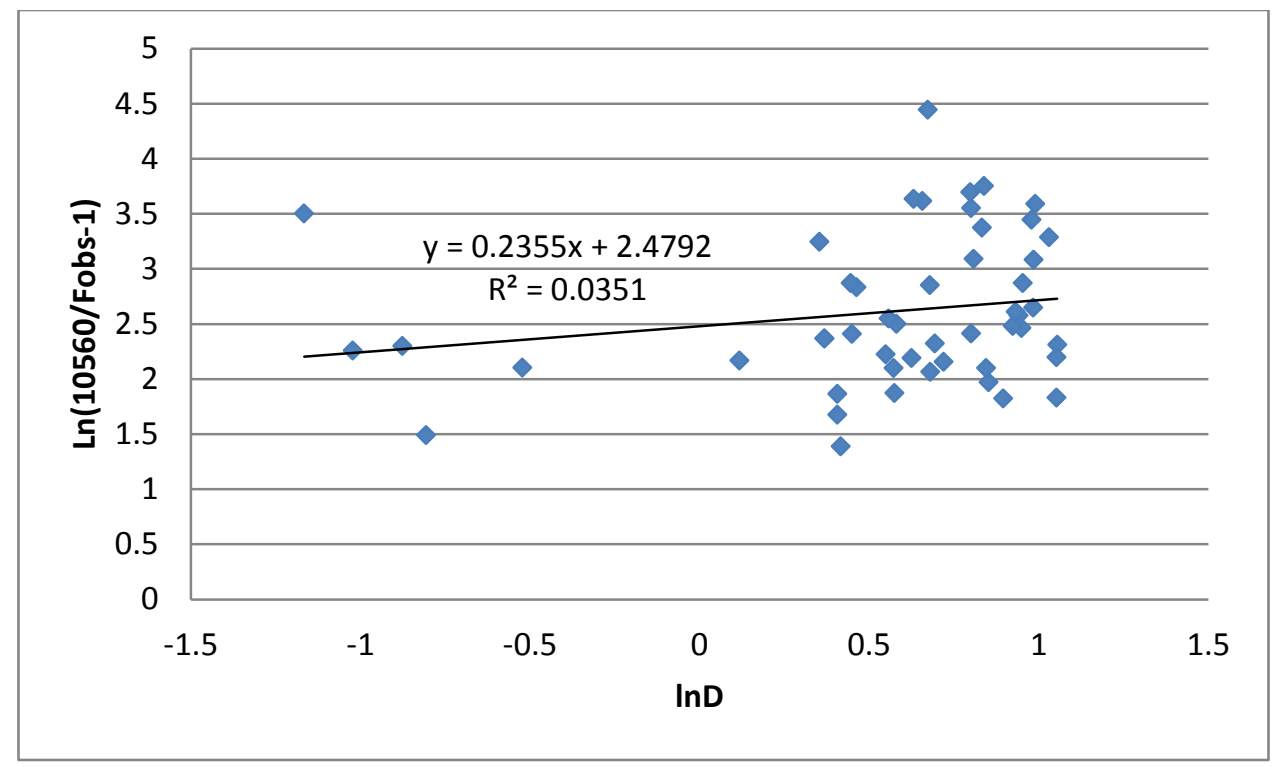

Figure 5.10: Transformed form of Longitudinal Damage Comparison $\left(\beta_{f 1}=1.0, \beta_{f 2}=0.8\right.$, $\left.\beta_{f 3}=0.8\right)$ (Using maximum observed value)

The above illustrations (Figures 5.9 and 5.10) are meant to suggest the magnitude of $\mathrm{C}_{1}$ and $\mathrm{C}_{2}$. But the above sets of plots do not suggest any strong correlations between Predicted and observed cracking readings.

Residual plots for these dataset are presented below (Figure 5.11), which depicts the fact that the residuals are fairly uniformly scattered on both side of $\mathrm{X}$ axis, but carries no slopes, meaning that there is hardly any correlation.
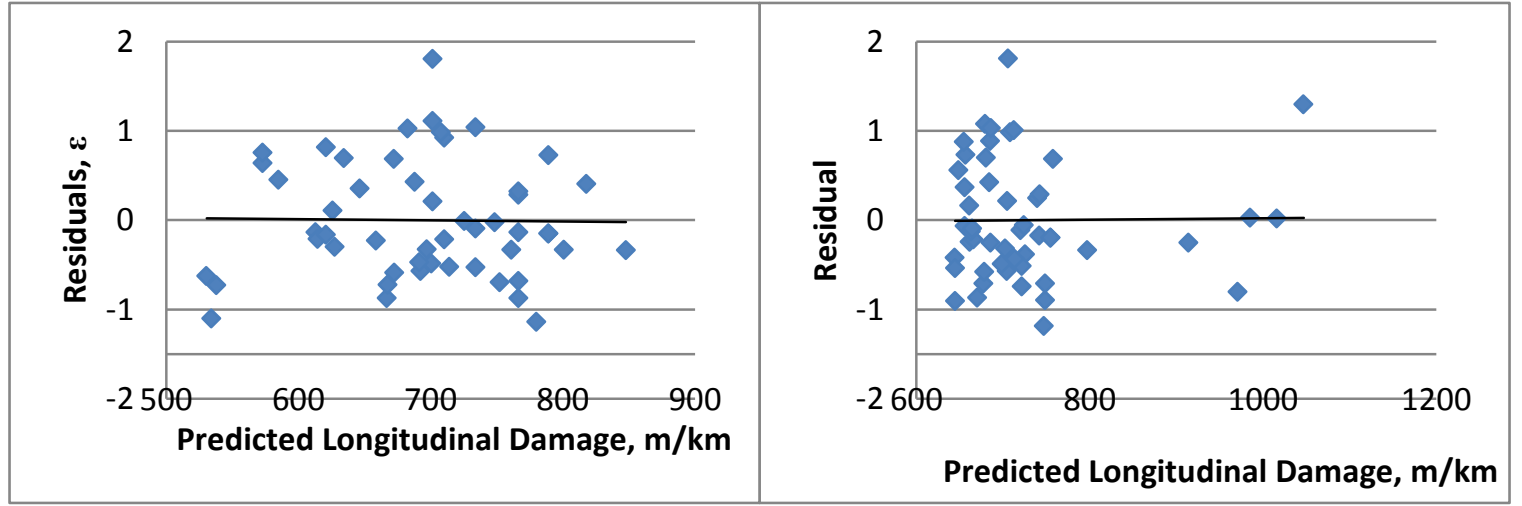

Figure 5.11: Residual Plots for Longitudinal Cracking damage(Using maximum observed value)

Residual plots (Figure 5.11) are showing no trends. The statistical results of these analyses are summarized in Table 5.2 
Table 5.2: Statistical Results for Longitudinal Damage Comparison

\begin{tabular}{|c|c|c|c|c|}
\hline $\begin{array}{c}\text { Calibration Parameter Set in } \\
\text { Fatigue Model }\end{array}$ & $\begin{array}{c}\text { No. Of } \\
\text { Observations }\end{array}$ & Bias & $\mathbf{R}^{\mathbf{2}}$ & $\begin{array}{c}\text { Standard } \\
\text { Deviation }\end{array}$ \\
\hline$\beta_{f 1}=1.0, \beta_{f 2}=1.0, \beta_{f 3}=1.0$ & 51 & -5663.3344 & 0.033 & 423.2995 \\
\hline$\beta_{f 1}=1.0, \beta_{f 2}=0.8, \beta_{f 3}=0.8$ & 50 & -5851.5228 & 0.0354 & 445.0570 \\
\hline
\end{tabular}

As can be seen from Table 5.2, the fits from the regression were not statistically significant and still contains large amount of bias for both sets of the parameters.

\subsubsection{Using Average Observed Cracking Data}

Further analyses are done with average longitudinal distress for wheel-path direction only. This time two sets of parameter are used: $\left(\beta_{f 1}=1.0, \beta_{f 2}=1.0, \beta_{f 3}=1.0\right),\left(\beta_{f 1}=1.0, \beta_{f 2}=0.9\right.$, $\beta_{f 3}=1.1$ ). The comparisons are presented below (Figure 5.12 and 5.13).also did not reflect any strong correlation.

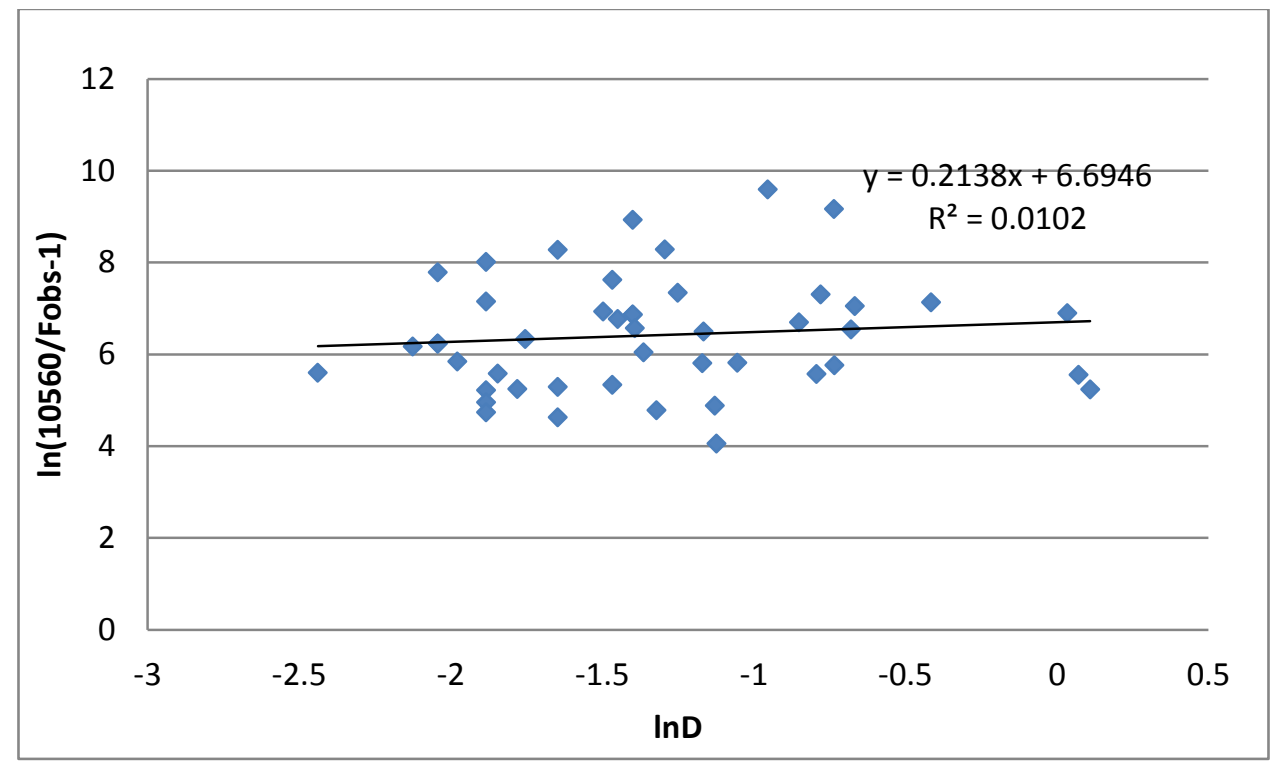

Figure 5.12: Transformed form of Longitudinal Damage Comparison $\left(\beta_{f 1}=1.0, \beta_{f 2}=1.0\right.$, $\left.\beta_{f 3}=1.0\right)$ (using average observed value) 


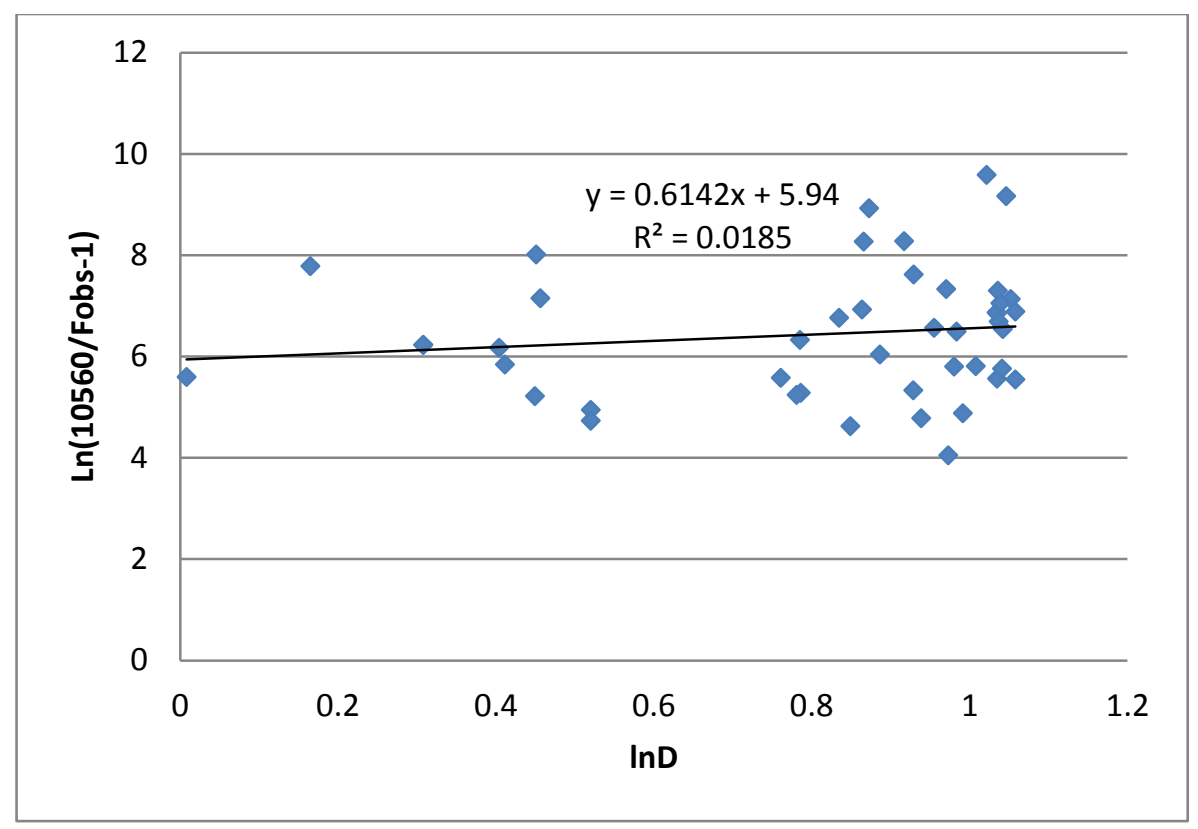

Figure 5.13: Transformed form of Longitudinal Damage Comparison $\left(\beta_{f 1}=1.0, \beta_{f 2}=0.9\right.$, $\left.\beta_{f 3}=1.1\right)$ (using average observed value)

Both Figure 5.12 and 5.13 also reflect that there are no strong correlations between these two distresses. 

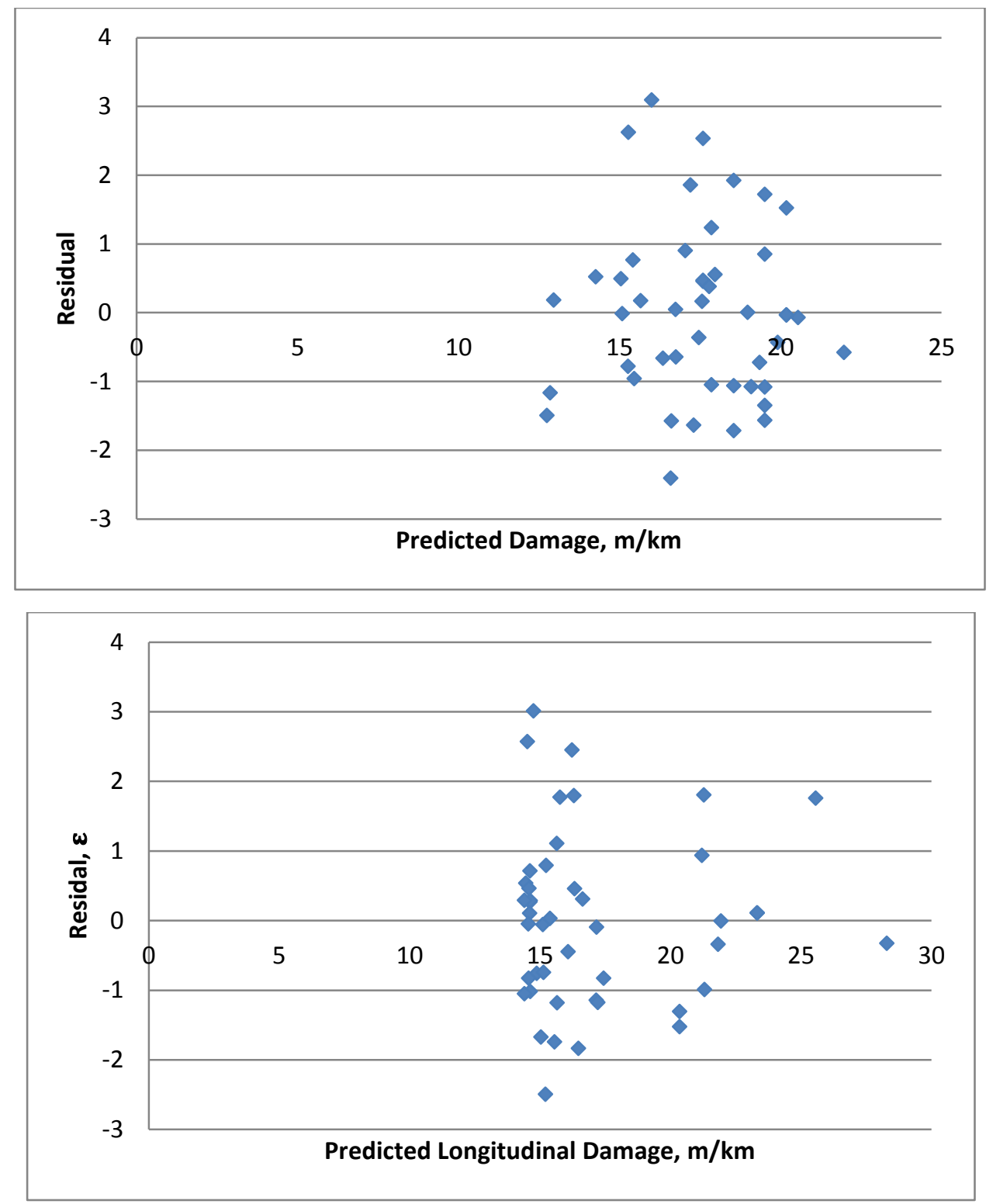

Figure 5.14: Residual plots for the Longitudinal Damage (using average observed value)

In Figure 5.14, though the residuals are dispersed around the axis, still it can be concluded that average observed data for wheel path location also returned minimal or no relationship with the prediction when analyzed with default parameter. Since fatigue cracking analyses did not return any conclusive results, clustering analyses can be ventured to investigate whether there is any improvements in the result output. 


\subsubsection{Clustering Analysis}

\subsubsection{Bottom-up Fatigue Cracking}

Since the section 5.1.2.2 suggests that better result can be found by doing clustering analysis, therefore in this section some clustering analyses are done to see whether there is any improvement in the model or not. Clustering analyses are done for the calibration parameter set $\left(\beta_{f 1}=1.0, \beta_{f 2}=0.8, \beta_{f 3}=0.8\right)$ only. This choice is because the standard deviation is the least for this set of parameters. Four factors are considered in the clustering analyses:

- Geo-climate Zones of Ontario

- Highway Functions

- Top Layer Material

- Top Layer Performance Grade

The following Figures 5.15, 5.16, 5.17 and 5.18 represent the clustering analysis by zone, highway series, top layer material and the top layer material grade respectively. The comparison results are summarized in Table 5.3.

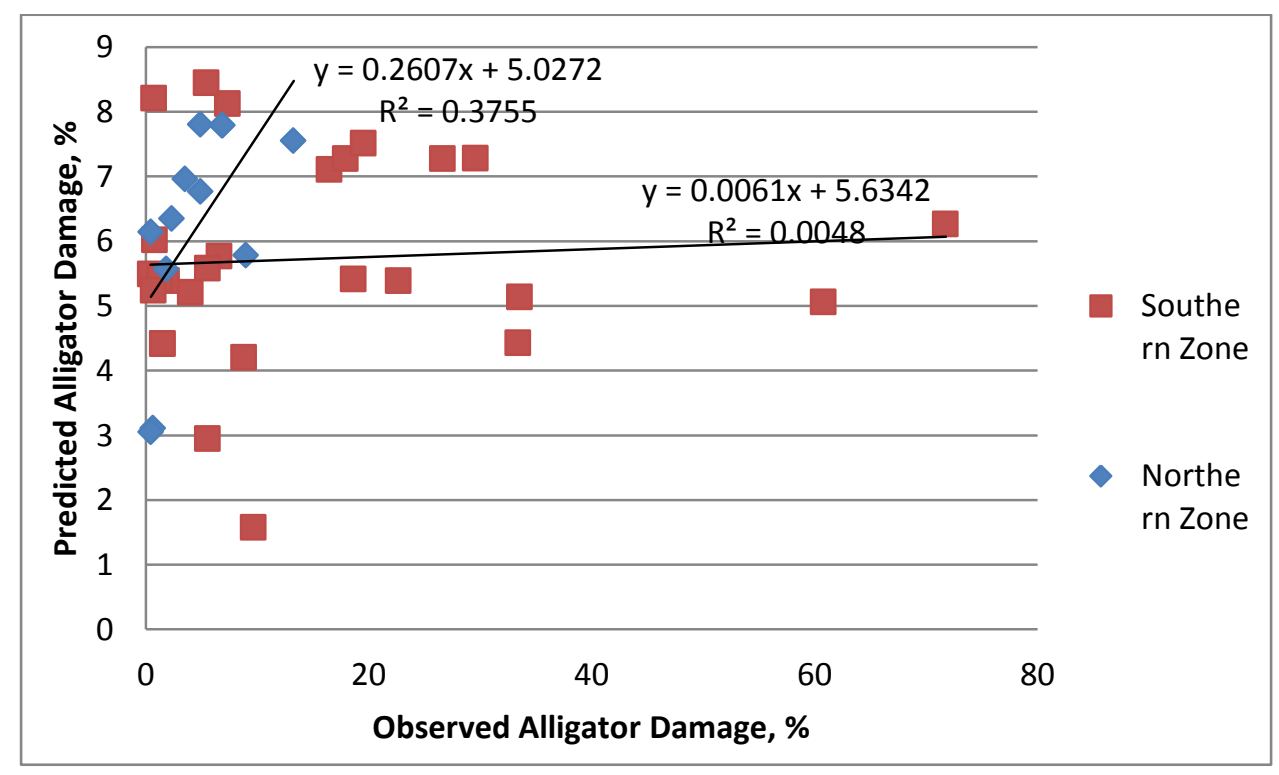

Figure 5.15: Clustering Analysis by Zone (Alligator Damage) 


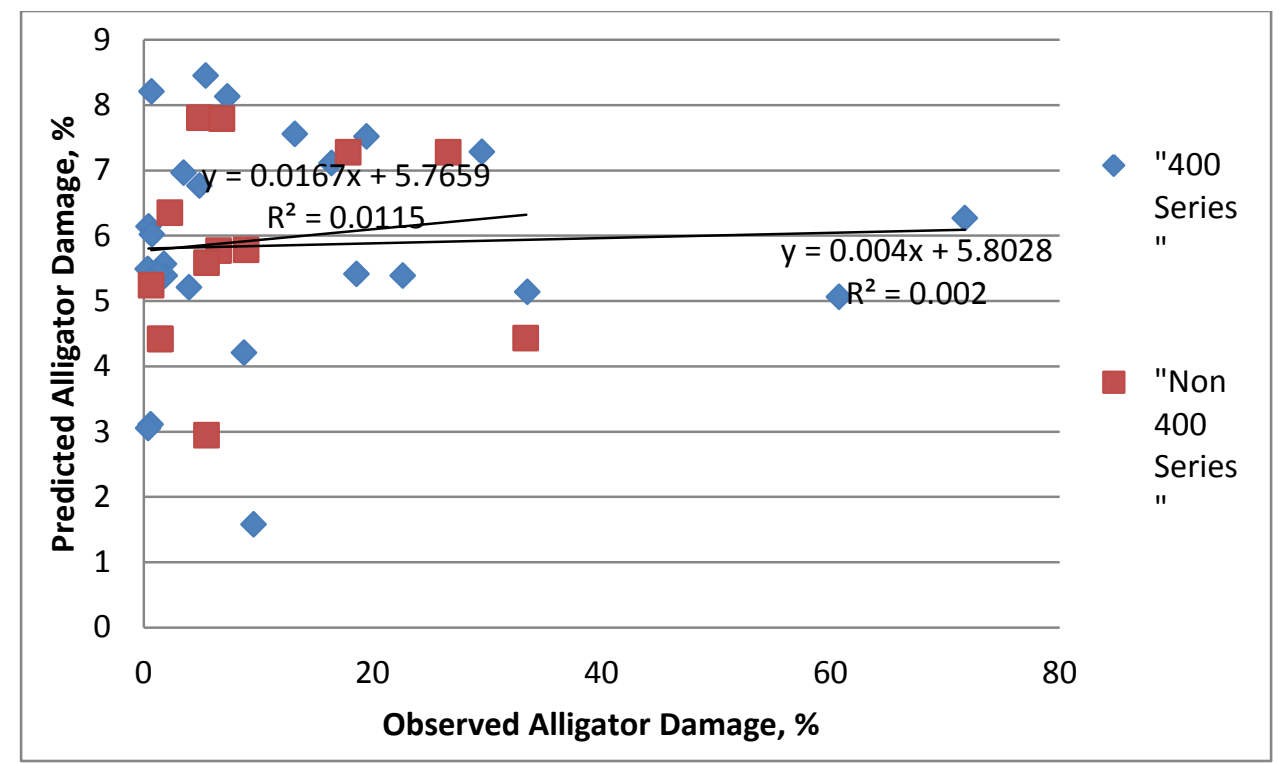

Figure 5.16: Clustering Analysis by Highway series (Alligator Damage)

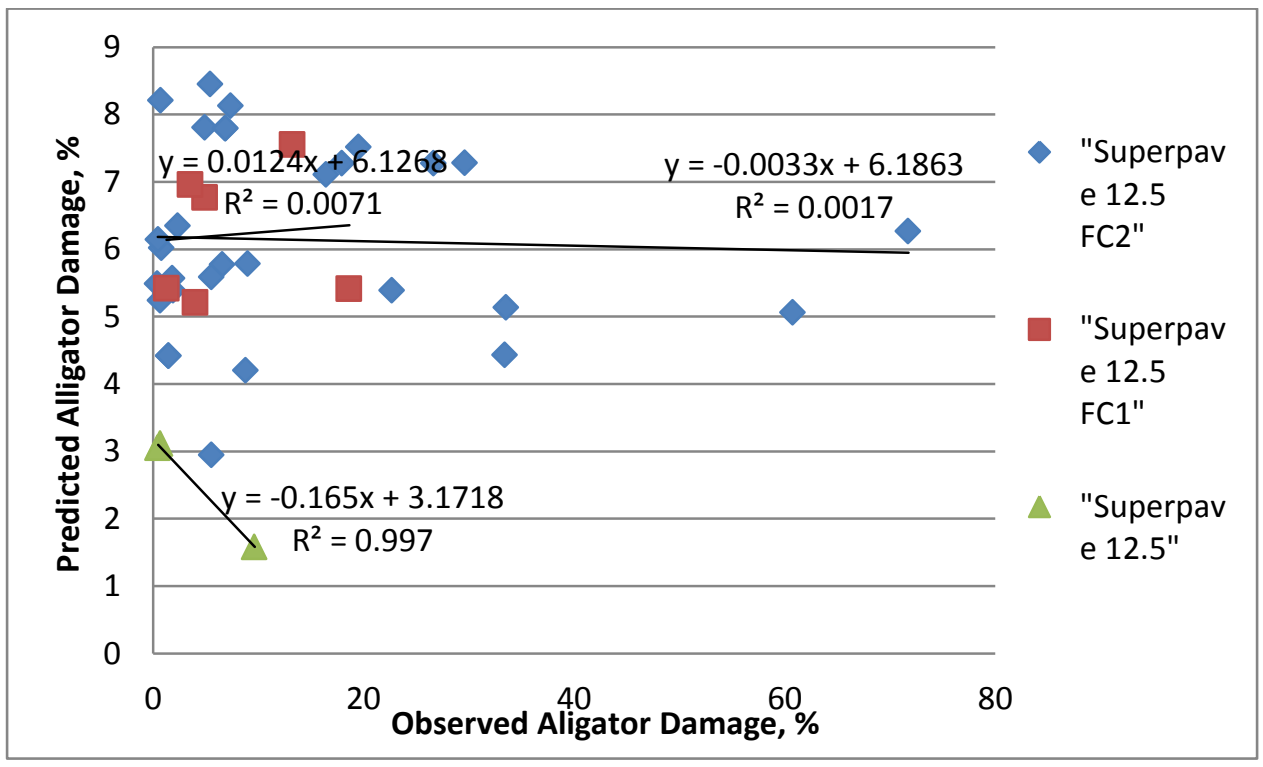

Figure 5.17: Clustering Analysis by Top-layer Material (Alligator Damage) 


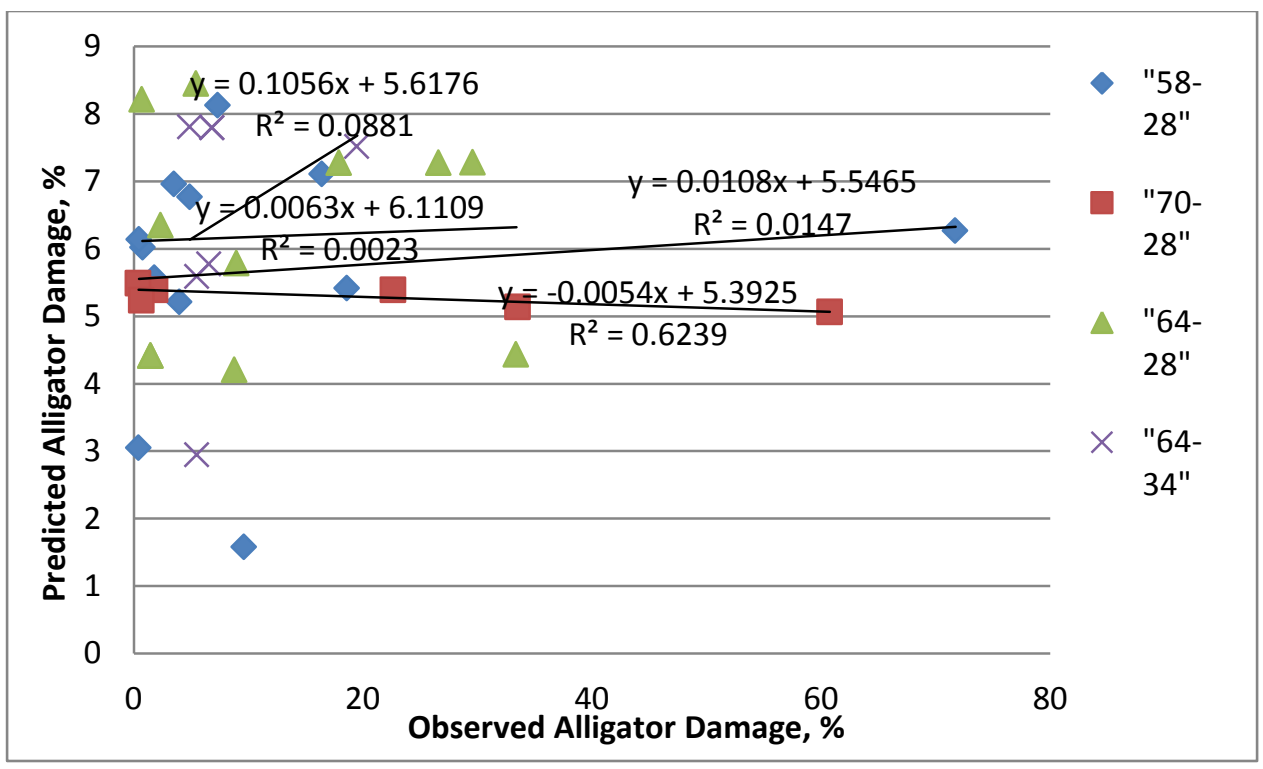

Figure 5.18: Clustering Analysis by Performance Grade (Alligator Damage)

Table 5.3: Statistical Comparison of Alligator Damage for Clustering Analysis

\begin{tabular}{|l|l|l|l|l|}
\hline \multirow{2}{*}{ Group } & Name & $\begin{array}{l}\text { No. Of } \\
\text { Observations }\end{array}$ & $\begin{array}{l}\mathbf{R}^{\mathbf{2}} \\
\text { Value }\end{array}$ & $\begin{array}{l}\text { Standard } \\
\text { Deviation }\end{array}$ \\
\hline \multirow{2}{*}{ Zone } & Southern Ontario & 27 & 0.0048 & 18.13 \\
\cline { 2 - 5 } & Northern Ontario & 12 & 0.3755 & 3.1763 \\
\hline \multirow{3}{*}{$\begin{array}{c}\text { Top Layer } \\
\text { Material }\end{array}$} & 400 Series & 14 & 0.0115 & 9.8267 \\
\cline { 2 - 5 } & Non-400 Series & 25 & 0.002 & 18.5631 \\
\hline \multirow{3}{*}{$\begin{array}{l}\text { Top Layer } \\
\text { Gerformance }\end{array}$} & Superpave 12.5 & 3 & 0.997 & 6.1127 \\
\cline { 2 - 5 } & Superpave 12.5 FC1 & 6 & 0.0071 & 6.7741 \\
\cline { 2 - 5 } & Superpave 12.5 FC2 & 30 & 0.0017 & 17.7293 \\
\cline { 2 - 5 } & $58-28$ & 13 & 0.0147 & 19.1037 \\
\cline { 2 - 5 } & $64-28$ & 11 & 0.0023 & 12.3501 \\
\cline { 2 - 5 } & $64-34$ & 6 & 0.0881 & 4.9199 \\
\hline
\end{tabular}

From the trendiness of Figures 5.15, 5.16, 5.17 and 5.18 and from Table 5.3 presented above we can conclude that the clustering analyses indicates the following (noting better fit to the data) -

- From the Zone clustering analyses, the model would perform better in Northern Ontario Zone.

- From Highway series, 400 series would have better results. 
- From Top layer material analyses, Superpave 12.5 would have excellent fit, but that results need to be excluded from this situation, since there are only three observations available in the dataset. In such case, Superpave 12.5 FCI would produce better result.

- From Top Layer Performance Grade, 70-28 grade pulls better fit to the model.

\subsubsection{Top-down Fatigue Cracking}

In this section some clustering analyses are done to see whether there is any improvement in the model or not. Clustering is done on the basis of the following groups for default calibration parameter only:

- Geo-climate Zones of Ontario

- Highway Functions

- Top Layer Material

- Top Layer Performance Grade

The following Figure 5.19, 5.20, 5.21 and 5.22 represents the clustering analysis by zone, highway series, top layer material and the top layer material grade respectively. The comparison results are summarized in Table 5.4.

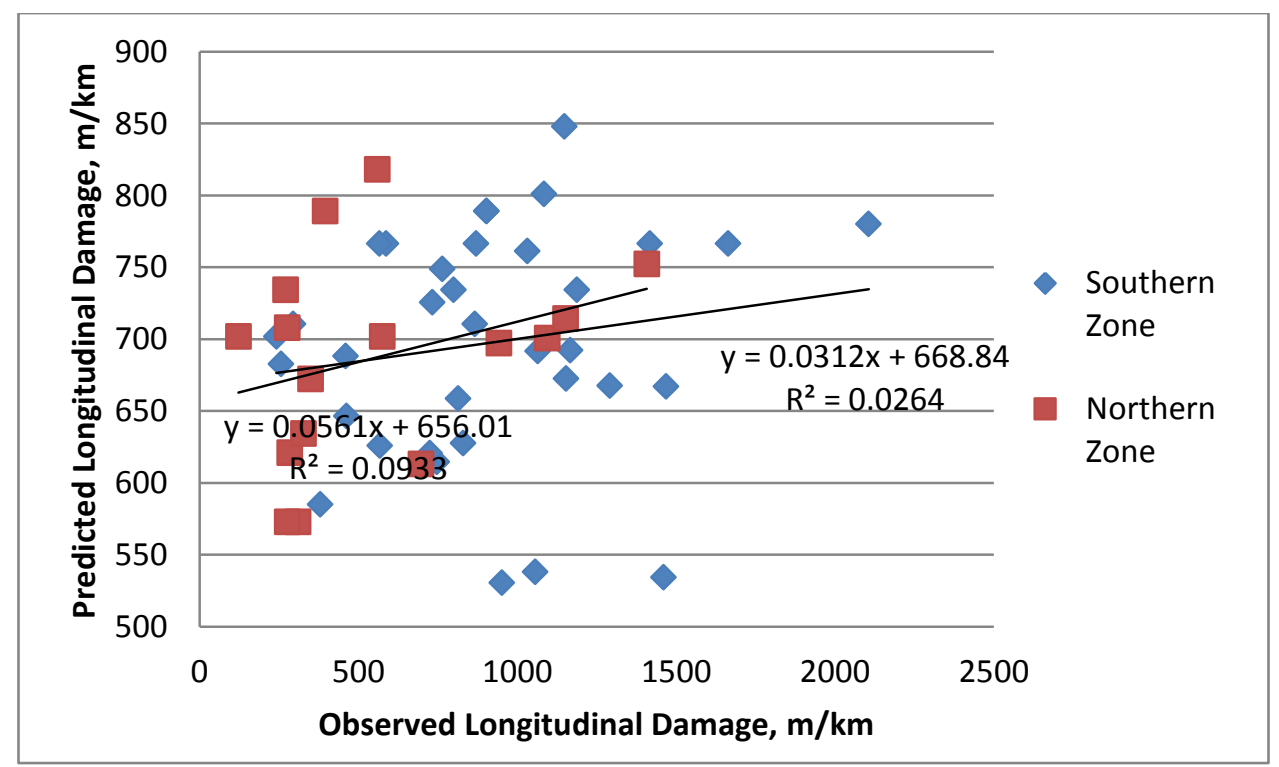

Figure 5.19: Clustering Analysis by Zone (Longitudinal Damage) 


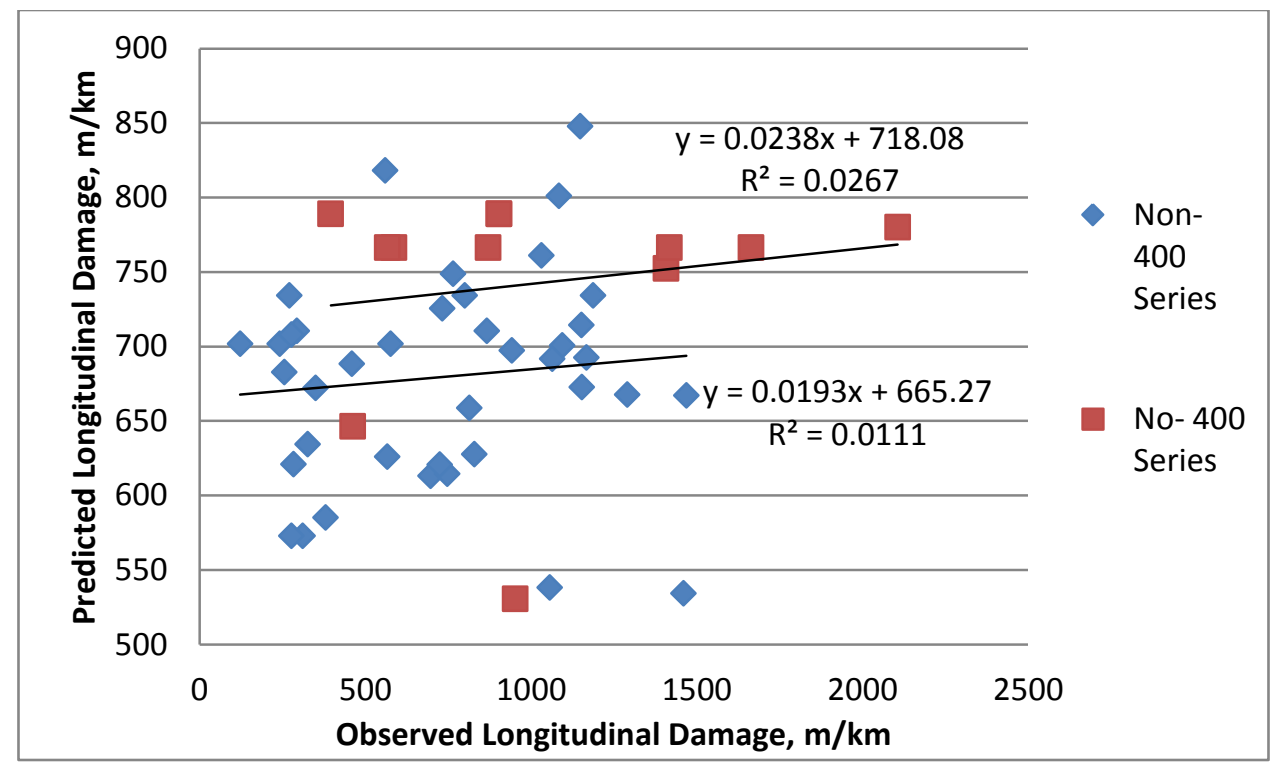

Figure 5.20: Clustering Analysis by Highway Series (Longitudinal Damage)

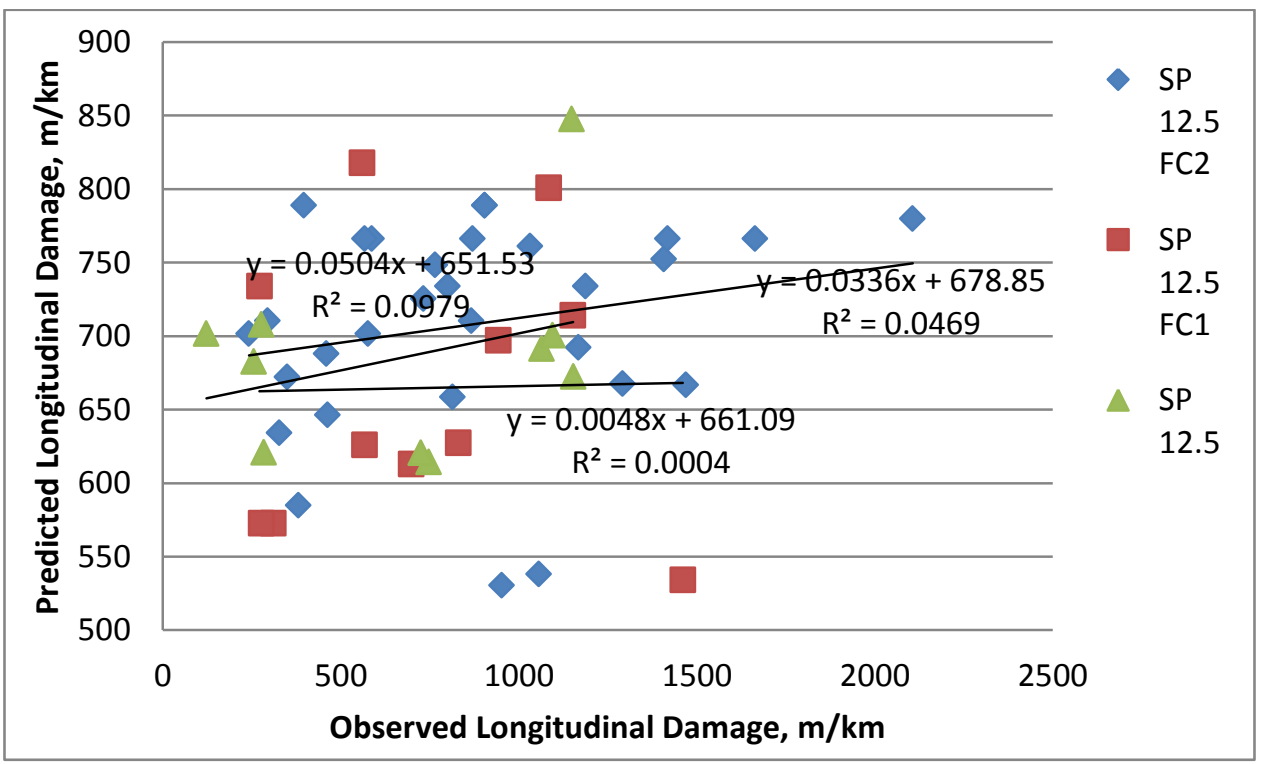

Figure 5.21: Clustering Analysis by Top Layer Material (Longitudinal Damage) 


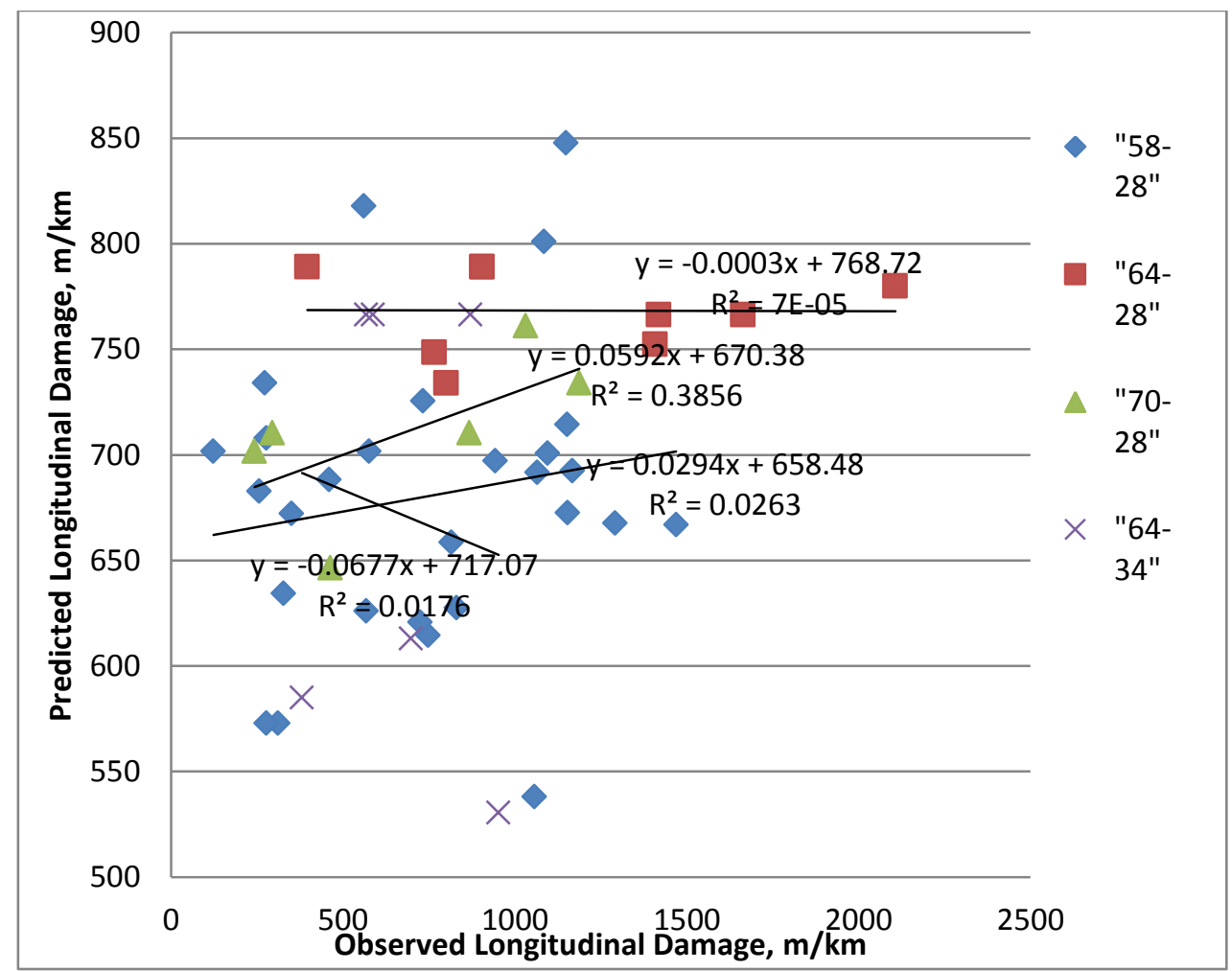

Figure 5.22: Clustering Analysis by Top Layer Material Grade (Longitudinal Damage)

Table 5.4: Statistical Comparison of Longitudinal Damage for Clustering Analysis

\begin{tabular}{|c|c|c|c|c|c|}
\hline Group & Name & $\begin{array}{l}\text { No. Of } \\
\text { Observations }\end{array}$ & Bias & $\begin{array}{l}\mathbf{R}^{2} \\
\text { Value }\end{array}$ & $\begin{array}{l}\text { Standard } \\
\text { Deviation }\end{array}$ \\
\hline \multirow{2}{*}{ Zone } & Southern Ontario & 35 & 7620.1249 & 0.0264 & 407.4008 \\
\hline & Northern Ontario & 16 & -1956.7905 & 0.0933 & 369.3686 \\
\hline \multirow{2}{*}{$\begin{array}{l}\text { Highway } \\
\text { Series }\end{array}$} & 400 Series & 12 & 3330.3869 & 0.0111 & 519.6481 \\
\hline & Non-400 Series & 39 & 2332.9675 & 0.0267 & 382.2989 \\
\hline \multirow{3}{*}{$\begin{array}{l}\text { Top Layer } \\
\text { Material }\end{array}$} & Superpave 12.5 & 10 & -10.1370 & 0.0979 & 402.9648 \\
\hline & Superpave 12.5 FC1 & 11 & -843.4159 & 0.0004 & 401.8845 \\
\hline & Superpave 12.5 FC2 & 30 & -4809.7815 & 0.0469 & 442.3941 \\
\hline \multirow{4}{*}{$\begin{array}{l}\text { Top Layer } \\
\text { Performance } \\
\text { Grade }\end{array}$} & $58-28$ & 28 & -1777.5189 & 0.0263 & 378.4482 \\
\hline & $64-28$ & 9 & 3449.4940 & 0.00007 & 534.1725 \\
\hline & $64-34$ & 6 & -26.3481 & 0.0176 & 248.8298 \\
\hline & $70-28$ & 6 & 179.3046 & 0.3856 & 378.4329 \\
\hline
\end{tabular}

From the Figure 5.19, 5.20, 5.21 and 5.22 and Table 5.4, we can conclude that the clustering analyses indicates the following (noting better fit to the data) - 
- From the Zone clustering analyses, the model would perform better in Northern Ontario Zone.

- From Highway series, non 400 series would have better results in Longitudinal damage clustering analyses.

- From Top layer material analyses, Superpave 12.5 would have better fit, noting the fact that there are only significantly less observations for this top layer type available in this dataset. In such case, Superpave 12.5 FC2 would produce better result, cause with increased number of observations, and a bit less fit and slightly increased standard deviation.

- From Top Layer Performance Grade, 70-28 grade pulls better fit to the model.

\subsection{Thermal Cracking}

In the software, five values of the calibration parameter $\left(\mathrm{K}_{\mathrm{t}}\right)$ of were used $(1.5,3,4,7$ and 10) and the corresponding predicted data were compared. After comparison, it is found that with the weighted observed value, use of calibration factor of 7 shows minimum average bias (Table 5.5). Damage comparison graph is presented below (Figure 5.23). A Graph of predicted damage against calibration factor for seven random sections were also plotted (Figure 5.24).

Table 5.5: Statistical Results for Different Calibration Parameter for Thermal Damage

\begin{tabular}{|c|c|c|c|c|c|}
\hline Parameter Value & 1.5 & 3 & 4 & 7 & 10 \\
\hline Bias & 43.7357 & 24.1063 & 12.5020 & -8.9793 & -15.7355 \\
\hline Standard Deviation & 50.9148 & 53.2223 & 54.8272 & 49.5812 & 46.6958 \\
\hline
\end{tabular}




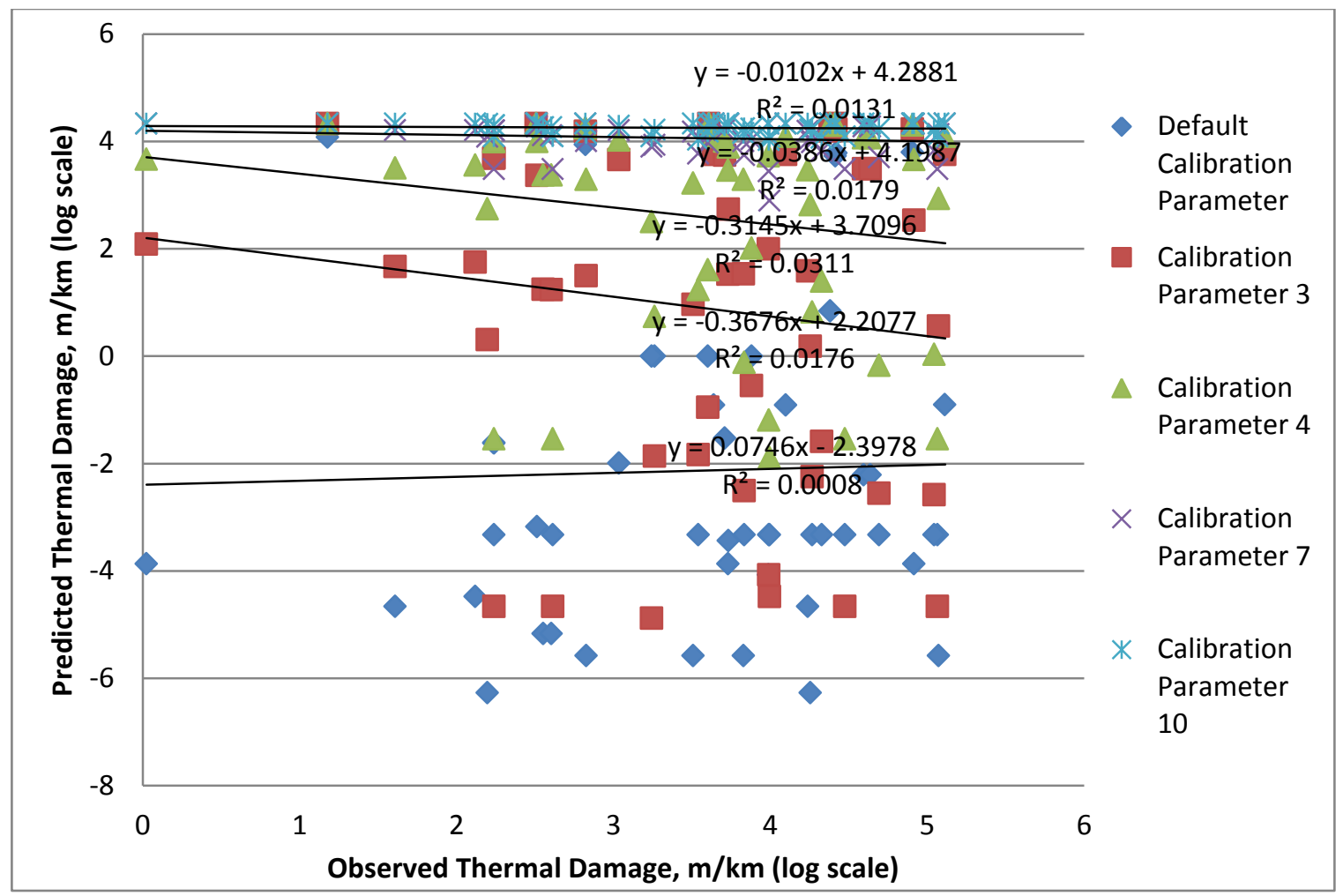

Figure 5.23: Thermal damage comparison

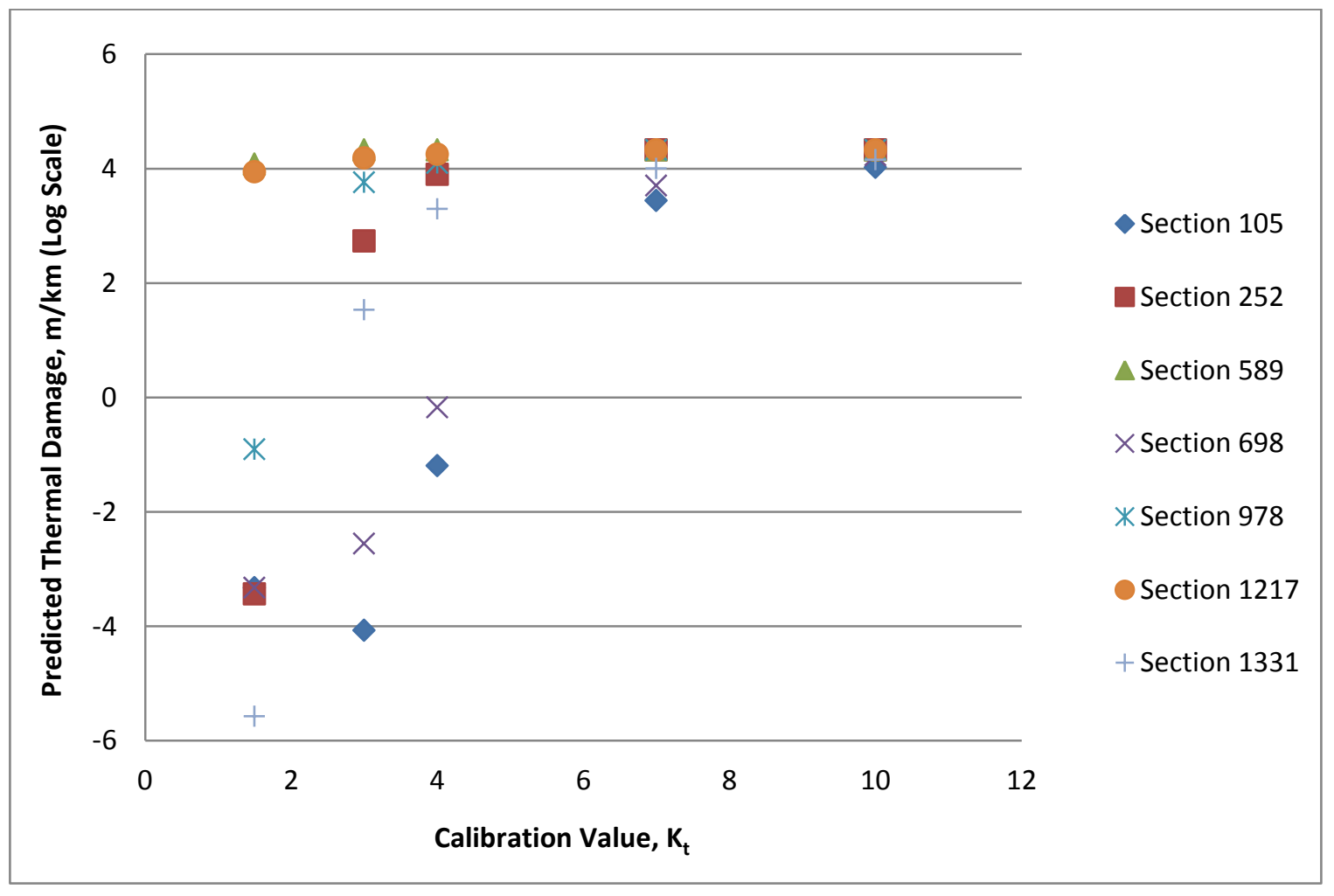

Figure 5.24: Calibration factor vs Predicted value for Thermal Damage 
From the above illustration (Figure 5.24), it needs to be mentioned that predicted thermal damage is increasing with Calibration value nonlinearly and is getting capped at $4 \mathrm{~m} / \mathrm{km}$ eventually.

Hence after analysis, calibration factor of 7 is considered as the final calibration parameter for the thermal damage. 


\section{Chapter 6 Summary, Conclusions and Recommendations}

\subsection{Summary}

The ultimate goal of this study was to calibrate the MEPDG cracking models for local conditions of Ontario. This is the first research on the local calibration of MEPDG cracking model for Ontario's superpave pavement. This study is partially funded by Ministry of Transportation Ontario (MTO).

An extensive literature review was done based on the former studies for local calibration.

Needs for the local calibration are analysed and the challenges are discussed. In this study calibration on the fatigue cracking model and the thermal cracking model are done. For the cracking model, observed data are processed to the compatible with the MEPDG format. Thus a calibration database is constructed by using the ARAN database from MTO and other traffic, climate and material input data.

Local calibration analyses are done with maximum value of observed distress. Then some clustering analyses are conducted also. Later in order to look for some improvements in results for the fatigue cracking analyses are done with the average value of observed distress. Based on Ontario zone, Highway series, Top layer material and its performance grade clustering analysis was conducted for the fatigue cracking model to check any possible cluster groups that may help to improve the performance of the model.

\subsection{Conclusion}

From the analysis described and explained in previous chapter, following conclusions can be drawn:

- All of the three cracking models (Alligator cracking model, Longitudinal cracking model and Thermal cracking model) with the default global calibration parameters under-predict the cracking in Ontario's flexible pavement. This research used initially maximum observed values for all the cracking models in order to obtain conservative design. Another set of analyses were done where average observed value was used in fatigue cracking model to investigate the possibility of improvements in the results. 
- Since clustering did not improve the results of fatigue cracking models significantly, the overall output does not suggest a strong correlation between the observed and predicted observations.

- Local calibration of thermal cracking model gives a value of 7.0 for the calibration parameter of $\mathrm{K}$ for level 3 with weighted observed damage. Though the bias and the standard deviations did not decrease significantly, this was the most improved value the calibration parameter.

\subsection{Recommendations}

Noting the analyses and results presented in the previous chapters, the following recommendations are suggested for future studies concerning local calibration of Cracking models in MEPDG:

- To make the local calibration successful and more accurate, the observed cracking data need to be improved significantly. Efforts need to be confined to improve the processing of the observed cracking data to be used in calibration of calibration model. Differentiating between alligator (bottom-up) cracking and longitudinal (top-down) cracking is always a difficult task. Cores or trenches of each crack can be taken to identify these two types of cracking. Moreover, ARAN segregates the cracks from its geometrical shapes, not from root cause. A detailing work can be done to confirm the segregation of the cracks by ARAN vehicle.

- A few number of new, reconstructed and rehabilitated pavement sections are used in this study. This number should be increased. Moreover, only King's highway was considered in this study. No secondary highway was considered. Therefore, secondary highway is needed to be considered to make the calibration process more appropriate, this will increase the number of observation. The more number of observation, decision making process on this point can be done with more confidence.

- Pavement section materials need to be characterized in details for level analysis to enhance the predicted data, so that level 1 (hierarchy input levels in AASHTOWare Pavement ME software) can be used for all the sections to be considered in the study. 
Moreover, a number of other asphalt materials (stone-mastic asphalt etc.) were omitted in this study. Hence, in future study these materials can be considered. 


\section{Appendix A Pavement Sections Selected for the Study}

Table A.1 Summary of the selected pavement sections

\begin{tabular}{|c|c|c|c|c|c|c|c|}
\hline Highway & LHRS & Offset & ID Session & Region & Direction & Sum of Length & Construction Type \\
\hline 3 & 12020 & 1.300 & 77 & WR & W_INC & 12194.9658 & Rehabilitation \\
\hline 3 & 12036 & 0.000 & 78 & WR & N_INC & 1196.4089 & Rehabilitation \\
\hline 6 & 13465 & 0.000 & 105 & CR & N_INC & 9866.0000 & New Construction \\
\hline 6 & 13570 & 0.000 & 106 & CR & N_INC & 6024.5570 & Rehabilitation \\
\hline 6 & 13570 & 5.900 & 107 & $\mathrm{CR}$ & N_INC & 7987.6876 & Rehabilitation \\
\hline 6 & 13580 & 1.000 & 108 & CR & N_INC & 4204.7876 & Rehabilitation \\
\hline 6 & 13585 & 0.300 & 109 & CR & N_INC & 3750.4516 & Rehabilitation \\
\hline 6 & 13585 & 3.244 & 110 & $\mathrm{CR}$ & N_INC & 951.5426 & Rehabilitation \\
\hline 6 & 13640 & 2.100 & 114 & $\mathrm{CR}$ & N_INC & 11411.0593 & Rehabilitation \\
\hline 6 & 13650 & 2.460 & 115 & CR & N_INC & 9378.2525 & Rehabilitation \\
\hline 7 & 14024 & 0.000 & 144 & ER & E_DEC & 8123.0000 & New Pavement \\
\hline 7 & 14100 & 0.000 & 149 & ER & W_INC & 12725.0000 & Rehabilitation \\
\hline 7 & 14270 & 0.000 & 166 & ER & E_DEC & 9165.5452 & Rehabilitation \\
\hline 7 & 14612 & 0.880 & 197 & WR & $\mathrm{E}$ & 7515.3818 & Rehabilitation \\
\hline 8 & 15970 & 1.300 & 219 & WR & $\mathrm{E}$ & 18992.1535 & Rehabilitation \\
\hline 10 & 16460 & 0.000 & 240 & CR & N_INC & 8361.2495 & Rehabilitation \\
\hline 10 & 16460 & 8.270 & 241 & $\mathrm{CR}$ & N_INC & 4166.5964 & Rehabilitation \\
\hline 10 & 16580 & 0.800 & 252 & WR & S_DEC & 15412.5682 & Rehabilitation \\
\hline 11 & 17285 & 18.200 & 265 & NER & N_INC & 12839.0300 & Rehabilitation \\
\hline 11 & 17360 & 3.900 & 271 & NER & N_DEC & 1397.0000 & Rehabilitation \\
\hline 11 & 17360 & 3.900 & 271 & NER & N_INC & 20780.7100 & Rehabilitation \\
\hline 11 & 17960 & 0.000 & 312 & NWR & W_INC & 3990.0000 & Rehabilitation \\
\hline 11 & 17970 & 0.000 & 313 & NWR & S_INC & 2235.8063 & Rehabilitation \\
\hline 11 & 17970 & 2.210 & 314 & NWR & S_INC & 6771.6845 & Rehabilitation \\
\hline 11 & 18030 & 14.430 & 323 & NWR & S_INC & 700.1322 & Rehabilitation \\
\hline 11 & 18105 & 0.000 & 328 & NWR & W_INC & 13008.3708 & Rehabilitation \\
\hline 11 & 18190 & 12.200 & 334 & NWR & W_INC & 29887.6992 & Rehabilitation \\
\hline 11 & 18240 & 0.200 & 337 & NWR & W_INC & 15432.7706 & Rehabilitation \\
\hline 11 & 17130 & 1.000 & 368 & NER & N_INC & 9137.6400 & New Construction \\
\hline 12 & 19380 & 0.000 & 424 & CR & $\mathrm{N}$ & 9907.6344 & Rehabilitation \\
\hline 15 & 20020 & 3.820 & 437 & ER & N_INC & 15049.0000 & Rehabilitation \\
\hline 17 & 20940 & 2.100 & 477 & NER & W_INC & 17168.2300 & Rehabilitation \\
\hline 17 & 22220 & 13.790 & 563 & NWR & E_DEC & 15807.5683 & Rehabilitation \\
\hline $17 \mathrm{~A}$ & 22250 & 0.000 & 574 & NWR & E_DEC & 8034.2395 & Rehabilitation \\
\hline
\end{tabular}




\begin{tabular}{|c|c|c|c|c|c|c|c|}
\hline $17 \mathrm{~A}$ & 22255 & 0.000 & 575 & NWR & E_DEC & 4406.0879 & Rehabilitation \\
\hline $17 \mathrm{~A}$ & 22260 & 0.000 & 576 & NWR & E_DEC & 6079.6726 & Rehabilitation \\
\hline $17 \mathrm{~A}$ & 22260 & 6.000 & 577 & NWR & E_DEC & 8300.0000 & Rehabilitation \\
\hline 17 & 22213 & 0.000 & 578 & NWR & E_DEC & 1229.8501 & Rehabilitation \\
\hline 21 & 24030 & 0.000 & 587 & WR & N_INC & 13182.5800 & Rehabilitation \\
\hline 21 & 24050 & 5.200 & 589 & WR & N_INC & 4106.0000 & Rehabilitation \\
\hline 21 & 24142 & 0.100 & 600 & WR & N_INC & 733.7368 & Rehabilitation \\
\hline 35 & 27816 & 0.000 & 670 & $\mathrm{CR}$ & N_INC & 3348.5179 & Rehabilitation \\
\hline 40 & 29110 & 6.200 & 679 & WR & N_INC & 1191.0000 & Rehabilitation \\
\hline 41 & 29580 & 2.800 & 697 & ER & N_INC & 13869.5199 & Rehabilitation \\
\hline 41 & 29590 & 3.900 & 698 & ER & N_INC & 6148.3360 & Rehabilitation \\
\hline 41 & 29590 & 11.300 & 699 & ER & N_INC & 15599.1816 & Rehabilitation \\
\hline 58 & 32740 & 0.000 & 719 & $\mathrm{CR}$ & N_INC & 4316.0000 & Reconstruction \\
\hline 60 & 33240 & 0.000 & 727 & ER & W_INC & 8345.0779 & Rehabilitation \\
\hline 60 & 33240 & 7.850 & 728 & ER & W_INC & 11707.6683 & Rehabilitation \\
\hline 62 & 33690 & 0.000 & 750 & ER & N_INC & 9520.9607 & Rehabilitation \\
\hline 62 & 33710 & 6.310 & 752 & ER & N_INC & 11817.0880 & Rehabilitation \\
\hline 63 & 34120 & 0.000 & 760 & NER & E INC & 18814.0000 & Rehabilitation \\
\hline 63 & 34133 & 4.771 & 761 & NER & E_INC & 17802.0000 & Rehabilitation \\
\hline 65 & 34560 & 8.200 & 775 & NER & W_INC & 14653.0000 & Rehabilitation \\
\hline 69 & 35523 & 12.300 & 790 & NER & N_INC & 25241.7832 & Rehabilitation \\
\hline 69 & 35550 & 14.000 & 791 & NER & N_INC & 12693.4282 & New Construction \\
\hline 89 & 38620 & 5.270 & 825 & $\mathrm{CR}$ & E_DEC & 2230.0000 & New Construction \\
\hline 89 & 38630 & 0.240 & 826 & $\mathrm{CR}$ & E_DEC & 6600.0000 & New Construction \\
\hline 93 & 39119 & 0.000 & 835 & WR & $\mathrm{N}$ & 11359.0417 & Rehabilitation \\
\hline 118 & 42620 & 0.000 & 887 & ER & $\mathrm{E}$ & 11616.6908 & Rehabilitation \\
\hline 144 & 46105 & 24.700 & 951 & NER & N_INC & 20031.9419 & Rehabilitation \\
\hline 144 & 46130 & 9.900 & 952 & NER & N_INC & 22070.1500 & Rehabilitation \\
\hline 400 & 46969 & 0.000 & 976 & NER & N_INC & 1231.7451 & Rehabilitation \\
\hline 400 & 46972 & 0.000 & 977 & NER & N_INC & 13430.2549 & Rehabilitation \\
\hline 400 & 46977 & 6.200 & 978 & NER & N_INC & 8058.6147 & Rehabilitation \\
\hline 401 & 47534 & 0.000 & 1042 & ER & E_DEC & 7138.0000 & Rehabilitation \\
\hline 401 & 47603 & 0.000 & 1052 & CR & E_DEC & 4045.0000 & Overlaying \\
\hline 402 & 48140 & 2.000 & 1217 & WR & E_DEC & 13378.0000 & Reconstruction \\
\hline 403 & 48335 & 0.000 & 1240 & WR & E_DEC & 7561.0000 & Rehabilitation \\
\hline 403 & 48255 & 1.650 & 1246 & $\mathrm{CR}$ & E_DEC & 29915.8100 & Overlaying \\
\hline 406 & 48652 & 0.626 & 1282 & CR & N_INC & 4846.6799 & New Construction \\
\hline 406 & 48652 & 1.326 & 1287 & $\mathrm{CR}$ & S_DEC & 4989.0000 & New Construction \\
\hline 410 & 49085 & 0.000 & 1298 & CR & N_INC & 4557.0000 & New Construction \\
\hline
\end{tabular}




\begin{tabular}{|l|l|l|l|l|l|l|l|}
\hline 417 & 49500 & 0.000 & 1331 & ER & E_DEC & 6160.0000 & Rehabilitation \\
\hline 417 & 49540 & 0.000 & 1332 & ER & E_DEC & 4136.0000 & Rehabilitation \\
\hline 1000 & 99998 & 27.500 & 1813 & ER & W_INC & 9756.0000 & Rehabilitation \\
\hline $403 \mathrm{C}$ & 48250 & 0.000 & 1245 & CR & N_DEC & 4026.4539 & Overlaying \\
\hline $403 \mathrm{C}$ & 48250 & 0.000 & 1260 & CR & N_DEC & 4026.4539 & Overlaying \\
\hline
\end{tabular}

Note:

WR-Western Region, ER- Eastern Region, CR- Central Region,

NER- North-Eastern Region, NWR- North Western Region

E-DEC - Decreasing East bound direction, E-INC- Increasing East bound direction

W-DEC - Decreasing west bound direction, E-INC- Increasing west bound direction

N-DEC - Decreasing North bound direction, E-INC- Increasing North bound direction

S-DEC - Decreasing South bound direction, E-INC- Increasing South bound direction 


\section{Appendix B Traffic Data for Pavement ME Analysis}

Table B.1: Recommended percentage of truck in design lane for Ontario

\begin{tabular}{|l|l|l|}
\hline $\begin{array}{l}\text { Number of lanes in } \\
\text { one direction }\end{array}$ & $\begin{array}{l}\text { Average annual daily traffic, } \\
\text { AADT (both direction) }\end{array}$ & $\begin{array}{l}\text { Lane distribution } \\
\text { factors }\end{array}$ \\
\hline \multirow{3}{*}{2} & All & 1.0 \\
\hline \multirow{4}{*}{3} & $<15,000$ & 0.9 \\
\cline { 2 - 3 } & $>15,000$ & 0.8 \\
\hline \multirow{3}{*}{4} & $<25,000$ & 0.8 \\
\cline { 2 - 3 } & $25,000-40,000$ & 0.7 \\
\cline { 2 - 3 } & $>40,000$ & 0.6 \\
\hline \multirow{3}{*}{5} & $<40,000$ & 0.7 \\
\cline { 2 - 3 } & $>40,000$ & 0.6 \\
\hline
\end{tabular}


Table B.2: Standard speed for different highway class in Ontario

\begin{tabular}{|c|c|}
\hline Facility type & Speed $(\mathrm{Km} / \mathrm{hr})$ \\
\hline Freeway & 100 \\
\hline Arterial & 80 \\
\hline Collector & 60 \\
\hline Local & 50 \\
\hline
\end{tabular}


Table B.3: Forecasting function of AADTT over pavement age

\begin{tabular}{|l|l|}
\hline Function & Eq. \\
\hline No growth (or, Negative growth) & AADTT $_{\text {Target year }}=1.0$ AADTT $_{\text {Base Year }}$ \\
\hline Linear growth & AADTT $_{\text {Target year }}=\left({\text { Growth rate }) \text { Age }+ \text { AADTT }_{\text {Base Year }}}\right.$ Compound growth $_{\text {Case Year }}($ Growth rate $)$ Age \\
\hline
\end{tabular}


Table B.4: Summary of TTC and FHWA vehicle class distribution used in AASHTOWare Pavement ME

\begin{tabular}{|c|c|c|c|c|c|c|c|c|c|c|c|c|c|}
\hline \multirow{2}{*}{$\begin{array}{l}\text { TTC } \\
\text { group }\end{array}$} & \multirow{2}{*}{$\begin{array}{l}\text { Bus } \\
(\%)\end{array}$} & \multirow{2}{*}{$\begin{array}{l}\text { Multi- } \\
\text { trailer }(\%)\end{array}$} & \multirow{2}{*}{ TTC description } & \multicolumn{10}{|c|}{ FHWA vehicle class } \\
\hline & & & & 4 & 5 & 6 & 7 & 8 & 9 & 10 & 11 & 12 & 13 \\
\hline 1 & $>2$ & $<2$ & Predominantly single-trailer trucks & 1.3 & 8.5 & 2.8 & 0.3 & 7.6 & 74 & 1.2 & 3.4 & 0.6 & 0.3 \\
\hline 2 & $>2$ & $<2$ & $\begin{array}{l}\text { Predominantly single-trailer trucks with a low percentage of } \\
\text { single-unit trucks }\end{array}$ & 2.4 & 14 & 4.5 & 0.7 & 7.9 & 66 & 1.4 & 2.2 & 0.3 & 0.2 \\
\hline 3 & $<2$ & $2-10$ & Predominantly single-trailer trucks & 0.9 & 12 & 3.6 & 0.2 & 6.7 & 62 & 4.8 & 2.6 & 1.4 & 6.2 \\
\hline 4 & $>2$ & $<2$ & $\begin{array}{l}\text { Predominantly single-trailer trucks with a low to moderate } \\
\text { amount of single-unit trucks }\end{array}$ & 2.4 & 23 & 5.7 & 1.4 & 8.1 & 55 & 1.7 & 2.2 & 0.2 & 0.4 \\
\hline 5 & $<2$ & $>10$ & Predominately single-trailer trucks & 0.9 & 14 & 3.5 & 0.6 & 6.9 & 54 & 5 & 2.7 & 1.2 & 11 \\
\hline 6 & $>2$ & $<2$ & $\begin{array}{l}\text { Mixed truck traffic with a higher percentage of single-unit } \\
\text { trucks }\end{array}$ & 2.8 & 31 & 7.3 & 0.8 & 9.3 & 45 & 2.3 & 1 & 0.4 & 0.3 \\
\hline 7 & $<2$ & $2-10$ & $\begin{array}{l}\text { Mixed truck traffic with a higher percentage of single-trailer } \\
\text { trucks }\end{array}$ & 1 & 24 & 4.2 & 0.5 & 10 & 42 & 5.8 & 2.6 & 1.3 & 8.4 \\
\hline 8 & $<2$ & $>10$ & $\begin{array}{l}\text { High percentage of single-trailer truck with some single-unit } \\
\text { trucks }\end{array}$ & 1.7 & 19 & 4.6 & 0.9 & 6.7 & 45 & 6 & 2.6 & 1.6 & 12 \\
\hline 9 & $>2$ & $<2$ & $\begin{array}{l}\text { Mixed truck traffic with about equal percentages of single- } \\
\text { unit and single-trailer trucks }\end{array}$ & 3.3 & 34 & 12 & 1.6 & 9.9 & 36 & 1 & 1.8 & 0.2 & 0.3 \\
\hline 10 & $<2$ & $2-10$ & $\begin{array}{l}\text { Mixed truck traffic with about equal percentages of single- } \\
\text { unit and single-trailer trucks }\end{array}$ & 0.8 & 31 & 6.9 & 0.1 & 7.8 & 38 & 3.7 & 1.2 & 4.5 & 6.7 \\
\hline 11 & $<2$ & $>10$ & $\begin{array}{l}\text { Mixed truck traffic with a higher percentage of single-trailer } \\
\text { trucks }\end{array}$ & 1.8 & 25 & 7.6 & 0.5 & 5 & 31 & 9.8 & 0.8 & 3.3 & 15 \\
\hline 12 & $>2$ & $<2$ & $\begin{array}{l}\text { Mixed truck traffic with a higher percentage of single-unit } \\
\text { trucks }\end{array}$ & 3.9 & 41 & 12 & 1.5 & 12 & 25 & 2.7 & 0.6 & 0.3 & 1.3 \\
\hline 13 & $<2$ & $>10$ & $\begin{array}{l}\text { Mixed truck traffic with about equal percentages of single- } \\
\text { unit and single-trailer trucks }\end{array}$ & 0.8 & 34 & 6.2 & 0.1 & 7.9 & 26 & 11 & 1.4 & 3.2 & 10 \\
\hline 14 & $>2$ & $<2$ & Predominantly single-unit trucks & 2.9 & 57 & 10 & 3.7 & 9.2 & 15 & 0.6 & 0.3 & 0.4 & 0.3 \\
\hline 15 & $<2$ & $2-10$ & Predominantly single-unit trucks & 1.8 & 57 & 8.5 & 1.8 & 6.2 & 14 & 5.4 & 0 & 0 & 5.7 \\
\hline 16 & $<2$ & $>10$ & Predominantly single-unit trucks & 1.3 & 48 & 11 & 1.9 & 6.7 & 13 & 4.3 & 0.5 & 0.1 & 13 \\
\hline 17 & $>25$ & $<2$ & $\begin{array}{l}\text { Mixed truck traffic with about equal single-unit and single- } \\
\text { trailer trucks }\end{array}$ & 36 & 15 & 13 & 0.5 & 15 & 18 & 0.5 & 0.8 & 0.1 & 1.5 \\
\hline
\end{tabular}


Table B.5: Axial per truck for southern Ontario

\begin{tabular}{|c|c|c|c|c|c|}
\hline FHWA class & Singles & Tandems & Tridems & Quads & Total \\
\hline 4 & 1.620 & 0.390 & 0.000 & 0.000 & 2.400 \\
\hline 5 & 2.000 & 0.000 & 0.000 & 0.000 & 2.000 \\
\hline 6 & 1.010 & 0.993 & 0.000 & 0.000 & 2.996 \\
\hline 7 & 1.314 & 0.989 & 0.030 & 0.000 & 3.382 \\
\hline 8 & 2.163 & 0.845 & 0.000 & 0.000 & 3.853 \\
\hline 9 & 1.055 & 1.968 & 0.003 & 0.000 & 5.000 \\
\hline 10 & 1.466 & 1.234 & 0.700 & 0.088 & 6.366 \\
\hline 11 & 4.546 & 0.168 & 0.000 & 0.000 & 4.882 \\
\hline 12 & 2.857 & 1.526 & 0.000 & 0.000 & 5.909 \\
\hline 13 & 1.201 & 2.058 & 0.848 & 0.024 & 7.957 \\
\hline
\end{tabular}


Table B.6: Axial per truck for northern Ontario

\begin{tabular}{|c|c|c|c|c|c|}
\hline FHWA class & Singles & Tandems & Tridems & Quads & Total \\
\hline 4 & 1.620 & 0.390 & 0.000 & 0.000 & 2.400 \\
\hline 5 & 2.000 & 0.000 & 0.000 & 0.000 & 2.000 \\
\hline 6 & 1.014 & 0.993 & 0.000 & 0.000 & 3.000 \\
\hline 7 & 1.244 & 0.962 & 0.043 & 0.000 & 3.297 \\
\hline 8 & 2.414 & 0.674 & 0.000 & 0.000 & 3.762 \\
\hline 9 & 1.048 & 1.955 & 0.014 & 0.000 & 5.000 \\
\hline 10 & 1.358 & 1.165 & 0.840 & 0.044 & 6.384 \\
\hline 11 & 3.849 & 0.538 & 0.000 & 0.000 & 4.925 \\
\hline 12 & 2.910 & 1.514 & 0.021 & 0.000 & 6.001 \\
\hline 13 & 1.100 & 2.012 & 0.945 & 0.011 & 8.003 \\
\hline
\end{tabular}


Table B.7: Single axial load distribution for southern Ontario

\begin{tabular}{|c|c|c|c|c|c|c|c|c|c|c|c|}
\hline \multicolumn{2}{|c|}{ Axle weight, $\mathrm{kg}$} & \multicolumn{10}{|c|}{ Frequency of a given axle weight range as a percentage } \\
\hline Min & Max & 4 & 5 & 6 & 7 & 8 & 9 & 10 & 11 & 12 & 13 \\
\hline 0 & 1360 & 1.8 & 0.07 & 0.19 & 0.28 & 0.42 & 0.04 & 0.39 & 0.1 & 0.02 & 0.44 \\
\hline 1361 & 1814 & 0.96 & 0.33 & 0.14 & 0.08 & 0.42 & 0.1 & 0.17 & 0.09 & 1.1 & 0.62 \\
\hline 1815 & 2267 & 2.91 & 5.4 & 0.89 & 0.45 & 2.13 & 0.62 & 0.44 & 0.57 & 0.02 & 0.85 \\
\hline 2268 & 2721 & 3.99 & 7.52 & 0.73 & 0.7 & 2.43 & 0.43 & 0.89 & 1.69 & 3.23 & 1.22 \\
\hline 2722 & 3175 & 6.8 & 6.65 & 0.95 & 0.87 & 3.56 & 0.44 & 0.93 & 6.75 & 8.18 & 1.14 \\
\hline 3176 & 3628 & 12 & 11.31 & 2.12 & 0.96 & 7.82 & 0.62 & 1.44 & 5.58 & 8.74 & 1.01 \\
\hline 3629 & 4082 & 11.7 & 13.95 & 4.73 & 1.5 & 7.21 & 1.22 & 1.48 & 4.29 & 8.71 & 0.99 \\
\hline 4083 & 4535 & 11.4 & 13.96 & 13.97 & 3.13 & 19.14 & 10.41 & 4.39 & 11.04 & 14.5 & 4.92 \\
\hline 4536 & 4989 & 10.3 & 10.71 & 18.4 & 5.11 & 13.03 & 22.57 & 12.87 & 14.92 & 15.76 & 12.6 \\
\hline 4990 & 5443 & 9 & 10.46 & 24.83 & 8.09 & 11.19 & 40.88 & 28.9 & 11.07 & 14.99 & 33.62 \\
\hline 5444 & 5896 & 7.4 & 5.04 & 10.68 & 3.7 & 3.97 & 14.53 & 15.16 & 7.08 & 6.41 & 17.87 \\
\hline 5897 & 6350 & 5.7 & 4.37 & 8.58 & 9.63 & 6.09 & 3.05 & 6.91 & 10.43 & 5.52 & 8.99 \\
\hline 6351 & 6803 & 4.3 & 2.28 & 4.56 & 11.06 & 5.69 & 1.04 & 3.37 & 7.9 & 4.17 & 3.33 \\
\hline 6804 & 7257 & 3.2 & 1.96 & 3.66 & 13.64 & 3.76 & 0.92 & 3.46 & 6.16 & 2.13 & 2.34 \\
\hline 7258 & 7711 & 2.58 & 1.65 & 1.45 & 11.37 & 2.13 & 0.9 & 3.14 & 3.66 & 1.42 & 1.29 \\
\hline 7712 & 8164 & 1.8 & 1.25 & 1.53 & 7 & 3.03 & 0.83 & 3.46 & 2.96 & 1.03 & 1.58 \\
\hline 8165 & 8618 & 1.4 & 0.8 & 1.37 & 5.94 & 1.45 & 0.49 & 2.87 & 1.75 & 0.32 & 1.08 \\
\hline 8619 & 9071 & 1 & 0.73 & 0.42 & 3.87 & 1.58 & 0.28 & 3.12 & 0.87 & 0.83 & 2.33 \\
\hline 9072 & 9525 & 0.75 & 0.5 & 0.35 & 5.89 & 1.41 & 0.16 & 1.96 & 0.66 & 0 & 0.72 \\
\hline 9526 & 9979 & 0.5 & 0.51 & 0.23 & 2.29 & 0.95 & 0.13 & 1.55 & 0.38 & 0.1 & 0.99 \\
\hline 9980 & 10432 & 0.25 & 0.27 & 0.04 & 1.74 & 0.59 & 0.11 & 1.15 & 0.14 & 0.08 & 0.47 \\
\hline 10433 & 10886 & 0.15 & 0.08 & 0.05 & 0.23 & 0.26 & 0.06 & 0.38 & 0.43 & 0.11 & 0.21 \\
\hline 10887 & 11339 & 0.1 & 0.06 & 0.02 & 0.25 & 0.18 & 0.03 & 0.35 & 0.19 & 0.19 & 0.18 \\
\hline 11340 & 11793 & 0 & 0.07 & 0.04 & 0.46 & 0.3 & 0.03 & 0.23 & 0 & 0.7 & 0.08 \\
\hline 11794 & 12246 & 0 & 0.02 & 0 & 0.04 & 0.12 & 0.01 & 0.11 & 0.75 & 1.27 & 0.17 \\
\hline 12247 & 12700 & 0 & 0.01 & 0 & 0.18 & 0.11 & 0.01 & 0.1 & 0 & 0 & 0.06 \\
\hline 12701 & 13154 & 0 & 0.01 & 0 & 0.11 & 0.06 & 0.01 & 0.13 & 0.18 & 0.24 & 0.18 \\
\hline 13155 & 13607 & 0 & 0.01 & 0 & 0 & 0.32 & 0 & 0.1 & 0.07 & 0 & 0 \\
\hline 13608 & 14061 & 0 & 0.01 & 0.05 & 0.06 & 0.11 & 0.01 & 0.05 & 0.18 & 0 & 0.09 \\
\hline 14062 & 14515 & 0 & 0.01 & 0 & 0.22 & 0.12 & 0.01 & 0.13 & 0 & 0 & 0.24 \\
\hline 14516 & 14968 & 0 & 0 & 0 & 0.13 & 0.05 & 0.01 & 0.1 & 0.04 & 0 & 0.1 \\
\hline 14969 & 15422 & 0 & 0 & 0 & 0.02 & 0.14 & 0.01 & 0.04 & 0.03 & 0 & 0 \\
\hline 15423 & 15875 & 0 & 0 & 0 & 0.23 & 0.13 & 0.01 & 0.07 & 0 & 0 & 0.1 \\
\hline 15876 & 16329 & 0 & 0 & 0 & 0.09 & 0.08 & 0.02 & 0.04 & 0.04 & 0 & 0 \\
\hline 16330 & 16782 & 0 & 0 & 0 & 0 & 0 & 0 & 0.01 & 0 & 0 & 0.12 \\
\hline 16783 & 17236 & 0 & 0 & 0 & 0.37 & 0.02 & 0 & 0.03 & 0 & 0 & 0.01 \\
\hline 17237 & 17690 & 0 & 0 & 0.02 & 0.06 & 0 & 0 & 0.01 & 0 & 0 & 0.04 \\
\hline 17691 & 18143 & 0.01 & 0 & 0 & 0.16 & 0 & 0.01 & 0.04 & 0 & 0.23 & 0 \\
\hline 18144 & 20412 & 0 & 0 & 0 & 0.09 & 0 & 0 & 0.03 & 0 & 0 & 0.02 \\
\hline Total & & 100 & 100 & 100 & 100 & 100 & 100 & 100 & 100 & 100 & 100 \\
\hline
\end{tabular}


Table B.8: Single axial load distribution for northern Ontario

\begin{tabular}{|c|c|c|c|c|c|c|c|c|c|c|c|}
\hline \multicolumn{2}{|c|}{ Axle weight, $\mathrm{kg}$} & \multicolumn{10}{|c|}{ Frequency of a given axle weight range as a percentage } \\
\hline Min & Max & Min & $\operatorname{Max}$ & Min & Max & Min & $\operatorname{Max}$ & Min & $\operatorname{Max}$ & Min & $\operatorname{Max}$ \\
\hline 0 & 1360 & 1.8 & 0.2 & 0.22 & 0 & 2.13 & 0.06 & 0.63 & 5.54 & 0.58 & 0.15 \\
\hline 1361 & 1814 & 0.96 & 0.61 & 0 & 0 & 1.88 & 0.09 & 0.2 & 0 & 0 & 0.45 \\
\hline 1815 & 2267 & 2.91 & 11.58 & 0.47 & 0.26 & 5.41 & 0.61 & 0.66 & 0 & 2.58 & 0.58 \\
\hline 2268 & 2721 & 3.99 & 10.37 & 0.36 & 0 & 6.2 & 0.42 & 0.66 & 0 & 1.27 & 0.61 \\
\hline 2722 & 3175 & 6.8 & 8.26 & 0.09 & 0.03 & 7.42 & 0.22 & 1.61 & 5.54 & 2.51 & 1.04 \\
\hline 3176 & 3628 & 12 & 11.4 & 7.07 & 0.17 & 9.95 & 0.77 & 2.06 & 0 & 6.42 & 1.13 \\
\hline 3629 & 4082 & 11.7 & 11.52 & 8.12 & 0.33 & 13.52 & 1.2 & 2.21 & 1.93 & 4.28 & 1.47 \\
\hline 4083 & 4535 & 11.4 & 12.32 & 10.22 & 3.28 & 13.61 & 4.72 & 3.17 & 6.96 & 12.66 & 3.71 \\
\hline 4536 & 4989 & 10.3 & 8.79 & 14.41 & 5.51 & 7.22 & 11.71 & 9.34 & 17.18 & 5.81 & 12.37 \\
\hline 4990 & 5443 & 9 & 8.64 & 30.23 & 3.8 & 8.17 & 42.47 & 27.56 & 4.45 & 22.22 & 33.58 \\
\hline 5444 & 5896 & 7.4 & 3.72 & 9.15 & 9.29 & 2.61 & 23.52 & 19.4 & 10.07 & 14.3 & 25.58 \\
\hline 5897 & 6350 & 5.7 & 2.32 & 5.2 & 23.78 & 4.01 & 4.64 & 8.64 & 1.93 & 6.63 & 10.57 \\
\hline 6351 & 6803 & 4.3 & 3.04 & 4.35 & 9.4 & 3.74 & 2.47 & 3.75 & 13.93 & 8.88 & 1.6 \\
\hline 6804 & 7257 & 3.2 & 1.53 & 3.12 & 17.47 & 4.88 & 1.94 & 3.57 & 13.42 & 1.45 & 1.41 \\
\hline 7258 & 7711 & 2.58 & 0.62 & 2.29 & 4.59 & 3 & 1.4 & 3 & 0 & 0 & 0.91 \\
\hline 7712 & 8164 & 1.8 & 1.66 & 1.45 & 2.23 & 1.26 & 0.66 & 3.31 & 7.05 & 1.04 & 1.67 \\
\hline 8165 & 8618 & 1.4 & 1.14 & 1.62 & 4.84 & 0.73 & 0.69 & 3.19 & 0 & 3.25 & 0.85 \\
\hline 8619 & 9071 & 1 & 0.91 & 1.41 & 4.01 & 1.42 & 0.38 & 2.37 & 7.05 & 0 & 0.91 \\
\hline 9072 & 9525 & 0.75 & 0.51 & 0 & 6.21 & 0.17 & 0.24 & 1.1 & 3.02 & 0 & 0.23 \\
\hline 9526 & 9979 & 0.5 & 0.12 & 0 & 1.78 & 0 & 0.25 & 1.19 & 0 & 0 & 0.21 \\
\hline 9980 & 10432 & 0.25 & 0.05 & 0 & 1.17 & 0.79 & 1.2 & 0.76 & 0 & 3.25 & 0 \\
\hline 10433 & 10886 & 0.15 & 0.42 & 0.22 & 0.29 & 0.74 & 0.08 & 0.27 & 0 & 1.25 & 0.06 \\
\hline 10887 & 11339 & 0.1 & 0.15 & 0 & 0.25 & 0 & 0.04 & 0.1 & 1.93 & 0.58 & 0 \\
\hline 11340 & 11793 & 0 & 0.12 & 0 & 1.15 & 0 & 0.06 & 0.29 & 0 & 0 & 0.07 \\
\hline 11794 & 12246 & 0 & 0 & 0 & 0 & 0 & 0 & 0.35 & 0 & 1.04 & 0 \\
\hline 12247 & 12700 & 0 & 0 & 0 & 0 & 0 & 0.02 & 0.17 & 0 & 0 & 0 \\
\hline 12701 & 13154 & 0 & 0 & 0 & 0 & 0 & 0.01 & 0.07 & 0 & 0 & 0 \\
\hline 13155 & 13607 & 0 & 0 & 0 & 0 & 0.82 & 0.02 & 0.04 & 0 & 0 & 0.28 \\
\hline 13608 & 14061 & 0 & 0 & 0 & 0 & 0 & 0.03 & 0.08 & 0 & 0 & 0 \\
\hline 14062 & 14515 & 0 & 0 & 0 & 0 & 0.32 & 0.01 & 0.09 & 0 & 0 & 0 \\
\hline 14516 & 14968 & 0 & 0 & 0 & 0.02 & 0 & 0 & 0.05 & 0 & 0 & 0.11 \\
\hline 14969 & 15422 & 0 & 0 & 0 & 0 & 0 & 0.02 & 0.01 & 0 & 0 & 0 \\
\hline 15423 & 15875 & 0 & 0 & 0 & 0.13 & 0 & 0.02 & 0.05 & 0 & 0 & 0.12 \\
\hline 15876 & 16329 & 0 & 0 & 0 & 0 & 0 & 0.02 & 0.01 & 0 & 0 & 0.23 \\
\hline 16330 & 16782 & 0 & 0 & 0 & 0 & 0 & 0.01 & 0 & 0 & 0 & 0.03 \\
\hline 16783 & 17236 & 0 & 0 & 0 & 0 & 0 & 0 & 0 & 0 & 0 & 0.07 \\
\hline 17237 & 17690 & 0 & 0 & 0 & 0.01 & 0 & 0 & 0 & 0 & 0 & 0 \\
\hline 17691 & 18143 & 0.01 & 0 & 0 & 0 & 0 & 0 & 0.03 & 0 & 0 & 0 \\
\hline 18144 & 20412 & 0 & 0 & 0 & 0 & 0 & 0 & 0.01 & 0 & 0 & 0 \\
\hline \multicolumn{2}{|c|}{ Total } & 100 & 100 & 100 & 100 & 100 & 100 & 100 & 100 & 100 & 100 \\
\hline
\end{tabular}


Table B.9: Tandem axial load distribution for southern Ontario

\begin{tabular}{|c|c|c|c|c|c|c|c|c|c|c|c|}
\hline \multicolumn{2}{|c|}{ Axle weight, $\mathrm{kg}$} & \multicolumn{10}{|c|}{ Frequency of a given axle weight range as a percentage } \\
\hline Min & $\operatorname{Max}$ & Min & Max & Min & Max & Min & Max & Min & Max & Min & Max \\
\hline 0 & 2721 & 5.28 & 0 & 1.47 & 0.73 & 4.03 & 0.24 & 0.35 & 0 & 0.25 & 0.54 \\
\hline 2722 & 3628 & 10 & 0 & 4.13 & 0.75 & 3.89 & 0.52 & 0.87 & 7.64 & 1.16 & 3.2 \\
\hline 3629 & 4535 & 11.9 & 0 & 23.53 & 1.24 & 3.99 & 2.44 & 1.45 & 10.37 & 2.59 & 6.79 \\
\hline 4536 & 5442 & 9.63 & 0 & 5.97 & 2.43 & 16.72 & 7.61 & 2.61 & 11.48 & 9.52 & 5.33 \\
\hline 5443 & 6350 & 8 & 0 & 7.9 & 4.81 & 16.55 & 8.85 & 6.74 & 6.64 & 10.48 & 7.18 \\
\hline 6351 & 7257 & 7.8 & 0 & 8.95 & 13.22 & 16.89 & 7.84 & 9.28 & 5.02 & 9.4 & 4.82 \\
\hline 7258 & 8164 & 6.8 & 0 & 8.93 & 12.24 & 10.76 & 7.95 & 7.71 & 9.86 & 13.5 & 3.36 \\
\hline 8165 & 9071 & 6.15 & 0 & 8.54 & 9.01 & 10.57 & 8.23 & 5.65 & 9.45 & 11.9 & 2.91 \\
\hline 9072 & 9979 & 5.8 & 0 & 5.77 & 4 & 6.36 & 7.44 & 4.61 & 13.19 & 13.83 & 2.51 \\
\hline 9980 & 10885 & 5.3 & 0 & 5.72 & 7.14 & 3.29 & 6.63 & 3.67 & 8.56 & 6.92 & 2.11 \\
\hline 10886 & 11793 & 4.7 & 0 & 4.03 & 6.9 & 1.64 & 5.86 & 3.41 & 0 & 4.29 & 2.3 \\
\hline 11794 & 12700 & 4.1 & 0 & 2.98 & 3.49 & 1.47 & 5.6 & 3.98 & 4.17 & 6.09 & 3.05 \\
\hline 12701 & 13607 & 3.33 & 0 & 2.95 & 2.48 & 1.17 & 5.79 & 5.04 & 4.61 & 2.2 & 2.97 \\
\hline 13608 & 14514 & 3.91 & 0 & 1.75 & 2.11 & 0.6 & 7.32 & 5.7 & 1.77 & 1.72 & 4.46 \\
\hline 14515 & 15422 & 2.22 & 0 & 1.65 & 3.48 & 0.67 & 8.91 & 7.03 & 1.59 & 1.34 & 6.64 \\
\hline 15423 & 16329 & 1.84 & 0 & 1.96 & 1.83 & 0.89 & 5.61 & 8.49 & 3.51 & 1.02 & 10.12 \\
\hline 16330 & 17236 & 1.44 & 0 & 0.54 & 2.12 & 0.35 & 1.71 & 7.61 & 0 & 0.38 & 10.97 \\
\hline 17237 & 18143 & 0.9 & 0 & 0.77 & 5.32 & 0.09 & 0.77 & 6.04 & 0 & 1.32 & 9.81 \\
\hline 18144 & 19051 & 0.5 & 0 & 0.51 & 4.91 & 0 & 0.31 & 4.56 & 1.44 & 1.62 & 5.24 \\
\hline 19052 & 19957 & 0.3 & 0 & 0.52 & 3.63 & 0.07 & 0.15 & 2.11 & 0 & 0.43 & 1.87 \\
\hline 19958 & 20865 & \begin{tabular}{|l|}
0.1 \\
\end{tabular} & 0 & 0.54 & 3.53 & 0 & 0.09 & 1.12 & 0.7 & 0 & 1.35 \\
\hline 20866 & 21772 & 0 & 0 & 0.41 & 1.47 & 0 & 0.05 & 0.72 & 0 & 0 & 0.61 \\
\hline 21773 & 22679 & 0 & 0 & 0.28 & 1.44 & 0 & 0.04 & 0.3 & 0 & 0 & 0.43 \\
\hline 22680 & 23587 & 0 & 0 & 0.09 & 0.35 & 0 & 0.01 & 0.21 & 0 & 0 & 0.41 \\
\hline 23588 & 24493 & 0 & 0 & 0.01 & 0.12 & 0 & 0.01 & 0.11 & 0 & 0 & 0.43 \\
\hline 24494 & 25401 & 0 & 0 & 0 & 0.36 & 0 & 0.01 & 0.2 & 0 & 0 & 0.29 \\
\hline 25402 & 26308 & 0 & 0 & 0.03 & 0.27 & 0 & 0.01 & 0.14 & 0 & 0 & 0.04 \\
\hline 26309 & 27215 & 0 & 0 & 0 & 0.08 & 0 & 0 & 0.09 & 0 & 0.04 & 0.02 \\
\hline 27216 & 28122 & 0 & 0 & 0 & 0.31 & 0 & 0 & 0.03 & 0 & 0 & 0.05 \\
\hline 28123 & 29029 & 0 & 0 & 0.03 & 0 & 0 & 0 & 0.09 & 0 & 0 & 0 \\
\hline 29030 & 29937 & 0 & 0 & 0 & 0.16 & 0 & 0 & 0.01 & 0 & 0 & 0 \\
\hline 29938 & 30844 & 0 & 0 & 0.04 & 0 & 0 & 0 & 0.01 & 0 & 0 & 0.01 \\
\hline 30845 & 31751 & 0 & 0 & 0 & 0 & 0 & 0 & 0.02 & 0 & 0 & 0.01 \\
\hline 31752 & 32659 & 0 & 0 & 0 & 0 & 0 & 0 & 0.02 & 0 & 0 & 0 \\
\hline 32659 & 33566 & 0 & 0 & 0 & 0 & 0 & 0 & 0.01 & 0 & 0 & 0.03 \\
\hline 33567 & 34473 & 0 & 0 & 0 & 0 & 0 & 0 & 0 & 0 & 0 & 0 \\
\hline 34474 & 35380 & 0 & 0 & 0 & 0.03 & 0 & 0 & 0 & 0 & 0 & 0.01 \\
\hline 35381 & 36287 & 0 & 0 & 0 & 0 & 0 & 0 & 0 & 0 & 0 & 0.03 \\
\hline 36288 & 38556 & 0 & 0 & 0 & 0.04 & 0 & 0 & 0.01 & 0 & 0 & 0.1 \\
\hline Total & & 100 & 0 & 100 & 100 & 100 & 100 & 100 & 100 & 100 & 100 \\
\hline
\end{tabular}


Table B.10: Tandem axial load distribution for northern Ontario

\begin{tabular}{|c|c|c|c|c|c|c|c|c|c|c|c|}
\hline \multicolumn{2}{|c|}{ Axle weight, $\mathrm{kg}$} & \multicolumn{10}{|c|}{ Frequency of a given axle weight range as a percentage } \\
\hline Min & Max & 4 & 5 & 6 & 7 & 8 & 9 & 10 & 11 & 12 & 13 \\
\hline 0 & 2721 & 5.28 & 0 & 0 & 0.07 & 5.8 & 0.1 & 0.51 & 0 & 0 & 0.92 \\
\hline 2722 & 3628 & 10 & 0 & 2.54 & 2.81 & 3.77 & 0.29 & 1.2 & 0 & 1.12 & 4.36 \\
\hline 3629 & 4535 & 11.9 & 0 & 24.63 & 0.32 & 11.98 & 1.26 & 1.78 & 0 & 0 & 6.47 \\
\hline 4536 & 5442 & 9.63 & 0 & 9.79 & 0.81 & 16.32 & 3.61 & 2.37 & 39.76 & 3.7 & 4.45 \\
\hline 5443 & 6350 & 8 & 0 & 3.94 & 24.58 & 27.48 & 4.76 & 3.98 & 60.24 & 6.17 & 7.05 \\
\hline 6351 & 7257 & 7.8 & 0 & 8.61 & 10.06 & 12.06 & 5.48 & 7.6 & 0 & 7.24 & 5.44 \\
\hline 7258 & 8164 & 6.8 & 0 & 10.85 & 6.22 & 0.83 & 4.86 & 6.11 & 0 & 10.13 & 1.86 \\
\hline 8165 & 9071 & 6.15 & 0 & 10.83 & 19.04 & 6.21 & 6.4 & 6.43 & 0 & 17.37 & 1.75 \\
\hline 9072 & 9979 & 5.8 & 0 & 3.29 & 2.01 & 4.91 & 6.58 & 3.44 & 0 & 19.34 & 1.45 \\
\hline 9980 & 10885 & 5.3 & 0 & 2.29 & 0.77 & 1.98 & 8.89 & 4.85 & 0 & 6.55 & 1.7 \\
\hline 10886 & 11793 & 4.7 & 0 & 0.67 & 1.69 & 1.98 & 8.71 & 3.85 & 0 & 3.85 & 1.33 \\
\hline 11794 & 12700 & 4.1 & 0 & 5.02 & 1.15 & 0.62 & 8.43 & 3.85 & 0 & 5.46 & 2.28 \\
\hline 12701 & 13607 & 3.33 & 0 & 2.54 & 0.84 & 0 & 6.32 & 5.2 & 0 & 5.34 & 3.17 \\
\hline 13608 & 14514 & 3.91 & 0 & 1.35 & 1.18 & 0 & 8.48 & 5.62 & 0 & 0 & 4.46 \\
\hline 14515 & 15422 & 2.22 & 0 & 0.83 & 0.66 & 5.54 & 10.66 & 6.55 & 0 & 6.26 & 10.31 \\
\hline 15423 & 16329 & 1.84 & 0 & 3.29 & 3.6 & 0 & 7.85 & 9.16 & 0 & 0 & 11.82 \\
\hline 16330 & 17236 & 1.44 & 0 & 2.64 & 5.48 & 0.52 & 3.73 & 7.84 & 0 & 6.26 & 14.12 \\
\hline 17237 & 18143 & 0.9 & 0 & 1.23 & 1.82 & 0 & 1.71 & 6.42 & 0 & 0 & 9.13 \\
\hline 18144 & 19051 & 0.5 & 0 & 1.65 & 3.33 & 0 & 0.61 & 5.47 & 0 & 0 & 3.66 \\
\hline 19052 & 19957 & 0.3 & 0 & 1.86 & 3.68 & 0 & 0.34 & 2.61 & 0 & 0 & 1.32 \\
\hline 19958 & 20865 & 0.1 & 0 & 0.7 & 2.58 & 0 & 0.23 & 1.34 & 0 & 0 & 0.67 \\
\hline 20866 & 21772 & 0 & 0 & 0.32 & 0.26 & 0 & 0.23 & 1.65 & 0 & 0 & 0.37 \\
\hline 21773 & 22679 & 0 & 0 & 0.77 & 2.59 & 0 & 0.23 & 0.37 & 0 & 0 & 0.32 \\
\hline 22680 & 23587 & 0 & 0 & 0.36 & 1.19 & 0 & 0.08 & 0.41 & 0 & 0 & 0.13 \\
\hline 23588 & 24493 & 0 & 0 & 0 & 0.06 & 0 & 0.11 & 0.22 & 0 & 0 & 0.33 \\
\hline 24494 & 25401 & 0 & 0 & 0 & 2.52 & 0 & 0.01 & 0.59 & 0 & 0 & 0.07 \\
\hline 25402 & 26308 & 0 & 0 & 0 & 0.27 & 0 & 0.02 & 0.33 & 0 & 0 & 0.85 \\
\hline 26309 & 27215 & 0 & 0 & 0 & 0.19 & 0 & 0.01 & 0 & 0 & 1.21 & 0.05 \\
\hline 27216 & 28122 & 0 & 0 & 0 & 0 & 0 & 0.01 & 0.1 & 0 & 0 & 0.09 \\
\hline 28123 & 29029 & 0 & 0 & 0 & 0 & 0 & 0 & 0.04 & 0 & 0 & 0.06 \\
\hline 29030 & 29937 & 0 & 0 & 0 & 0.22 & 0 & 0 & 0.06 & 0 & 0 & 0 \\
\hline 29938 & 30844 & 0 & 0 & 0 & 0 & 0 & 0 & 0 & 0 & 0 & 0 \\
\hline 30845 & 31751 & 0 & 0 & 0 & 0 & 0 & 0 & 0 & 0 & 0 & 0.01 \\
\hline 31752 & 32659 & 0 & 0 & 0 & 0 & 0 & 0 & 0 & 0 & 0 & 0 \\
\hline 32659 & 33566 & 0 & 0 & 0 & 0 & 0 & 0 & 0 & 0 & 0 & 0 \\
\hline 33567 & 34473 & 0 & 0 & 0 & 0 & 0 & 0 & 0 & 0 & 0 & 0 \\
\hline 34474 & 35380 & 0 & 0 & 0 & 0 & 0 & 0 & 0 & 0 & 0 & 0 \\
\hline 35381 & 36287 & 0 & 0 & 0 & 0 & 0 & 0 & 0 & 0 & 0 & 0 \\
\hline 36288 & 38556 & 0 & 0 & 0 & 0 & 0 & 0 & 0.05 & 0 & 0 & 0 \\
\hline \multicolumn{2}{|c|}{ Total } & 100 & 0 & 100 & 100 & 100 & 100 & 100 & 100 & 100 & 100 \\
\hline
\end{tabular}


Table B.11: Tridem axial load distribution for southern Ontario

\begin{tabular}{|c|c|c|c|c|c|c|c|c|c|c|c|}
\hline \multicolumn{2}{|c|}{ Axle weight, kg } & \multicolumn{6}{|c|}{ Frequency of aiven axle weight range as a percentage } \\
\hline Min & Max & 4 & 5 & 6 & 7 & 8 & 9 & 10 & 11 & 12 & 13 \\
\hline 0 & 5443 & 0 & 0 & 0 & 4.27 & 0 & 39.91 & 4.98 & 0 & 0 & 6.5 \\
\hline 5444 & 6803 & 0 & 0 & 0 & 9.25 & 0 & 7.59 & 9.66 & 0 & 0 & 11.03 \\
\hline 6804 & 8164 & 0 & 0 & 0 & 10.95 & 0 & 19.97 & 9.53 & 0 & 0 & 6.55 \\
\hline 8165 & 9525 & 0 & 0 & 0 & 0.28 & 0 & 5.9 & 7.21 & 0 & 0 & 3.69 \\
\hline 9526 & 10886 & 0 & 0 & 0 & 14.25 & 0 & 0.67 & 5.22 & 0 & 0 & 2.44 \\
\hline 10887 & 12246 & 0 & 0 & 0 & 1.96 & 0 & 5.32 & 5.06 & 0 & 0 & 2.3 \\
\hline 12247 & 13607 & 0 & 0 & 0 & 4.52 & 0 & 2.18 & 4.38 & 0 & 0 & 2.18 \\
\hline 13608 & 14968 & 0 & 0 & 0 & 2.1 & 0 & 8.21 & 4.32 & 0 & 0 & 4.16 \\
\hline 14969 & 16329 & 0 & 0 & 0 & 12.3 & 0 & 3.59 & 4.56 & 0 & 0 & 4.46 \\
\hline 16330 & 17690 & 0 & 0 & 0 & 0.64 & 0 & 1.73 & 4.82 & 0 & 0 & 4.54 \\
\hline 17691 & 19050 & 0 & 0 & 0 & 0 & 0 & 3.42 & 5.87 & 0 & 0 & 3.9 \\
\hline 19051 & 20411 & 0 & 0 & 0 & 0.5 & 0 & 1.22 & 5.44 & 0 & 0 & 7.33 \\
\hline 20412 & 21772 & 0 & 0 & 0 & 0 & 0 & 0 & 6.96 & 0 & 0 & 11.94 \\
\hline 21773 & 23133 & 0 & 0 & 0 & 9.85 & 0 & 0 & 6.31 & 0 & 0 & 14.85 \\
\hline 23134 & 24494 & 0 & 0 & 0 & 2.99 & 0 & 0.29 & 5.68 & 0 & 0 & 8.24 \\
\hline 24495 & 25854 & 0 & 0 & 0 & 6.69 & 0 & 0 & 4.5 & 0 & 0 & 3.49 \\
\hline 25855 & 27215 & 0 & 0 & 0 & 9.35 & 0 & 0 & 2.2 & 0 & 0 & 1.43 \\
\hline 27216 & 28576 & 0 & 0 & 0 & 4.55 & 0 & 0 & 1.25 & 0 & 0 & 0.34 \\
\hline 28577 & 29937 & 0 & 0 & 0 & 5.55 & 0 & 0 & 0.6 & 0 & 0 & 0.35 \\
\hline 29938 & 31298 & 0 & 0 & 0 & 0 & 0 & 0 & 0.32 & 0 & 0 & 0.16 \\
\hline 31299 & 32658 & 0 & 0 & 0 & 0 & 0 & 0 & 0.31 & 0 & 0 & 0.04 \\
\hline 32659 & 34019 & 0 & 0 & 0 & 0 & 0 & 0 & 0.25 & 0 & 0 & 0.01 \\
\hline 34020 & 35380 & 0 & 0 & 0 & 0 & 0 & 0 & 0.28 & 0 & 0 & 0.06 \\
\hline 35381 & 36741 & 0 & 0 & 0 & 0 & 0 & 0 & 0.11 & 0 & 0 & 0 \\
\hline 36742 & 38102 & 0 & 0 & 0 & 0 & 0 & 0 & 0.04 & 0 & 0 & 0 \\
\hline 38103 & 39462 & 0 & 0 & 0 & 0 & 0 & 0 & 0.05 & 0 & 0 & 0 \\
\hline 39463 & 40823 & 0 & 0 & 0 & 0 & 0 & 0 & 0.09 & 0 & 0 & 0.01 \\
\hline 40824 & 42184 & 0 & 0 & 0 & 0 & 0 & 0 & 0 & 0 & 0 & 0 \\
\hline 42185 & 43545 & 0 & 0 & 0 & 0 & 0 & 0 & 0 & 0 & 0 & 0 \\
\hline 43546 & 44906 & 0 & 0 & 0 & 0 & 0 & 0 & 0 & 0 & 0 & 0 \\
\hline 44907 & 47628 & 0 & 0 & 0 & 0 & 0 & 0 & 0 & 0 & 0 & 0 \\
\hline Total & 0 & 0 & 0 & 100 & 0 & 100 & 100 & 0 & 0 & 100 \\
\hline
\end{tabular}


Table B.12: Tridem axial load distribution for northern Ontario

\begin{tabular}{|c|c|c|c|c|c|c|c|c|c|c|c|}
\hline \multicolumn{6}{|c|}{ Axle weight, kg } & \multicolumn{6}{|c|}{ Frequency of a given axle weight range as a percentage } \\
\hline Min & Max & 4 & 5 & 6 & 7 & 8 & 9 & 10 & 11 & 12 & 13 \\
\hline 0 & 5443 & 0 & 0 & 0 & 0 & 0 & 7.02 & 5.25 & 0 & 0 & 5.62 \\
\hline 5444 & 6803 & 0 & 0 & 0 & 20.17 & 0 & 5.16 & 7.54 & 0 & 100 & 13.66 \\
\hline 6804 & 8164 & 0 & 0 & 0 & 0 & 0 & 0 & 8.65 & 0 & 0 & 6.55 \\
\hline 8165 & 9525 & 0 & 0 & 0 & 44.49 & 0 & 0.19 & 6.67 & 0 & 0 & 2.23 \\
\hline 9526 & 10886 & 0 & 0 & 0 & 9.56 & 0 & 0.86 & 4.91 & 0 & 0 & 2.02 \\
\hline 10887 & 12246 & 0 & 0 & 0 & 0 & 0 & 5.33 & 4.48 & 0 & 0 & 1.16 \\
\hline 12247 & 13607 & 0 & 0 & 0 & 0 & 0 & 1.05 & 4.85 & 0 & 0 & 1.75 \\
\hline 13608 & 14968 & 0 & 0 & 0 & 0 & 0 & 77.01 & 5.07 & 0 & 0 & 2.42 \\
\hline 14969 & 16329 & 0 & 0 & 0 & 0 & 0 & 0.13 & 5.21 & 0 & 0 & 3.41 \\
\hline 16330 & 17690 & 0 & 0 & 0 & 0 & 0 & 0 & 4.96 & 0 & 0 & 4.28 \\
\hline 17691 & 19050 & 0 & 0 & 0 & 0 & 0 & 2.78 & 7.72 & 0 & 0 & 4.74 \\
\hline 19051 & 20411 & 0 & 0 & 0 & 0 & 0 & 0 & 6.04 & 0 & 0 & 10.07 \\
\hline 20412 & 21772 & 0 & 0 & 0 & 13.2 & 0 & 0 & 5.54 & 0 & 0 & 13.11 \\
\hline 21773 & 23133 & 0 & 0 & 0 & 12.58 & 0 & 0.28 & 6.9 & 0 & 0 & 17.58 \\
\hline 23134 & 24494 & 0 & 0 & 0 & 0 & 0 & 0.19 & 5.39 & 0 & 0 & 6.99 \\
\hline 24495 & 25854 & 0 & 0 & 0 & 0 & 0 & 0 & 4.26 & 0 & 0 & 2.47 \\
\hline 25855 & 27215 & 0 & 0 & 0 & 0 & 0 & 0 & 2.05 & 0 & 0 & 0.51 \\
\hline 27216 & 28576 & 0 & 0 & 0 & 0 & 0 & 0 & 1.57 & 0 & 0 & 0.48 \\
\hline 28577 & 29937 & 0 & 0 & 0 & 0 & 0 & 0 & 0.98 & 0 & 0 & 0.27 \\
\hline 29938 & 31298 & 0 & 0 & 0 & 0 & 0 & 0 & 0.87 & 0 & 0 & 0.07 \\
\hline 31299 & 32658 & 0 & 0 & 0 & 0 & 0 & 0 & 0.47 & 0 & 0 & 0.55 \\
\hline 32659 & 34019 & 0 & 0 & 0 & 0 & 0 & 0 & 0.29 & 0 & 0 & 0.06 \\
\hline 34020 & 35380 & 0 & 0 & 0 & 0 & 0 & 0 & 0.18 & 0 & 0 & 0 \\
\hline 35381 & 36741 & 0 & 0 & 0 & 0 & 0 & 0 & 0.09 & 0 & 0 & 0 \\
\hline 36742 & 38102 & 0 & 0 & 0 & 0 & 0 & 0 & 0.04 & 0 & 0 & 0 \\
\hline 38103 & 39462 & 0 & 0 & 0 & 0 & 0 & 0 & 0 & 0 & 0 & 0 \\
\hline 39463 & 40823 & 0 & 0 & 0 & 0 & 0 & 0 & 0 & 0 & 0 & 0 \\
\hline 40824 & 42184 & 0 & 0 & 0 & 0 & 0 & 0 & 0 & 0 & 0 & 0 \\
\hline 42185 & 43545 & 0 & 0 & 0 & 0 & 0 & 0 & 0.02 & 0 & 0 & 0 \\
\hline 43546 & 44906 & 0 & 0 & 0 & 0 & 0 & 0 & 0 & 0 & 0 & 0 \\
\hline 44907 & 47628 & 0 & 0 & 0 & 0 & 0 & 0 & 0 & 0 & 0 & 0 \\
\hline Total & 0 & 0 & 0 & 100 & 0 & 100 & 100 & 0 & 100 & 100 \\
\hline
\end{tabular}


Table B.13: Quad axial load distribution for southern Ontario

\begin{tabular}{|c|c|c|c|c|c|c|c|c|c|c|c|}
\hline \multicolumn{2}{|c|}{ Axle weight, kg } & \multicolumn{10}{|c|}{ Frequency of a given axle weight range as a percentage } \\
\hline Min & Max & 4 & 5 & 6 & 7 & 8 & 9 & 10 & 11 & 12 & 13 \\
\hline 0 & 5443 & 0 & 0 & 0 & 0 & 0 & 0 & 1.24 & 0 & 0 & 4.29 \\
\hline 5444 & 6803 & 0 & 0 & 0 & 0 & 0 & 0 & 4.17 & 0 & 0 & 8.96 \\
\hline 6804 & 8164 & 0 & 0 & 0 & 0 & 0 & 0 & 6.18 & 0 & 0 & 13.81 \\
\hline 8165 & 9525 & 0 & 0 & 0 & 0 & 0 & 0 & 6.07 & 0 & 0 & 5.32 \\
\hline 9526 & 10886 & 0 & 0 & 0 & 0 & 0 & 0 & 4.72 & 0 & 0 & 0.76 \\
\hline 10887 & 12246 & 0 & 0 & 0 & 0 & 0 & 0 & 5.88 & 0 & 0 & 0 \\
\hline 12247 & 13607 & 0 & 0 & 0 & 0 & 0 & 0 & 3.56 & 0 & 0 & 2.2 \\
\hline 13608 & 14968 & 0 & 0 & 0 & 0 & 0 & 0 & 2.04 & 0 & 0 & 2.95 \\
\hline 14969 & 16329 & 0 & 0 & 0 & 0 & 0 & 0 & 2.87 & 0 & 0 & 13.86 \\
\hline 16330 & 17690 & 0 & 0 & 0 & 0 & 0 & 0 & 2.37 & 0 & 0 & 0.82 \\
\hline 17691 & 19050 & 0 & 0 & 0 & 0 & 0 & 0 & 3.58 & 0 & 0 & 3.17 \\
\hline 19051 & 20411 & 0 & 0 & 0 & 0 & 0 & 0 & 3.03 & 0 & 0 & 8.65 \\
\hline 20412 & 21772 & 0 & 0 & 0 & 0 & 0 & 0 & 5.41 & 0 & 0 & 2.04 \\
\hline 21773 & 23133 & 0 & 0 & 0 & 0 & 0 & 0 & 6.93 & 0 & 0 & 5.77 \\
\hline 23134 & 24494 & 0 & 0 & 0 & 0 & 0 & 0 & 8.53 & 0 & 0 & 11.66 \\
\hline 24495 & 25854 & 0 & 0 & 0 & 0 & 0 & 0 & 6.93 & 0 & 0 & 7.89 \\
\hline 25855 & 27215 & 0 & 0 & 0 & 0 & 0 & 0 & 4.36 & 0 & 0 & 0.23 \\
\hline 27216 & 28576 & 0 & 0 & 0 & 0 & 0 & 0 & 3.85 & 0 & 0 & 0.39 \\
\hline 28577 & 29937 & 0 & 0 & 0 & 0 & 0 & 0 & 3.72 & 0 & 0 & 0 \\
\hline 29938 & 31298 & 0 & 0 & 0 & 0 & 0 & 0 & 3.79 & 0 & 0 & 0 \\
\hline 31299 & 32658 & 0 & 0 & 0 & 0 & 0 & 0 & 3.13 & 0 & 0 & 3.09 \\
\hline 32659 & 34019 & 0 & 0 & 0 & 0 & 0 & 0 & 3.6 & 0 & 0 & 4.14 \\
\hline 34020 & 35380 & 0 & 0 & 0 & 0 & 0 & 0 & 1.5 & 0 & 0 & 0 \\
\hline 35381 & 36741 & 0 & 0 & 0 & 0 & 0 & 0 & 0.79 & 0 & 0 & 0 \\
\hline 36742 & 38102 & 0 & 0 & 0 & 0 & 0 & 0 & 0.35 & 0 & 0 & 0 \\
\hline 38103 & 39462 & 0 & 0 & 0 & 0 & 0 & 0 & 1.02 & 0 & 0 & 0 \\
\hline 39463 & 40823 & 0 & 0 & 0 & 0 & 0 & 0 & 0.16 & 0 & 0 & 0 \\
\hline 40824 & 42184 & 0 & 0 & 0 & 0 & 0 & 0 & 0.06 & 0 & 0 & 0 \\
\hline 42185 & 43545 & 0 & 0 & 0 & 0 & 0 & 0 & 0.16 & 0 & 0 & 0 \\
\hline 43546 & 44906 & 0 & 0 & 0 & 0 & 0 & 0 & 0 & 0 & 0 & 0 \\
\hline 44907 & 47628 & 0 & 0 & 0 & 0 & 0 & 0 & 0 & 0 & 0 & 0 \\
\hline \multicolumn{2}{|c|}{ Total } & 0 & 0 & 0 & 0 & 0 & 0 & 100 & 0 & 0 & 100 \\
\hline
\end{tabular}


Table B.14: Quad axial load distribution for northern Ontario

\begin{tabular}{|c|c|c|c|c|c|c|c|c|c|c|c|}
\hline \multicolumn{2}{|c|}{ Axle weight, kg } & \multicolumn{6}{|l|}{ Frequency of a given axle weight range as a percentage } \\
\hline Min & Max & 4 & 5 & 6 & 7 & 8 & 9 & 10 & 11 & 12 & 13 \\
\hline 0 & 5,443 & 0 & 0 & 0 & 0 & 0 & 0 & 3.18 & 0 & 0 & 5.81 \\
\hline 5,444 & 6,803 & 0 & 0 & 0 & 0 & 0 & 0 & 5.33 & 0 & 0 & 9.56 \\
\hline 6,804 & 8,164 & 0 & 0 & 0 & 0 & 0 & 0 & 10.25 & 0 & 0 & 3.09 \\
\hline 8,165 & 9,525 & 0 & 0 & 0 & 0 & 0 & 0 & 5.2 & 0 & 0 & 0 \\
\hline 9,526 & 10,886 & 0 & 0 & 0 & 0 & 0 & 0 & 1.99 & 0 & 0 & 0 \\
\hline 10,887 & 12,246 & 0 & 0 & 0 & 0 & 0 & 0 & 3.35 & 0 & 0 & 0 \\
\hline 12,247 & 13,607 & 0 & 0 & 0 & 0 & 0 & 0 & 2.62 & 0 & 0 & 3.09 \\
\hline 13,608 & 14,968 & 0 & 0 & 0 & 0 & 0 & 0 & 2.12 & 0 & 0 & 6.47 \\
\hline 14,969 & 16,329 & 0 & 0 & 0 & 0 & 0 & 0 & 4.23 & 0 & 0 & 3.84 \\
\hline 16,330 & 17,690 & 0 & 0 & 0 & 0 & 0 & 0 & 2.48 & 0 & 0 & 9.37 \\
\hline 17,691 & 19,050 & 0 & 0 & 0 & 0 & 0 & 0 & 1.01 & 0 & 0 & 0 \\
\hline 19,051 & 20,411 & 0 & 0 & 0 & 0 & 0 & 0 & 0.23 & 0 & 0 & 0 \\
\hline 20,412 & 21,772 & 0 & 0 & 0 & 0 & 0 & 0 & 7.56 & 0 & 0 & 3.37 \\
\hline 21,773 & 23,133 & 0 & 0 & 0 & 0 & 0 & 0 & 3.05 & 0 & 0 & 2.44 \\
\hline 23,134 & 24,494 & 0 & 0 & 0 & 0 & 0 & 0 & 4.18 & 0 & 0 & 45.93 \\
\hline 24,495 & 25,854 & 0 & 0 & 0 & 0 & 0 & 0 & 7.42 & 0 & 0 & 0.09 \\
\hline 25,855 & 27,215 & 0 & 0 & 0 & 0 & 0 & 0 & 3.19 & 0 & 0 & 6.94 \\
\hline 27,216 & 28,576 & 0 & 0 & 0 & 0 & 0 & 0 & 5.91 & 0 & 0 & 0 \\
\hline 28,577 & 29,937 & 0 & 0 & 0 & 0 & 0 & 0 & 6.43 & 0 & 0 & 0 \\
\hline 29,938 & 31,298 & 0 & 0 & 0 & 0 & 0 & 0 & 5.29 & 0 & 0 & 0 \\
\hline 31,299 & 32,658 & 0 & 0 & 0 & 0 & 0 & 0 & 4.38 & 0 & 0 & 0 \\
\hline 32,659 & 34,019 & 0 & 0 & 0 & 0 & 0 & 0 & 8.45 & 0 & 0 & 0 \\
\hline 34,020 & 35,380 & 0 & 0 & 0 & 0 & 0 & 0 & 1.64 & 0 & 0 & 0 \\
\hline 35,381 & 36,741 & 0 & 0 & 0 & 0 & 0 & 0 & 0 & 0 & 0 & 0 \\
\hline 36,742 & 38,102 & 0 & 0 & 0 & 0 & 0 & 0 & 0 & 0 & 0 & 0 \\
\hline 38,103 & 39,462 & 0 & 0 & 0 & 0 & 0 & 0 & 0 & 0 & 0 & 0 \\
\hline 39,463 & 40,823 & 0 & 0 & 0 & 0 & 0 & 0 & 0.51 & 0 & 0 & 0 \\
\hline 40,824 & 42,184 & 0 & 0 & 0 & 0 & 0 & 0 & 0 & 0 & 0 & 0 \\
\hline 42,185 & 43,545 & 0 & 0 & 0 & 0 & 0 & 0 & 0 & 0 & 0 & 0 \\
\hline 43,546 & 44,906 & 0 & 0 & 0 & 0 & 0 & 0 & 0 & 0 & 0 & 0 \\
\hline 44,907 & 47,628 & 0 & 0 & 0 & 0 & 0 & 0 & 0 & 0 & 0 & 0 \\
\hline Total & 0 & 0 & 0 & 0 & 0 & 0 & 100 & 0 & 0 & 100 \\
\hline
\end{tabular}


Table B.15: Ontario's traffic information for the selected pavement sections

\begin{tabular}{|c|c|c|c|c|c|c|c|c|}
\hline S. No. & Section ID & HWY & Zone & Design Life (Years) & $\begin{array}{l}\text { Total } \\
\text { ADTT }\end{array}$ & No. of lanes & Facility Type & $\begin{array}{l}\text { TTC } \\
\text { Class } \\
\end{array}$ \\
\hline 1 & 77 & 3 & SO & 11 & 10400 & 2 & Arterial & 11 \\
\hline 2 & 78 & 3 & SO & 11 & 10100 & 2 & Collector & 11 \\
\hline 3 & 79 & 3 & SO & 15 & 12045 & 2 & Collector & 11 \\
\hline 4 & 80 & 3 & SO & 15 & 6000 & 2 & Arterial & 11 \\
\hline 5 & 105 & 6 & SO & 12 & 19600 & 2 & Collector & 11 \\
\hline 6 & 156 & 7 & NO & 10 & 4850 & 2 & Arterial & 11 \\
\hline 7 & 166 & 7 & NO & 11 & 9550 & 2 & Arterial & 11 \\
\hline 8 & 197 & 7 & $\mathrm{SO}$ & 9 & 21300 & 2 & Freeway & 11 \\
\hline 9 & 206 & 7 & $\mathrm{SO}$ & 9 & 21300 & 2 & Freeway & 11 \\
\hline 10 & 252 & 10 & $\mathrm{NO}$ & 10 & 4900 & 2 & Arterial & 11 \\
\hline 11 & 253 & 10 & NO & 10 & 4900 & 2 & Arterial & 11 \\
\hline 12 & 323 & 11 & NO & 11 & 5050 & 2 & Freeway & 11 \\
\hline 13 & 334 & 11 & NO & 9 & 750 & 2 & Freeway & 11 \\
\hline 14 & 436 & 15 & SO & 12 & 6600 & 2 & Arterial & 11 \\
\hline 15 & 437 & 15 & $\mathrm{SO}$ & 12 & 5350 & 2 & Arterial & 11 \\
\hline 16 & 477 & 17 & NO & 10 & 6700 & 2 & Freeway & 11 \\
\hline 17 & 574 & 17 & NO & 9 & 2400 & 2 & Freeway & 11 \\
\hline 18 & 575 & 17 & NO & 9 & 2650 & 2 & Freeway & 11 \\
\hline 19 & 576 & 17 & NO & 9 & 2850 & 2 & Freeway & 11 \\
\hline 20 & 577 & 17 & NO & 9 & 3100 & 2 & Freeway & 11 \\
\hline 21 & 578 & 17 & NO & 9 & 2750 & 2 & Freeway & 11 \\
\hline 22 & 613 & 23 & NO & 10 & 5950 & 2 & Arterial & 11 \\
\hline 23 & 670 & 35 & SO & 12 & 6700 & 2 & Arterial & 11 \\
\hline 24 & 673 & 35 & $\mathrm{SO}$ & 11 & 6700 & 2 & Arterial & 11 \\
\hline 25 & 697 & 41 & $\mathrm{SO}$ & 8 & 2400 & 2 & Arterial & 11 \\
\hline 26 & 698 & 41 & $\mathrm{SO}$ & 9 & 1450 & 2 & Arterial & 11 \\
\hline 27 & 719 & 58 & SO & 8 & 16000 & 2 & Freeway & 11 \\
\hline 28 & 835 & 93 & SO & 13 & 8150 & 2 & Arterial & 11 \\
\hline 29 & 887 & 118 & NO & 8 & 1500 & 2 & Arterial & 11 \\
\hline 30 & 951 & 144 & NO & 12 & 990 & 2 & Arterial & 11 \\
\hline 31 & 952 & 144 & $\mathrm{NO}$ & 12 & 990 & 2 & Arterial & 11 \\
\hline 32 & 1240 & 403 & $\mathrm{SO}$ & 10 & 41500 & 2 & Freeway & 11 \\
\hline 33 & 1255 & 403 & $\mathrm{SO}$ & 10 & 41500 & 2 & Freeway & 11 \\
\hline 34 & 1297 & 410 & $\mathrm{SO}$ & 9 & 116900 & 3 & Freeway & 11 \\
\hline 35 & 1301 & 410 & SO & 9 & 116900 & 3 & Freeway & 11 \\
\hline
\end{tabular}




\section{Appendix C Climatic Data for Pavement ME Analysis}

Table C.1: Ontario's weather stations

\begin{tabular}{|c|c|c|c|c|c|}
\hline Station & Station name & Location & Latitude & Longitude & Elevation \\
\hline 15801 & Armstrong & Armstrong Airport & 50.294 & -88.905 & 322 \\
\hline 94932 & Atikokan & Atikokan & 48.750 & -91.617 & 395 \\
\hline 15806 & Big Trout Lake & Big Trout Lake & 53.833 & -89.867 & 224 \\
\hline 94862 & Chapleau & Chapleau & 47.833 & -83.433 & 428 \\
\hline 94797 & Earlton & Earlton Airport & 47.700 & -79.850 & 243 \\
\hline 94864 & Geraldton & Geraldton & 49.700 & -86.950 & 331 \\
\hline 94888 & Geraldton & Geraldton Airport & 49.783 & -86.931 & 349 \\
\hline 94803 & Gore Bay & Gore Bay Airport & 45.883 & -82.567 & 194 \\
\hline 14998 & Graham & Graham Airport & 49.267 & -90.583 & 503 \\
\hline 4797 & Hamilton & Hamilton Airport & 43.172 & -79.934 & 238 \\
\hline 14899 & Kapuskasing & Kapuskasing Airport & 49.414 & -82.468 & 226 \\
\hline 14999 & Kenora & Kenora Airport & 49.790 & -94.365 & 410 \\
\hline 94799 & Killaloe & Killaloe & 45.567 & -77.417 & 174 \\
\hline 94805 & London & London Airport & 43.033 & -81.151 & 278 \\
\hline 94857 & Mount Forest & Mount Forest & 43.983 & -80.750 & 415 \\
\hline 15804 & Nakina & Nakina Airport & 50.183 & -86.700 & 325 \\
\hline 4705 & North Bay & North Bay Airport & 46.364 & -79.423 & 370 \\
\hline 4772 & Ottawa & Macdonald-Cartier International Airport & 45.323 & -75.669 & 114 \\
\hline 4706 & Ottawa & Ottawa Rockcliff Airport & 45.450 & -75.633 & 54 \\
\hline 54706 & Petawawa & Petawawa Airport & 45.950 & -77.317 & 130 \\
\hline 94842 & Sault Ste Marie & Sault Ste Marie Airport & 46.483 & -84.509 & 192 \\
\hline 94858 & Simcoe & Simcoe & 42.850 & -80.267 & 240 \\
\hline 15909 & Sioux Lookout & Sioux Lookout Airport & 50.117 & -91.900 & 383 \\
\hline 4713 & Stirling & Stirling & 44.317 & -77.633 & 139 \\
\hline 94828 & Sudbury & Sudbury Airport & 46.625 & -80.799 & 347 \\
\hline 94804 & Thunder Bay & Thunder Bay Airport & 48.369 & -89.327 & 199 \\
\hline 94831 & Timmins & Victor Power Airport & 48.570 & -81.377 & 295 \\
\hline 54753 & Toronto & Buttonville Airport & 43.862 & -79.370 & 198 \\
\hline 94791 & Toronto & Lester B. Pearson International Airport & 43.677 & -79.631 & 173 \\
\hline 4715 & Trenton & Trenton Airport & 44.117 & -77.533 & 86 \\
\hline 94808 & White River & White River & 48.600 & -85.283 & 379 \\
\hline 94809 & Wiarton & Wiarton Airport & 44.746 & -81.107 & 222 \\
\hline 94810 & Windsor & Windsor Airport & 42.276 & -82.956 & 190 \\
\hline 15807 & Winisk & Winisk Airport & 55.233 & -85.117 & 13 \\
\hline
\end{tabular}


Table C.2: Location parameters for the selected pavement sections

\begin{tabular}{|c|c|c|c|c|c|}
\hline Highway & LHRS & Offset & Latitude & Longitude & Elevation \\
\hline 3 & 12020 & 1.300 & 190.634266100 & 42.774039190 & -81.016301460 \\
\hline 3 & 12036 & 0.000 & 212.665138900 & 42.788359920 & -81.146524190 \\
\hline 6 & 13465 & 0.000 & 211.677502600 & 43.210822770 & -79.968180570 \\
\hline 6 & 13570 & 0.000 & 215.499159000 & 43.334617430 & -79.948367570 \\
\hline 6 & 13570 & 5.900 & 222.240677400 & 43.364260250 & -79.988737570 \\
\hline 6 & 13580 & 1.000 & 256.349080000 & 43.424880910 & -80.077258320 \\
\hline 6 & 13585 & 0.300 & 275.856525200 & 43.435461900 & -80.100769850 \\
\hline 6 & 13585 & 3.244 & 286.956160100 & 43.449142960 & -80.118405560 \\
\hline 6 & 13640 & 2.100 & 419.087932200 & 43.902694390 & -80.636682300 \\
\hline 6 & 13650 & 2.460 & 388.625780400 & 43.967379940 & -80.726383120 \\
\hline 7 & 14024 & 0.000 & 98.117111310 & 45.271584420 & -75.970983920 \\
\hline 7 & 14100 & 0.000 & 179.712102400 & 44.803362130 & -76.658990710 \\
\hline 7 & 14270 & 0.000 & 249.739715100 & 44.303396350 & -78.541505550 \\
\hline 7 & 14612 & 0.880 & 300.618910900 & 43.374739400 & -80.700739780 \\
\hline 8 & 15970 & 1.300 & 315.714399000 & 43.473262950 & -81.209669560 \\
\hline 10 & 16460 & 0.000 & 254.968805000 & 43.807338810 & -79.924285990 \\
\hline 10 & 16460 & 8.270 & 376.703819700 & 43.852533580 & -79.985333350 \\
\hline 10 & 16580 & 0.800 & 391.995266000 & 44.321536770 & -80.652957620 \\
\hline 11 & 17285 & 18.200 & 246.049552300 & 47.320331630 & -79.808416100 \\
\hline 11 & 17360 & 3.900 & 174.276225500 & 47.851756020 & -79.913493790 \\
\hline 11 & 17360 & 3.900 & 232.017612300 & 47.958322180 & -80.014014340 \\
\hline 11 & 17960 & 0.000 & 183.342964200 & 49.018954500 & -88.257336170 \\
\hline 11 & 17970 & 0.000 & 233.879069300 & 49.020620370 & -88.303536830 \\
\hline 11 & 17970 & 2.210 & 178.811648900 & 48.954978480 & -88.339912090 \\
\hline 11 & 18030 & 14.430 & 204.191309300 & 48.534784100 & -88.953861180 \\
\hline 11 & 18105 & 0.000 & 205.563059200 & 48.380664590 & -89.472473400 \\
\hline 11 & 18190 & 12.200 & 446.858393800 & 48.676809300 & -90.961441610 \\
\hline 11 & 18240 & 0.200 & 387.320053400 & 48.725183820 & -91.602275880 \\
\hline 11 & 17130 & 1.000 & 278.801874300 & 45.606948060 & -79.402836550 \\
\hline
\end{tabular}




\begin{tabular}{|c|c|c|c|c|c|}
\hline 12 & 19380 & 0.000 & 219.176201000 & 44.356745230 & -79.103948790 \\
\hline 15 & 20020 & 3.820 & 63.700598580 & 44.387456330 & -76.323759160 \\
\hline 17 & 20940 & 2.100 & 196.329115300 & 46.338289310 & -79.547621370 \\
\hline 17 & 22220 & 13.790 & 337.635013500 & 49.743398550 & -95.103788850 \\
\hline $17 \mathrm{~A}$ & 22250 & 0.000 & 324.739564600 & 49.772367610 & -94.332286120 \\
\hline $17 \mathrm{~A}$ & 22255 & 0.000 & 294.985837500 & 49.801454510 & -94.401498890 \\
\hline $17 \mathrm{~A}$ & 22260 & 0.000 & 312.884347100 & 49.800941690 & -94.484615410 \\
\hline $17 \mathrm{~A}$ & 22260 & 6.000 & 300.353636000 & 49.792432200 & -94.519510000 \\
\hline 17 & 22213 & 0.000 & 320.907307500 & 49.740173140 & -94.653559230 \\
\hline 21 & 24030 & 0.000 & 148.506118600 & 43.214300150 & -81.880308190 \\
\hline 21 & 24050 & 5.200 & 161.373432100 & 43.414103620 & -81.705917480 \\
\hline 21 & 24142 & 0.100 & 174.388242100 & 44.177411320 & -81.611945060 \\
\hline 35 & 27816 & 0.000 & 170.393283800 & 43.992909440 & -78.610728730 \\
\hline 40 & 29110 & 6.200 & 150.177048800 & 42.424193680 & -82.150409230 \\
\hline 41 & 29580 & 2.800 & 248.058892400 & 44.846150420 & -77.179890180 \\
\hline 41 & 29590 & 3.900 & 238.155938000 & 44.976489000 & -77.257828020 \\
\hline 41 & 29590 & 11.300 & 364.217035500 & 45.093325950 & -77.253306840 \\
\hline 58 & 32740 & 0.000 & 146.573543000 & 43.097177510 & -79.189551360 \\
\hline 60 & 33240 & 0.000 & 138.908988400 & 45.597516030 & -77.297390440 \\
\hline 60 & 33240 & 7.850 & 138.913675700 & 0.000000000 & 0.000000000 \\
\hline 62 & 33690 & 0.000 & 75.940867350 & 44.264817990 & -77.443857170 \\
\hline 62 & 33710 & 6.310 & 143.891008400 & 44.440813290 & -77.461858780 \\
\hline 63 & 34120 & 0.000 & 207.063990000 & 46.347876370 & -79.334803580 \\
\hline 63 & 34133 & 4.771 & 240.155008700 & 46.414080400 & -79.209208840 \\
\hline 65 & 34560 & 8.200 & 246.373889400 & 47.638523470 & -80.032778630 \\
\hline 69 & 35523 & 12.300 & 172.531979300 & 46.174359330 & -80.717445910 \\
\hline 69 & 35550 & 14.000 & 193.206074800 & 46.279137710 & -80.799191250 \\
\hline 89 & 38620 & 5.270 & 186.725089800 & 44.145166740 & -79.894716600 \\
\hline 89 & 38630 & 0.240 & 212.469391200 & 44.140587570 & -79.915435310 \\
\hline 93 & 39119 & 0.000 & 206.340295600 & 44.665597150 & -79.844135640 \\
\hline 118 & 42620 & 0.000 & 384.139477400 & 44.992542450 & -78.094539400 \\
\hline 144 & 46105 & 24.700 & 358.941464400 & 47.507558140 & -81.841351550 \\
\hline
\end{tabular}




\begin{tabular}{|l|l|l|l|l|l|}
\hline 144 & 46130 & 9.900 & 320.132619400 & 47.705815340 & -81.753062260 \\
\hline 400 & 46969 & 0.000 & 150.549906700 & 44.800267550 & -79.723825820 \\
\hline 400 & 46972 & 0.000 & 148.300506800 & 44.813241860 & -79.739523580 \\
\hline 400 & 46977 & 6.200 & 170.283844200 & 44.966924040 & -79.774466780 \\
\hline 401 & 47534 & 0.000 & 78.247344830 & 43.982788710 & -78.224253800 \\
\hline 401 & 47603 & 0.000 & 68.817853620 & 43.852953380 & -79.022398810 \\
\hline 402 & 48140 & 2.000 & 187.994637000 & 42.991139580 & -81.996939950 \\
\hline 403 & 48335 & 0.000 & 186.288489300 & 43.183174700 & -80.123866110 \\
\hline 403 & 48255 & 1.650 & 129.363559100 & 43.550980430 & -79.700122220 \\
\hline 406 & 48652 & 0.626 & 150.357369000 & 43.081894310 & -79.236266240 \\
\hline 406 & 48652 & 1.326 & 149.964854800 & 43.064155330 & -79.235473160 \\
\hline 410 & 49085 & 0.000 & 221.971850700 & 43.744401810 & -79.825688930 \\
\hline 417 & 49500 & 0.000 & 32.924362170 & 45.342519570 & -75.819553480 \\
\hline 417 & 49540 & 0.000 & 72.297886580 & 45.329213990 & -75.863642090 \\
\hline 1000 & 99998 & 27.500 & 69.274741430 & 44.517057580 & -75.786503600 \\
\hline $403 \mathrm{C}$ & 48250 & 0.000 & 117.554644800 & 43.624991840 & -79.640009340 \\
\hline $403 \mathrm{C}$ & 48250 & 0.000 & 117.554644800 & 43.624991840 & -79.640009340 \\
\hline
\end{tabular}




\section{Appendix D Material and Structural Data for Pavement ME Analysis}

Table D.1: Ontario's typical superpave properties

\begin{tabular}{|c|c|c|c|c|c|c|c|c|}
\hline \multirow{2}{*}{$\begin{array}{l}\text { Asphalt } \\
\text { Layer }\end{array}$} & \multirow{2}{*}{$\begin{array}{l}\text { Unit Weight } \\
\left(\mathrm{Kg} / \mathrm{m}^{3}\right)\end{array}$} & \multirow[b]{2}{*}{ Region } & \multirow{2}{*}{$\begin{array}{c}\text { Effective } \\
\text { Binder } \\
\text { Content }(\%)\end{array}$} & \multirow{2}{*}{$\begin{array}{c}\text { Air } \\
\text { Voids } \\
(\%) \\
\end{array}$} & \multicolumn{4}{|c|}{ Sieve Passing \% } \\
\hline & & & & & $\begin{array}{c}19 \\
\mathrm{~mm}\end{array}$ & $\begin{array}{l}9.5 \\
\mathrm{~mm}\end{array}$ & $\begin{array}{l}4.75 \\
\mathrm{~mm}\end{array}$ & $\begin{array}{c}0.075 \\
\mathrm{~mm}\end{array}$ \\
\hline SP 12.5 & 2460 & All & 11.8 & 4 & 100 & 83.2 & 54 & 4 \\
\hline \multirow{4}{*}{$\begin{array}{c}\text { SP } 12.5 \\
\text { FC1 }\end{array}$} & 2530 & WR & \multirow{4}{*}{11.8} & \multirow{4}{*}{4} & \multirow{4}{*}{100} & \multirow{4}{*}{83.2} & \multirow{4}{*}{54} & \multirow{4}{*}{4} \\
\hline & 2520 & $\mathrm{CR}$ & & & & & & \\
\hline & 2390 & ER & & & & & & \\
\hline & 2520 & NR & & & & & & \\
\hline \multirow{4}{*}{$\begin{array}{c}\text { SP } 12.5 \\
\text { FC2 }\end{array}$} & 2530 & WR & \multirow{4}{*}{10.8} & \multirow{4}{*}{4} & \multirow{4}{*}{100} & \multirow{4}{*}{83.2} & \multirow{4}{*}{54} & \multirow{4}{*}{4} \\
\hline & 2520 & $\mathrm{CR}$ & & & & & & \\
\hline & 2390 & ER & & & & & & \\
\hline & 2520 & NR & & & & & & \\
\hline SP 19.0 & 2460 & All & 11.2 & 4 & 96.9 & 72.5 & 52.8 & 3.9 \\
\hline SP 25.0 & 2469 & All & 10.4 & 4 & 89.1 & 63.3 & 49.3 & 3.8 \\
\hline
\end{tabular}


Table D.2: Ontario's typical Marshall mix properties

\begin{tabular}{|c|c|c|c|c|c|c|c|c|}
\hline \multirow{2}{*}{$\begin{array}{l}\text { Asphalt } \\
\text { Layer }\end{array}$} & \multirow{2}{*}{$\begin{array}{l}\text { Unit Weight } \\
\left(\mathrm{Kg} / \mathrm{m}^{3}\right)\end{array}$} & \multirow[b]{2}{*}{ Region } & \multirow{2}{*}{$\begin{array}{l}\text { Effective } \\
\text { Binder Content } \\
(\%)\end{array}$} & \multirow{2}{*}{$\begin{array}{l}\text { Air } \\
\text { Voids } \\
(\%) \\
\end{array}$} & \multicolumn{4}{|c|}{ Sieve Passing \% } \\
\hline & & & & & $\begin{array}{l}19 \\
\mathrm{~mm}\end{array}$ & $\begin{array}{l}9.5 \\
\mathrm{~mm}\end{array}$ & $\begin{array}{l}4.75 \\
\mathrm{~mm} \\
\end{array}$ & $\begin{array}{l}0.075 \\
\mathrm{~mm}\end{array}$ \\
\hline DFC & 2520 & \multirow{10}{*}{ All } & 12.4 & 3.5 & 100 & 82.5 & 52.5 & 2.5 \\
\hline $\begin{array}{l}\text { HDBC \& } \\
\text { HDB }\end{array}$ & 2460 & & 10.9 & 4 & 97 & 63 & 43.5 & 3 \\
\hline MDBC & 2500 & & 12.3 & 4 & 97 & 63 & 40 & 3 \\
\hline HL-1 & 2520 & & 12.4 & 4 & 100 & 82.5 & 55 & 2.5 \\
\hline HL-2 & 2410 & & 14.2 & 5 & 100 & 100 & 92.5 & 5.5 \\
\hline HL-3 & 2520 & & 12.4 & 4 & 100 & 82.5 & 55 & 2.5 \\
\hline HL-4 & 2480 & & 12.2 & 4 & 100 & 72 & 53.5 & 3 \\
\hline HL-5 & 2520 & & 10.9 & 4 & 97 & 72 & 53.5 & 3 \\
\hline HL-6 & 2460 & & 10.9 & 4 & 97 & 72 & 53.5 & 3 \\
\hline HL-8 & 2460 & & 10.9 & 4 & 97 & 63 & 42.5 & 3 \\
\hline
\end{tabular}


Table D.3: Ontario's recommended asphalt stabilized material properties

\begin{tabular}{|c|c|c|c|c|c|c|c|c|}
\hline \multirow{2}{*}{$\begin{array}{l}\text { Asphalt } \\
\text { Layer }\end{array}$} & \multirow{2}{*}{$\begin{array}{l}\text { Unit Weight } \\
\left(\mathrm{Kg} / \mathrm{m}^{3}\right)\end{array}$} & \multirow[b]{2}{*}{ Region } & \multirow{2}{*}{$\begin{array}{l}\text { Effective Binder } \\
\text { Content }(\%)\end{array}$} & \multirow{2}{*}{$\begin{array}{c}\text { Air } \\
\text { Voids } \\
(\%)\end{array}$} & \multicolumn{4}{|c|}{ Sieve Passing \% } \\
\hline & & & & & $\begin{array}{c}19 \\
\mathrm{~mm}\end{array}$ & $\begin{array}{r}9.5 \\
\mathrm{~mm} \\
\end{array}$ & $\begin{array}{l}4.75 \\
\mathrm{~mm}\end{array}$ & $\begin{array}{c}0.075 \\
\mathrm{~mm}\end{array}$ \\
\hline CIR & 2240 & \multirow{3}{*}{ All } & 12.5 & 9 & 100 & 83 & 63 & 6 \\
\hline CIREAM & 2110 & & 13.5 & 13.5 & 100 & 83 & 63 & 6 \\
\hline EAS & 2170 & & 11.7 & 10 & 97 & 73 & 58 & 7 \\
\hline
\end{tabular}


Table D.4: Ontario's typical granular material properties

\begin{tabular}{|c|c|c|c|c|c|c|c|c|}
\hline \multirow{2}{*}{$\begin{array}{c}\text { Granular } \\
\text { Type }\end{array}$} & \multirow{2}{*}{$\begin{array}{c}\text { Resilient } \\
\text { Modulus } \\
(\mathrm{MPa})\end{array}$} & \multirow{2}{*}{$\begin{array}{c}\text { Liquid } \\
\text { Limit }\end{array}$} & \multirow{2}{*}{$\begin{array}{c}\text { Plasticity } \\
\text { Index }\end{array}$} & $\begin{array}{c}25 \\
\mathrm{~mm}\end{array}$ & $\begin{array}{c}19 \\
\mathrm{~mm}\end{array}$ & $9.5 \mathrm{~mm}$ & $\begin{array}{c}4.75 \\
\mathrm{~mm}\end{array}$ & $\begin{array}{c}0.075 \\
\mathrm{~mm}\end{array}$ \\
\hline Granular A & 250 & 6 & 0 & 100 & 92.5 & 61.5 & 45 & 5 \\
\hline Granular B-I & 150 & 11 & 0 & 75 & - & - & 60 & 4 \\
\hline Granular B-II & 200 & 11 & 0 & 75 & - & - & 37.5 & 5 \\
\hline Granular O & 200 & 6 & 0 & 100 & 97.5 & 70 & 60 & 2.5 \\
\hline
\end{tabular}


Table D.5: Ontario's typical chemically stabilized base material properties

\begin{tabular}{|c|c|c|c|c|c|c|}
\hline $\begin{array}{c}\text { Material } \\
\text { Type }\end{array}$ & $\begin{array}{c}\text { Unit Weight } \\
\left(\mathrm{Kg} / \mathrm{m}^{3}\right)\end{array}$ & $\begin{array}{c}\text { Poison } \\
\text { Ratio }\end{array}$ & $\begin{array}{c}\text { Modulus of } \\
\text { Rupture } \\
(\mathrm{MPa})\end{array}$ & $\begin{array}{c}\text { Resilient } \\
\text { Modulus } \\
(\mathrm{MPa})\end{array}$ & $\begin{array}{c}\text { Thermal Conductivity } \\
(\mathrm{w} / \mathrm{m}-\mathrm{K})\end{array}$ & $\begin{array}{c}\text { Heat } \\
\text { capacity } \\
(\mathrm{J} / \mathrm{kg}-\mathrm{K})\end{array}$ \\
\hline OGDL & 1700 & 0.4 & 4.5 & 400 & 2.16 & 1172 \\
\hline CTB & 2400 & 0.2 & 4.5 & 690 & 2.16 & 1172 \\
\hline
\end{tabular}


Table D.6: Ontario's typical fine sub-grade soil property

\begin{tabular}{|c|c|c|c|c|c|c|c|c|}
\hline \multirow{2}{*}{$\begin{array}{c}\text { Granular } \\
\text { Type }\end{array}$} & \multirow{2}{*}{$\begin{array}{c}\text { Resilient Modulus } \\
\text { (MPa) }\end{array}$} & \multirow{2}{*}{$\begin{array}{c}\text { Liquid } \\
\text { Limit }\end{array}$} & \multirow{2}{*}{$\begin{array}{c}\text { Plasticity } \\
\text { Index }\end{array}$} & $\begin{array}{c}19 \\
\mathrm{~mm}\end{array}$ & $\begin{array}{c}9.5 \\
\mathrm{~mm}\end{array}$ & $\begin{array}{c}4.75 \\
\mathrm{~mm}\end{array}$ & $\begin{array}{c}0.075 \\
\mathrm{~mm}\end{array}$ & $\begin{array}{c}0.002 \\
\mathrm{~mm}\end{array}$ \\
\hline CL & 20 & 26 & 12 & 100 & 99 & 97 & 80 & 30 \\
\hline CI & 20 & 41 & 21 & 100 & 100 & 99 & 88 & 37 \\
\hline CH & 20 & 67 & 43 & 100 & 100 & 99 & 92 & 60 \\
\hline $\begin{array}{c}\text { CL }- \\
\text { ML }\end{array}$ & 22 & 22 & 6 & 100 & 99 & 98 & 84 & 16 \\
\hline ML & 25 & 26 & 3 & 100 & 100 & 96 & 74 & 11 \\
\hline MI & 25 & 42 & 15 & 100 & 100 & 100 & 82 & 25 \\
\hline MH & 20 & 53 & 21 & 100 & 100 & 100 & 84 & 40 \\
\hline SM & 35 & 18 & 4 & 98 & 94 & 90 & 29 & 8 \\
\hline SC & 30 & 22 & 10 & 100 & 100 & 93 & 32 & 13 \\
\hline
\end{tabular}


Table D.7: Layer Thickness for the selected pavement sections

\begin{tabular}{|c|c|c|c|c|c|c|c|c|c|}
\hline Highway & LHRS & Offset & ID Session & Layer 1 & Layer 2 & Layer 3 & Layer 4 & Layer 5 & Layer 6 \\
\hline 3 & 12020 & 1.300 & 77 & 40 & 60 & 70 & 200 & 150 & 0 \\
\hline 3 & 12036 & 0.000 & 78 & 40 & 60 & 70 & 200 & 150 & 0 \\
\hline 6 & 13465 & 0.000 & 105 & 40 & 50 & 110 & 0 & 150 & 550 \\
\hline 6 & 13570 & 0.000 & 106 & 40 & 50 & 110 & 700 & 0 & 0 \\
\hline 6 & 13570 & 5.900 & 107 & 40 & 50 & 110 & 700 & 0 & 0 \\
\hline 6 & 13580 & 1.000 & 108 & 40 & 50 & 110 & 700 & 0 & 0 \\
\hline 6 & 13585 & 0.300 & 109 & 40 & 50 & 110 & 700 & 0 & 0 \\
\hline 6 & 13585 & 3.244 & 110 & 40 & 50 & 110 & 700 & 0 & 0 \\
\hline 6 & 13640 & 2.100 & 114 & 40 & 50 & 50 & 225 & 0 & 0 \\
\hline 6 & 13650 & 2.460 & 115 & 40 & 50 & 50 & 225 & 0 & 0 \\
\hline 7 & 14024 & 0.000 & 144 & 40 & 60 & 70 & 150 & 450 & 0 \\
\hline 7 & 14612 & 0.880 & 197 & 40 & 60 & 60 & 300 & 0 & 0 \\
\hline 8 & 15970 & 1.300 & 219 & 40 & 80 & 300 & 200 & 350 & 0 \\
\hline 8 & 16000 & 1.000 & 221 & 50 & 120 & 0 & 0 & 0 & 0 \\
\hline 10 & 16460 & 0.000 & 240 & 40 & 50 & 50 & 500 & 0 & 0 \\
\hline 10 & 16460 & 8.270 & 241 & 40 & 50 & 50 & 500 & 0 & 0 \\
\hline 10 & 16580 & 0.800 & 252 & 50 & 100 & 200 & 0 & 0 & 0 \\
\hline 11 & 18030 & 14.430 & 323 & 55 & 75 & 50 & 250 & 450 & 300 \\
\hline 11 & 18105 & 0.000 & 328 & 50 & 90 & 150 & 600 & 0 & 0 \\
\hline 11 & 17130 & 1.000 & 368 & 40 & 50 & 50 & 150 & $150-650$ & 0 \\
\hline 12 & 19380 & 0.000 & 424 & 50 & 125 & 20 & 119 & 225 & 610 \\
\hline 12 & 19390 & 0.000 & 425 & 50 & 125 & 20 & 119 & 225 & 610 \\
\hline 12 & 19410 & 0.690 & 426 & 50 & 125 & 20 & 119 & 225 & 610 \\
\hline 15 & 20020 & 3.820 & 437 & 40 & 60 & 60 & 150 & 450 & 0 \\
\hline 21 & 24050 & 5.200 & 589 & 60 & 75 & 320 & 0 & 0 & 0 \\
\hline 21 & 24142 & 0.100 & 600 & 40 & 110 & 100 & 200 & 560 & 0 \\
\hline 23 & 24600 & 0.300 & 613 & 40 & 50 & 50 & 100 & 0 & 0 \\
\hline 23 & 24600 & 0.300 & 613 & 40 & 50 & 50 & 100 & 0 & 0 \\
\hline 35 & 27816 & 0.000 & 670 & 40 & 50 & 130 & 550 & 0 & 0 \\
\hline 40 & 29110 & 6.200 & 679 & 40 & 120 & 100 & 300 & 450 & 0 \\
\hline 41 & 29580 & 2.800 & 697 & 40 & 50 & 200 & 0 & 0 & 0 \\
\hline 41 & 29590 & 3.900 & 698 & 40 & 50 & 200 & 190 & 150 & 0 \\
\hline 41 & 29590 & 11.300 & 699 & 40 & 50 & 200 & 190 & 150 & 0 \\
\hline 58 & 32740 & 0.000 & 719 & 50 & 100 & 50 & 225 & 0 & 0 \\
\hline 60 & 33240 & 0.000 & 727 & 50 & 150 & 145 & 150 & 0 & 0 \\
\hline 60 & 33240 & 7.850 & 728 & 50 & 150 & 145 & 150 & 0 & 0 \\
\hline 93 & 39119 & 0.000 & 835 & 40 & 100 & 150 & 450 & 0 & 0 \\
\hline 118 & 42620 & 0.000 & 887 & 50 & 150 & 0 & 125 & 125 & 0 \\
\hline
\end{tabular}




\begin{tabular}{|c|c|c|c|c|c|c|c|c|c|}
\hline 400 & 46969 & 0.000 & 976 & 40 & 50 & 100 & 40 & 420 & 0 \\
\hline 400 & 46972 & 0.000 & 977 & 40 & 50 & 100 & 40 & 420 & 0 \\
\hline 400 & 46977 & 6.200 & 978 & 40 & 50 & 100 & 40 & 420 & 0 \\
\hline 401 & 47200 & 0.000 & 1016 & 40 & 50 & 225 & 300 & 0 & 0 \\
\hline 401 & 47603 & 0.000 & 1052 & 40 & 50 & 160 & 320 & 550 & 0 \\
\hline 402 & 48140 & 2.000 & 1217 & 40 & 120 & 80 & 100 & 550 & 0 \\
\hline 403 & 48335 & 0.000 & 1240 & 40 & 100 & 120 & 225 & 375 & 0 \\
\hline $403 C$ & 48250 & 0.000 & 1245 & 40 & 40 & 200 & 300 & 0 & 0 \\
\hline 403 & 48255 & 1.650 & 1246 & 40 & 40 & 200 & 300 & 0 & 0 \\
\hline $403 C$ & 48250 & 0.000 & 1260 & 40 & 40 & 200 & 300 & 0 & 0 \\
\hline 406 & 48652 & 0.626 & 1282 & 40 & 60 & 100 & 450 & 0 & 0 \\
\hline 406 & 48652 & 1.326 & 1287 & 40 & 60 & 100 & 450 & 0 & 0 \\
\hline 1000 & 99998 & 27.500 & 1813 & 40 & 100 & 260 & 0 & 0 & 0 \\
\hline 3 & 12038 & 0.000 & 79 & 40 & 60 & 150 & 230 & 0 & 0 \\
\hline 3 & 12045 & 0.000 & 80 & 40 & 60 & 150 & 230 & 0 & 0 \\
\hline 410 & 49076 & 0.000 & 1297 & 40 & 100 & 100 & 100 & 150 & 410 \\
\hline 410 & 49085 & 0.000 & 1298 & 40 & 100 & 80 & 100 & 150 & 410 \\
\hline 417 & 49500 & 0.000 & 1331 & 40 & 100 & 40 & 185 & 225 & 0 \\
\hline 417 & 49540 & 0.000 & 1332 & 40 & 100 & 40 & 185 & 225 & 0 \\
\hline 89 & 38620 & 5.270 & 825 & 40 & 110 & 130 & 170 & 120 & 240 \\
\hline 89 & 38630 & 0.240 & 826 & 40 & 110 & 130 & 170 & 120 & 240 \\
\hline
\end{tabular}




\section{References}

AASHTO. (2008). "Mechanistic-Empirical Pavement Design Guide: A Manual of Practice", American Association of State Highway and Transportation Officials, Washington DC.

AASHTO (2010). "Guide for the Local Calibration of the Mechanical-Empirical Pavement Design Guide", American Association of State Highway and Transportation Officials, Washington DC.

Amin H. (2015). "Local Calibration of AASHTOWare® Using Ontario Pavement Management System Data PMS2", Thesis. PhD, University of Waterloo.

Ashphatpro (2015), http://theasphaltpro.com/article/mepdg-requires-calibration, February 01, 2015.

Corley-Lay, J., Jadoun, F. M., Mastin, J. N., and Kim, Y. R. (2010). "Comparison of Flexible Pavement Distresses Monitored by North Carolina Department of Transportation and LongTerm Pavement Performance Program." Transportation Research Record, (2153), 91-96.

Gautam, G. P. (2015). “Local Calibration of MEPDG Rutting Models for Ontario's Superpave Pavements". Thesis. MASc, Ryerson University.

Hall, K. D., Xiao, D. X., Wang, K. C.P., (2011). "Calibration of the MEPDG for Flexible Pavement Design in Arkansas", Transportation Research Record, (2226), 135-141.

Huang, Y. H., (2004). "Pavement Analysis and Design”, Pearson Prentice Hall, Pearson Prentice Hall Upper Saddle River, NJ 07458.

Jadoun, F. M. (2011). "Calibration of the Flexible Pavement Distress Prediction Models in the Mechanistic Empirical Pavement Design Guide (MEPDG) for North Carolina." Dissertation, Doctor of Philosophy, North Carolina State University

Jannat, G. (2012). "Database Development for Ontario's Local Calibration of MechanisticEmpirical Pavement Design Guide (MEPDG) Distress Model." Thesis, MASc, Ryerson University.

Jannat, G., Yuan, X., Shehata, M. (2014). "Development of regression Eq.s for local calibration of rutting and IRI as predicted by the MEPDG mdoel for flexible pavement using Ontario's long term PMS data", International Journal of Pavement Engineering, Vol. 17, Issue 02, pp 166-175 . 
Kang, M., and Adams, T. M. "Local Calibration for Fatigue Cracking Models Used in the Mechanistic Empirical Pavement Design Guide." Proc., Mid-Continent Transportation Research Symposium.

Kazmierowski, T., He, Z., and Kerr, B. (2001). "A Second Generation PMS for the Ministry of Transportation of Ontario." Ontario Ministry of Transportation, $5^{\text {th }} \quad$ International Conference on Managing Pavements, August 2001, Seattle, WA.

Li, J., Pierce, L. M., and Uhlmeyer, J. (2009). "Calibration of flexible pavement in mechanisticempirical pavement design guide for Washington state." Transportation Research Record, (2095), 73-83.

Mallela, J., Titus-Glover, L., Sadasivam, S., Bhattacharya, B., Darter, M., Quintus, H. V (2013). "Implementation of the AASHTO Mechanistic-Empirical Pavement Design Guide for Colorado". Colorado Department of Transportation, Report no- CDOT-2013-4.

Momin, S.A.(2011). "Local Calibration of Mechanistic Empirical Pavement Design Guide for North Eastern United States", Thesis, MASC, The University of Texas, Arlington.

Ministry of Transportation Ontario (MTO) (2013). “ARAN's ivision User Guide”.

Ministry of Transportation Ontario (MTO) (2012). “Ontario's Default Parameters for AASHTOWare Pavement ME Design Interim Report 2012”.

Ministry of Transportation Ontario (MTO) (2016). “Ontario’s Default Parameters for AASHTOWare Pavement ME Design Interim Report 2016".

Muthadi, N.R.(2007)." Local Calibration of MEPDG for Flexible Pavement Design”, Thesis, MASc, North Carolina State University.

Myers, L. A., Roque, R., Birgisson, B., (2001). "Propagation Mechanisms for Surface-Initiated Longitudinal Wheel-path Cracks, Transportation Research Record 1778 _ 113. Paper No. 01-0433

NCHRP (2004). “Guide for Mechanistic-Empirical Design of New and Rehabilitated Pavement Structures", Final Document, Appendix II-1, 'Calibration of Fatigue Cracking Models for Flexible Pavement, National Cooperative Highway Research Program Transportation Research Board National Research Council, 1-37A Report.

NCHRP (2006). "Research Results Digest 308." Transportation Researh Board, Washington, 24. NCHRP (2010). “Top-Down Cracking of Hot-Mix Asphalt Layers: Models for Initiation and Propagation". Contractor's Final Report for NCHRP Project 1-42A. 
Roadtalk (2016), Ontario's Transportation Technology Transfer Digest, Ministry of Transportation Ontario (MTO), Spring, 2016.

Shook, J. F., Finn, F. N., Witczak, M. W., and Monismith, C. L (1982). "Thickness Design of Asphalt Pavements - The Asphalt Institute Method". 5th International Conference on the Structural Design of Asphalt Pavements, Volume 1.

Souliman, M. I., Mamlouk, M. S., El-Basyouny, M. M., and Zapata, C. E.(2010) "Calibration of the AASHTO MEPDG for flexible pavement for Arizona conditions." Proc., 89th Annual Meeting of the Transportation Research Board, Transportation Research Board.

Tarefder, R., Rodriguez-Ruiz, J.I. (2013). "Local Calibration of MEPDG for flexible Pavements in New Mexico" Journal of Transportation Engineering, 10.1061/(ASCE)TE.19435436.0000576, 981-991.

Terzaghi, K., and Hogentogler, C. A. (1929). "Interrelationship of load, road and subgrade." Public Roads, 37-64.

Von Quintus, H. L., Darter, M., \& Mallela, J. (2009). Recommended Practice for Local 22 Calibration of the ME Pavement Design Guide. Round Rock, Texas: Applied 23 Research Associates, Inc.-Transportation Sector.

Williams, D. R. C., and Shaidur, R. (2013). "Mechanistic-Empirical Pavement Design Guide Calibration for Pavement Rehabilitation." SPR 718 Institute for Transportation Iowa State University, 2711 South Loop Drive, Suite 4700 Ames, IA 50010-8664.

Waseem, A. (2013). "Methodology Development and Local Calibration of MEPDG Permanent Deformation Models for Ontario's Flexible Pavements." MASc, Ryerson University, Canada.

WSDOT, (2005), "Washington State Department of Transportation's Pavement Guide Interactive", Washington State Department of Transportation. 